\title{
Struktur und Dynamik des Feinwurzelsystems von tropischen Bergwäldern in Abhängigkeit von der Meereshöhe in Südecuador
}

\author{
Dissertation \\ zur Erlangung des Doktorgrades \\ der Mathematisch-Naturwissenschaftlichen Fakultäten \\ der Georg-August-Universität zu Göttingen
}

vorgelegt von

\section{Marina Röderstein}

aus Alsfeld

Göttingen, 29.05.2006 
D 7

Referent: Prof. Dr. Ch. Leuschner

Korreferent: PD Dr. M. Kessler

Tag der mündlichen Prüfung: 04.07.2006 
„By the time the elfin forest has been reached, the forest floor is a mass of roots and stems, like a mangrove swamp.”

A tropical rain forest

Howard T. Odum

in Andenken an meine Großeltern

Walter \& Elisabeth, Paul \& Lina 


\section{Danksagung}

Zuerst möchte ich Prof. Christoph Leuschner danken, der das Thema zur Verfügung stellte, mir so ermöglichte noch einmal in Südamerika zu arbeiten und mir bei Fragen jederzeit zur Verfügung stand.

Ebenso möchte ich meinem Betreuer Dr. Dietrich Hertel danken, der ein offenes Ohr für Fragen oder Probleme hatte und seine Unterstützung während der Arbeit.

Der Arbeitsgruppe in Weende möchte ich für die nette und freundliche Atmosphäre danken. Mein besonderer Dank gilt Sandra, Heinz, Gerald, Jürgen, Maria, Annika, Marieke, Astrid, Viviana, Doris und Kerstin, sie wissen wofür. Den TA’s gebührt Dank für ihre stetige Hilfsbereitschaft. Weiterhin möchte ich Christian Bertsch danken, der mit seiner Diplomarbeit einen wichtigen Beitrag zu diesem Projekt geleistet hat. Ganz besonders möchte ich mich bei Frau Dr. Marie-Luise Schnetter für Ihre hilfreiche Unterstützung bedanken. Eine große Hilfe sind und waren mir Kay, Angelika, Chris, Thommy und Christoph.

Den Mitarbeitern der Bereichsbibliothek Forst, Göttingen, gilt mein Dank für ihre freundliche Unterstützung in der Beschaffung von Literatur!

Ohne die hilfreiche Unterstützung vieler Kollegen, die mir freundlicherweise Daten zur Verfügung gestellten haben, während der Geländearbeit und der Zeit in Ecuador, wäre die Arbeit nicht möglich gewesen. In Vertretung für alle, die ich leider an dieser Stelle nicht aufzählen kann, seien Nathalie, Alfredo, Felix, Paul Emck, Suse, Betti .... und alle, die zwischen 2001 und 2003 auf der ECSF gelebt und gearbeitet haben, erwähnt.

Ganz herzlichen Dank an alle meine „Transporter“ für Kleinigkeiten auf und von der ECSF! Muchas gracias a la familia Feijóo, Sra. Maria, Roberth, Rocio, Tati y los niños, Karina, Jefferson y Angel por todo. Gracias a la NCI en Loja. Especialmente gracias a Sonia Sotomayor.

También gracias a mis amigos en Colombia por todo el tiempo que nosotros nos conocemos! Für die Übernahme des Korreferates danke ich recht herzlich PD Dr. Michael Kessler. Der Deutschen Forschungsgemeinschaft (DFG) sei für die finanzielle Unterstützung für dieses Projekt gedankt.

Und zum Schluß: Danke - meinen Eltern, der Familie und meinen Freunden für einfach alles! 


\section{Inhaltsverzeichnis}

$1 \quad$ Einleitung $\ldots \ldots \ldots \ldots \ldots \ldots \ldots \ldots \ldots \ldots \ldots \ldots \ldots \ldots \ldots \ldots \ldots \ldots, 1$

2 Das Untersuchungsgebiet $\ldots \ldots \ldots \ldots \ldots \ldots \ldots \ldots \ldots \ldots \ldots \ldots \ldots, 3$

$2.1 \quad$ Topographische Lage $\ldots \ldots \ldots \ldots \ldots \ldots \ldots \ldots \ldots \ldots \ldots \ldots, 3$

$2.1 .1 \quad$ Untersuchungsflächen $\ldots \ldots \ldots \ldots \ldots \ldots \ldots \ldots \ldots \ldots \ldots$

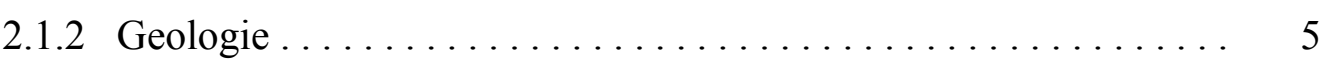

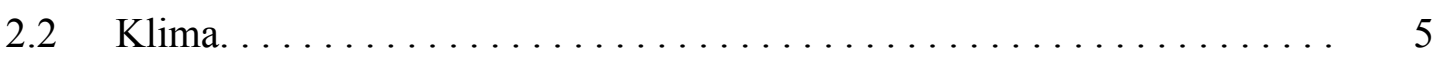

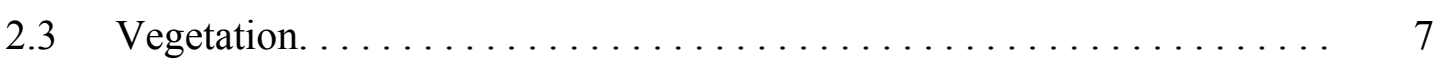

$2.3 .1 \quad$ Höhenzonierung $\ldots \ldots \ldots \ldots \ldots \ldots \ldots \ldots \ldots \ldots \ldots \ldots$

$2.3 .2 \quad$ Bestandesstruktur $\ldots \ldots \ldots \ldots \ldots \ldots \ldots \ldots \ldots \ldots \ldots \ldots$

$2.3 .3 \quad$ Artenzusammensetzung im Untersuchungsgebiet ......... 8

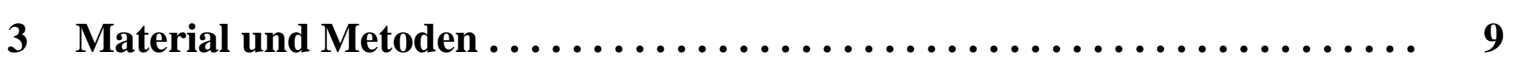

$3.1 \quad$ Auswahl der Untersuchungsstellen im Bestand ................

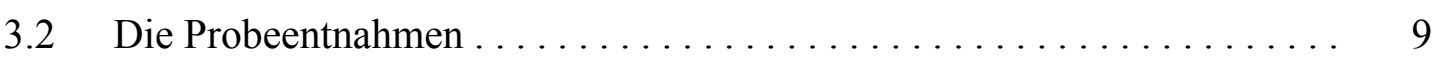

\begin{tabular}{|l|l|}
\hline 3.2 .1 & $\begin{array}{l}\text { Probeentnahme der Feinwurzelbodenproben - Das sequential } \\
\text { coring-Verfahren ............................... }\end{array}$ \\
\hline
\end{tabular}

3.2 .2 Die Auflagemächtigkeit .....................

$3.2 .3 \quad$ Der Bodenwassergehalt $\ldots \ldots \ldots \ldots \ldots \ldots \ldots \ldots \ldots \ldots, 10$

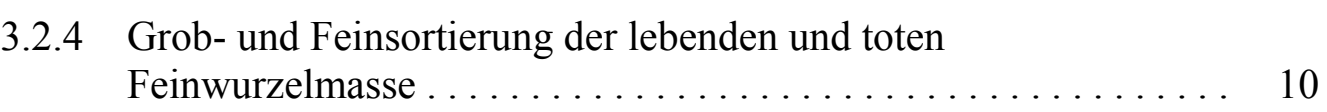

$3.3 \quad$ Bestimmung der Jahresproduktion, Umsatzrate, Jahresstreuproduktion und Mortalitätsrate von Feinwurzeln der drei Versuchsflächen ........ 11

$3.3 .1 \quad$ Die Minimum-Maximum-Methode $\ldots \ldots \ldots \ldots \ldots \ldots \ldots$. 11

$3.3 .2 \quad$ Die compartmental flow-Methode $\ldots \ldots \ldots \ldots \ldots \ldots \ldots, 12$

\begin{tabular}{llll}
\hline 3.3 .3 & Regeneration der Feinwurzeln - Die ingrowth core-Methode .... 13 \\
\hline
\end{tabular}

\begin{tabular}{llll}
\hline 3.4 & Untersuchungen zum Feinwurzelstreuabbau in litter bags $\ldots \ldots \ldots \ldots$ & 13 \\
\hline
\end{tabular}

\begin{tabular}{lll}
\hline 3.5 & Untersuchungen zur Morphologie der Feinwurzeln . . . . . . . . . . . . 14 & 14 \\
\hline
\end{tabular}

$3.5 .1 \quad$ Wurzelspitzenhäufigkeit $\ldots \ldots \ldots \ldots \ldots \ldots \ldots \ldots \ldots \ldots \ldots$

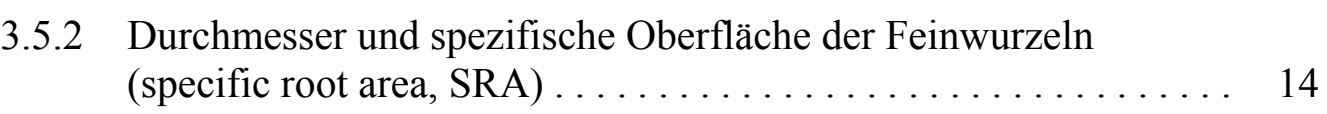

\begin{tabular}{llll}
\hline 3.6 & Bestandesspitzenzahl und Wurzelflächenindex (RAI) ............ 15 \\
\hline
\end{tabular}

\begin{tabular}{|lrl}
\hline 3.6 .1 & Bestandesspitzenzahl und - dichte $\ldots \ldots \ldots \ldots \ldots \ldots \ldots$ & 15 \\
\hline
\end{tabular} 
3.6.2 Wurzelflächenindex (root area index, RAI) ............ 15

3.7 Bestimmung der Kohlenstoff- und Stickstoffkonzentrationen der

Feinwurzeln ........................... 15

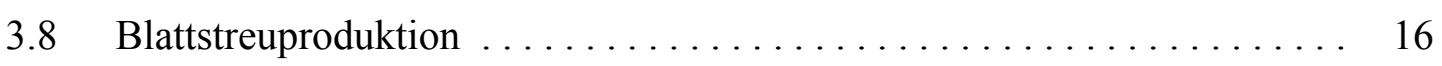

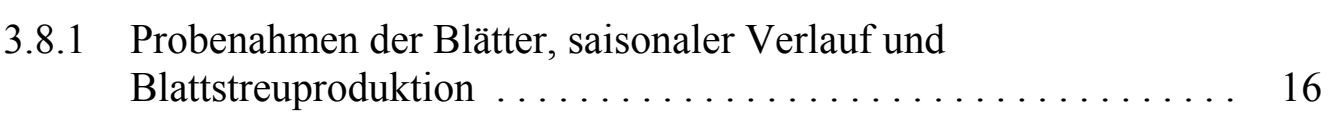

3.8.2 Spezifische Oberfläche der Blätter (spezific leaf area, SLA) 16

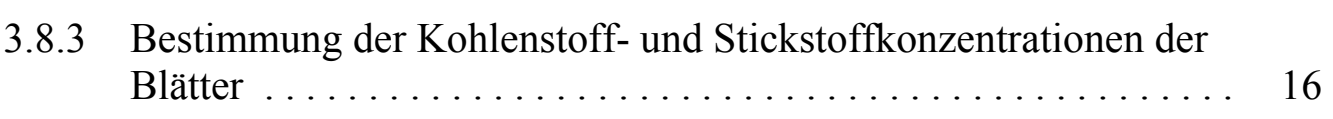

$3.9 \quad$ Statistische Auswertung .................... 16

$4 \quad$ Ergebnisse $\ldots \ldots \ldots \ldots \ldots \ldots \ldots \ldots \ldots \ldots \ldots \ldots \ldots \ldots \ldots \ldots$ 18

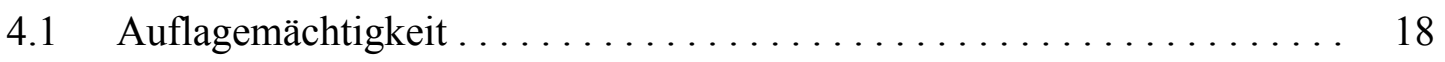

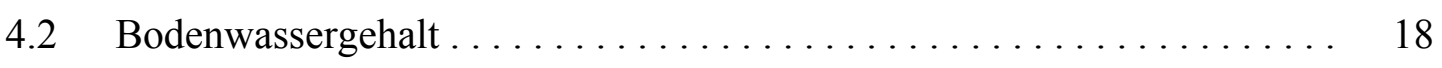

$4.3 \quad$ Mittlere Feinwurzelbio und -nekromasse .................. 20

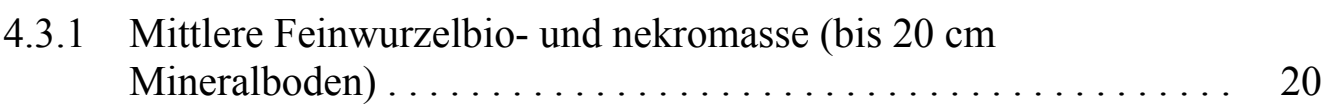

\begin{tabular}{|lll}
\hline 4.3 .2 & Feinwurzelmassen inklusive des Mineralbodens von $20-40 \mathrm{~cm} \ldots$ & 21 \\
\hline
\end{tabular}

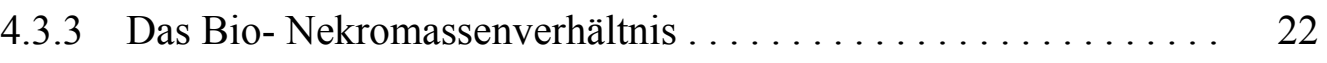

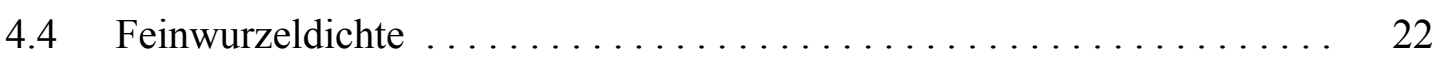

$4.4 .1 \quad$ Vertikalverteilung der Feinwurzeldichte ............ 22

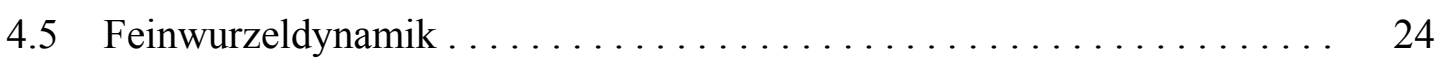

4.5.1 Saisonale Veränderung von lebender und toter Feinwurzelmasse. . 24

$4.5 .2 \quad$ Die unterschiedenen Methoden ................ 26

4.5.2.1 Die Minimum-Maximum-Methode ........... 26

4.5.2.2 Die compartmental flow-Methode .......... 26

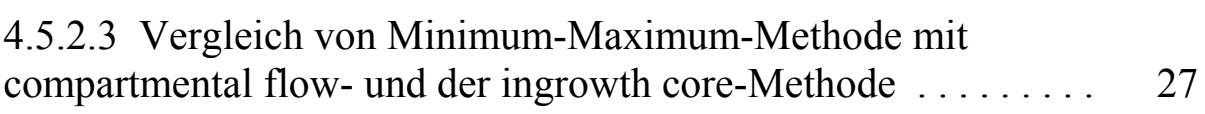

$4.5 .3 \quad$ Feinwurzelmortalität und -umsatz ................ 28

4.5.3.1 Die Minimum-Maximum-Methode ........... 28

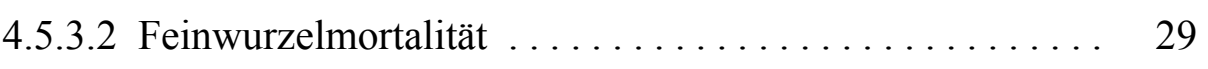

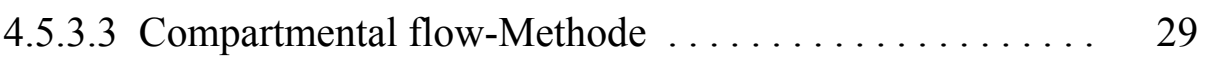

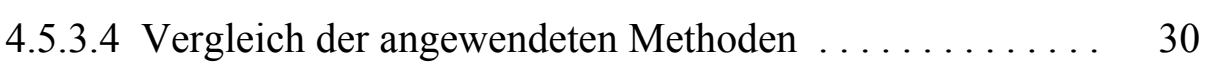

4.5.3.5 Umsatz- und Mortalitätsrate der Feinwurzeln ........ . 31 


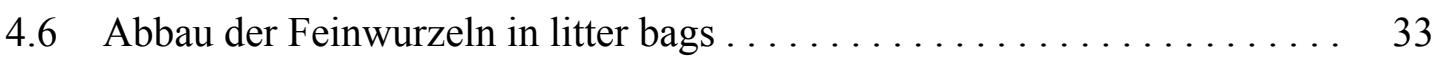

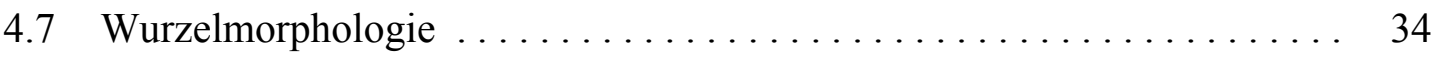

$4.7 .1 \quad$ Durchmesser der Feinwurzeln ...................... 34

\begin{tabular}{|llll}
\hline 4.7 .2 & Spezifische Wurzeloberfläche (specific root area, SRA) ........ 34 \\
\hline
\end{tabular}

$4.7 .3 \quad$ Spezifische Wurzelspitzenhäufigkeit $\ldots \ldots \ldots \ldots \ldots \ldots \ldots$

\begin{tabular}{|lll|}
\hline 4.8 & Bestandesspitzenanzahl und Spitzendichte und Wurzelflächenindex ..... & 36 \\
\hline
\end{tabular}

\begin{tabular}{|llll}
\hline $4.8 .1 \quad$ Bestandesspitzenanzahl und Spitzendichte der Feinwurzeln . . . . 36 & 36 \\
\hline
\end{tabular}

4.8.2 Der Wurzelflächenindex (root area index, RAI) ........... 37

$4.9 \quad$ C- und N-Gehalte der Feinwurzeln $\ldots \ldots \ldots \ldots \ldots \ldots \ldots \ldots \ldots \ldots \ldots \ldots \ldots$

$4.9 .1 \quad$ Das Kohlenstoff-Stickstoffverhältnis von Feinwurzeln ....... 38

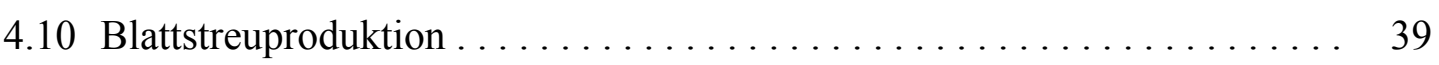

\begin{tabular}{|lll}
\hline 4.10 .1 & Saisonale Blattstreuproduktion $\ldots \ldots \ldots \ldots \ldots \ldots \ldots \ldots$ & 39 \\
\hline
\end{tabular}

\begin{tabular}{|llll}
\hline 4.10 .2 & Jahressumme des Blattstreufalls ..................... 39 \\
\hline
\end{tabular}

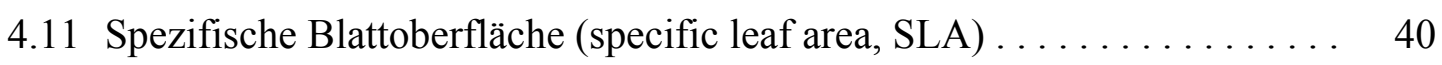

4.11 .1 Die jährliche Blattstreufläche (leaf area fallen, LAF) ........ 41

4.12 Das Kohlenstoff-Stickstoffverhältnis der abgefallenen Blätter ........ 41

5 Diskussion $\ldots \ldots \ldots \ldots \ldots \ldots \ldots \ldots \ldots \ldots \ldots \ldots \ldots \ldots \ldots \ldots \ldots \ldots, 43$

5.1 Der Einfluss der Meereshöhe auf Masse, Morphologie und räumliche Verteilung der Feinwurzeln von tropischen Bergwäldern ............ 43

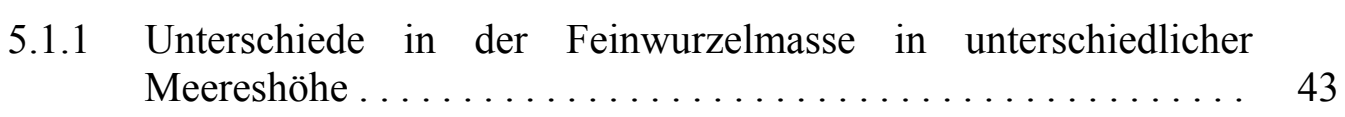

$5.1 .1 .1 \quad$ Bio- und nekromassen der Feinwurzeln ........... 43

5.1.1.2 Die Beziehung zwischen Feinwurzelbiomasse und der oberirdischen Pflanzenbiomasse .................... . 44

5.1.1.3 Der $\quad$ Einfluss $\quad$ der $\quad$ Umweltfaktoren auf die Feinwurzelmassen im Höhengradienten ................. . 47

5.1.1.4 $\quad \delta^{13} \mathrm{C}$ und $\delta^{15} \mathrm{~N}$ in Feinwurzeln aus unterschiedlicher Meereshöhe .............................. 51

5.1.2 Der Einfluss der Meereshöhe auf die Morphologie und die Kohlenstoffspeicherung der Feinwurzeln $\ldots \ldots \ldots \ldots \ldots . \quad 51$

$5.1 .2 .1 \quad$ Morphologie der Feinwurzeln ................ 51

5.1.2.2 Die Kohlenstoffspeicherung der Wurzeln in tropischen

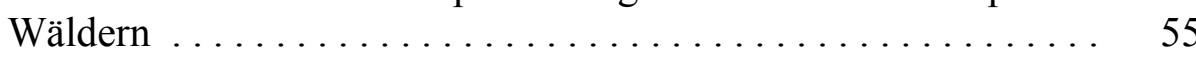


$5.1 .3 \quad$ Die räumliche Verteilung der Feinwurzeln im Höhengradienten . 55

5.2 Dynamik des Feinwurzelsystems der drei Bergwälder: Produktion, Umsatz, Mortalität . . ..................... 56

$5.2 .1 \quad$ Methodenvergleich zur Feinwurzelproduktion ............ 57

$5.2 .2 \quad$ Die Feinwurzelproduktion $\ldots \ldots \ldots \ldots \ldots \ldots \ldots \ldots \ldots$

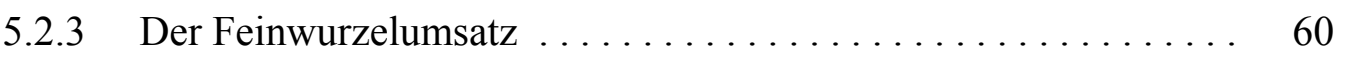

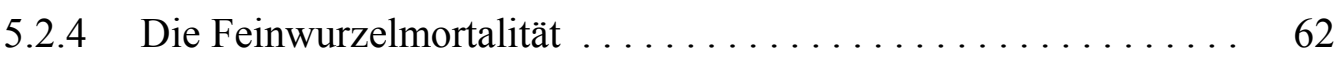

5.3 Untersuchungen zur Blattstreuproduktion in tropischen Bergwäldern . . . 64

$5.3 .1 \quad$ Die Blattstreuproduktion im Höhengradienten ............ 64

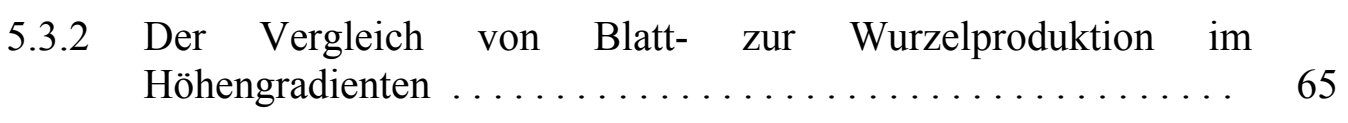

\begin{tabular}{|lcll}
\hline 5.3 .3 & Die spezifische Blattfläche auf den drei Höhenstufen . . . . . . . . 66 \\
\hline
\end{tabular}

$5.3 .4 \quad$ Das C/N-Verhältnis der Blattstreu im Höhengradienten . . . . . . . . 66

6 Zusammenfassung ............................. 68

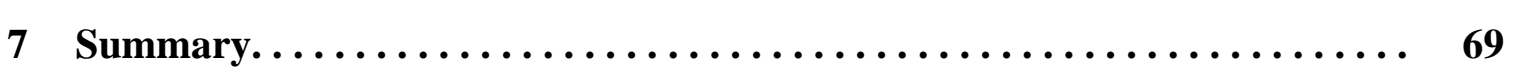

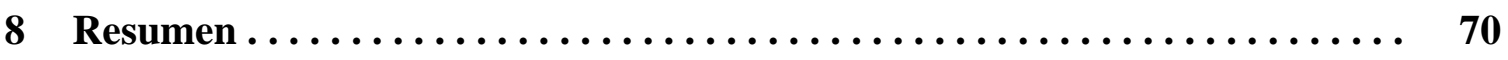

Literaturverzeichnis .............................. 71

Abbildungsverzeichnis ................................ 84

Tabellenverzeichnis ............................... 87

Abkürzungsverzeichnis ............................... 89

Anhang ....................................... 90 


\section{Einleitung}

Ein Regenwald im Klimaxstadium befindet sich in einem dynamischen Gleichgewicht (WHitMoRe 1993), welches durch einen Kreislauf gekennzeichnet ist, in dem es zum ungefähr ausgeglichenen Aufbau von Biomasse durch Photosynthese und dem Abbau von Nekromasse durch Zersetzung kommt. Anthropogene Einflüsse verändern dieses Gleichgewicht, besonders in tropischen Bergregionen nachhaltig. Deshalb gehören sie neben Korallenriffen zu denen am stärksten gefährdeten Lebensräumen.

Tropische Bergregenwälder sind durch steile Hanglagen und mit steigender Meereshöhe sich verschlechternden Wachstumsbedingungen geprägt. Mit steigender Höhe nimmt die oberirdische Biomasse von Pflanzen in der Regel ab (STADTMÜLLER 1987). Parallel dazu ist vor allem bei immergrünen Bäumen zu beobachten, dass mit zunehmender Meereshöhe der Anteil der Assimilate bevorzugt in die unterirdischen Pflanzenteile, vor allem die Feinwurzeln, verlagert wird (VoGT et al. 1986, 1996). Gerade bei Nährstoffmangel oder sich verschlechternder Luftversorgung im Boden wird mehr Biomasse in (Fein-)Wurzeln investiert (BROUWER 1983, VoGT et al. 1987, LÕHMUS et al. 1989, OSTONEN et al. 2005).

Wurzeln dienen zur Verankerung der Pflanzen im Boden, sind Speicherorgane und nehmen aus unterschiedlichen Bodenhorizonten lebensnotwendiges Wasser und Nährstoffe auf, zum Teil mit Unterstützung von Mykorrhiza-Pilzen (PregitZer 2002, KotTKE et al. 2004). Dies geschieht oft in einem engen Kosten-Nutzen Verhältnis, welches die Pflanze dazu zwingt, mit den vorhandenen Ressourcen sehr sparsam umzugehen und sie so zu investieren, dass sie damit im Konkurrenzkampf mit anderen Pflanzen einen möglichst großen Vorteil erzielen.

In tropischen Tieflandwäldern erfuhren vor allem die leichter zugänglichen oberirdischen Kompartimente in der biologischen Forschung viel Beachtung (VITOUSEK 1984, RAICH 1998, CLARK et al. 2001a, NEPSTAD et al. 2002, LEWIS et al. 2004); dies gilt in ähnlicher Weise für tropische Bergwälder (Fölster \& DE LAs SAlas 1976, KitAYAMA \& AiBA 2002, AiBA et al. 2005). Doch gerade Feinwurzeln spielen eine wichtige Rolle in tropischen Bergregenwäldern. Ökosystemare Untersuchungen zu Feinwurzelsystemen in Wäldern wurden bisher vor allem in den gemäßigten Zonen Mitteleuropas (z.B. PERSSON 1983, Hertel 1999) und Nordamerikas (Vogt et al. 1996, PregitZer 2002) durchgeführt. Die meisten Untersuchungen an Feinwurzeln in tropische Regionen fanden bisher im tropischen Tiefland statt (u.a. STARK \& Spratt 1977, Cuevas \& MEdina 1988, Cavelier 1992, Cavelier et al. 1996, Ostertag 1998, McGroddy \& Silver 2000, Clark et al. 2001b, GREEN et al. 2005) und nur sehr selten in tropisch hochmontanen Wäldern (Edwards \& GrubB, 1977,1982, CAVElier 1996, KitAyAma \& AibA 2002, Hertel et al. 2003). Dabei ist insbesondere über die Anpassungsmechanismen des Feinwurzelsystems an tropische montane Bedingungen bislang nur wenig bekannt. 
In der vorliegenden Arbeit wird die Rolle der Feinwurzeln in der bauminternen Kohlenstoffverteilung in drei Bergregenwaldbeständen Südecuadors entlang eines Höhengradienten untersucht.

Anhand der Veränderung von Feinwurzelbio- und nekromasse sowie dem Verhältnis der unter- zur oberirdischen Streuproduktion auf drei unterschiedlichen Höhenstufen sollen Dynamik und Allokationsmuster vergleichend untersucht werden.

Für die Beantwortung folgender Fragen wurden sowohl morphologische als auch strukturelle Daten zum Feinwurzelsystem und zum Blattwerk zusammen mit wichtigen Umweltfaktoren erhoben:

1. Wie verändern sich Masse, Morphologie und räumliche Verteilung der Feinwurzeln mit zunehmender Meereshöhe?

2. Welche Dynamik zeigt das Feinwurzelsystem in diesem Bergregenwaldgebiet?

3. Wie verändert sich die Blattstreuproduktion entlang des Höhengradienten? 


\section{Untersuchungsgebiet}

\subsection{Topographische Lage}

Die vorliegenden Untersuchungen wurden in den Waldbeständen der Reserva Biológica und des Podocarpus Nationalparks durchgeführt. Die Reserva Biológica ist ein ca. 1000 ha großes Gebiet der Stiftung Nature and Culture International (NCI), zu der die Forschungsstation Estación Científica San Francisco (ECSF) gehört. Sie liegt zwischen den Provinzhauptstädten Loja und Zamora, in der Provinz Zamora-Chinchipe, im südlichen Andenhochland von Ecuador (Abb. 2.1).

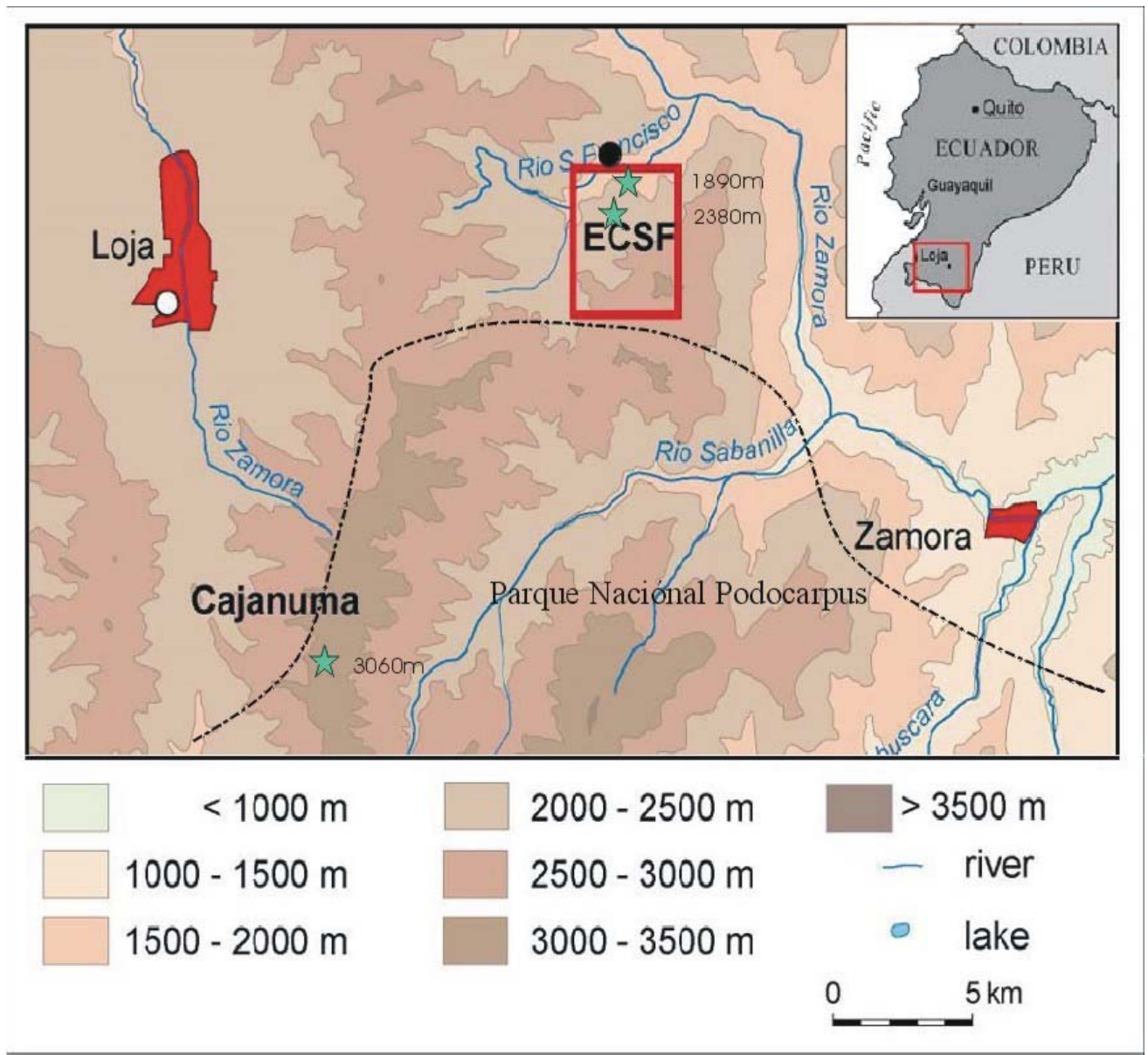

Abb. 2.1: Lage der drei Untersuchungsflächen im Bereich des Stationsgebietes (Rechteck) und im Bereich des Podocarpus Nationalparks (Grenze des Podocarpus Nationalparkes gestrichelt). (aus: www.bergregenwald.de, Karten, verändert)

Das Gebiet der Reserva liegt auf einem überwiegend nord-westlich ausgerichteten Hang der Cordillera El Consuelo, einem Ausläufer der Cordillera Real (Ost-Kordillere). Es steigt von ca. 1800 m auf eine Höhe von ca. 3200 m an. Südlich grenzt der Podocarpus Nationalpark mit einer Fläche von $1460 \mathrm{~km}^{2}$ an die Reserva Biológica an. Er erstreckt sich über die West- und Ostseite der Ost-Kordillere und weist Höhenunterschiede von ca. 3000 m auf. 


\subsubsection{Untersuchungsflächen}

Die höchsten Erhebungen im nördlichen Teil der Cordillera Real steigen bis über 5500 m an. Im Bereich des Untersuchungsgebietes allerdings gibt es, durch die Cuenca-HuancabambaDepression, nur Erhebungen bis ca. 3200 m. In dieser Region wurden die drei Untersuchungsflächen entlang eines Höhengradienten ausgewählt.

Tab. 2.1: Meereshöhe und geografische Lage (aus eigenen GPS Messungen), mittlere Inklination (Hangneigung, 2003/04 (MOSER)), mittlere Exposition (Hangrichtung von Norden ausgehend, 2003/04 (MOSER)), Bodentyp, 2002 (ABIY) und 2005 (IOST)), geologisches Substrat (SAuer (1971)), Median des pH in KCl, 2002/03 (SOETHE), mittlere Jahrestemperatur und Niederschlag im Untersuchungszeitraum 2002/03 (beides ЕMCK), mittlere Luftfeuchtigkeit, 2003/04 (MOSER). Alle Angaben mit Aufnahmedatum aus persönlichen Mitteilungen, außer Sauer (1971).

Study site $1 \quad$ Study site $2 \quad$ Study site 3

Elevation (m asl)

Geographic coodinates

Inclination $\left(^{\circ}\right)$

Exposition $\left({ }^{\circ}\right)$

Soil type

(FAO taxonomy)

Geological substrate

$\mathrm{pH}(\mathrm{KCl})$ value

Annual mean temperature $\left({ }^{\circ} \mathrm{C}\right)$

Annual precipitation $\left(\mathrm{mm} \mathrm{yr}^{-1}\right)$

Mean relative air humidity (\%)
$1890 \mathrm{~m}$

$\mathrm{S} 03^{\circ} 58^{\prime} 34^{\prime \prime}$
W $79^{\circ} 04^{\prime} 65^{\prime \prime}$ 31 259 Inceptisol
Gleyic Cambizol

\section{Metamorphic} shale

1930

90.8 2380m

$3060 \mathrm{~m}$

S $03^{\circ} 59^{\prime} 19^{\prime \prime}$
W $79^{\circ} 04^{\prime} 55^{\prime \prime}$

$\mathrm{S} 04^{\circ} 06^{\prime} 71^{\prime \prime}$ W $79^{\circ} 10^{\prime} 58^{\prime \prime}$

27

67
Spodsol Podzol Cambizol

$\begin{array}{lc}\text { Inceptisol } & \text { Spodsol } \\ \text { Gleyic } & \text { Podzol } \\ \text { Cambizol } & \end{array}$

Metamorphic shale mica slate

3.2

2.5

12.9

9.5

5790

4480

93.3

93.5 


\subsubsection{Geologie}

Die Cordillera Real ist aus paläozoischen bis präkambrischem metamorphen Gesteinen aufgebaut. In den Gebieten östlich von Loja treten miozäne Sedimente von Phyllit- und Graphitschiefern auf. Im Süden, am Knoten von Cajanuma, dort wo sich die dritte Untersuchungsfläche befindet, kommen Quarzit und Glimmerschiefer zum Vorschein. Mit Wasser gesättigte tonige Massen in der Umgebung von Loja begünstigen Erdrutsche, besonders bei geneigten Schichten (SAUER 1971).

\subsection{Klima}

Die Cordillera Real stellt sowohl eine morphologische Grenze als auch eine Klimascheide zwischen der interandinen Senke und dem Amazonasgebiet dar. Dies gilt insbesondere für den Süden Ecuadors, in dem sich das Untersuchungsgebiet befindet. Daraus ergibt sich eine spezielle Niederschlagssituation. Mit acht bis zehn Monaten Regenzeit wird das Stationsgebiet als semi- bis subhumid klassifiziert (RICHTER 2003). Im allgemeinen fallen die höchsten Niederschläge etwa zwischen April und Juli hervorgerufen durch südostpassatische Steigungsregen. Verhältnismäßig weniger Niederschläge fallen in der „trockeneren Zeit“ zwischen September und Februar.

Die höchste mittlere Jahrestemperatur und die niedrigsten jährlichen Regenmengen wurde in 1950 m Höhe gemessen. Das Klima im Untersuchungszeitraum kann dort als subhumid bezeichnet werden. Während die mittlere Jahrestemperatur mit zunehmender Höhe abnahm, nahmen die Niederschläge beträchtlich zu. Mit $5790 \mathrm{~mm}$ pro Jahr sind sie in $2680 \mathrm{~m}$ Höhe besonders hoch. Das Klima in dem Gebiet zwischen 2380 und 3060 m Höhe ist demnach perhumid (unveröffentlichte Daten, EMCK).

Wie aus den Abbildungen 2 A-C zu ersehen ist, waren die monatlichen Temperaturschwankungen im Untersuchungszeitraum auf allen Höhenstufen gering. Dies entspricht dem Temperaturverhalten („Tageszeitenklima“) in Gebieten der inneren Tropen (WALTER 1964). Dagegen waren bei Niederschlägen an allen drei Stationen Unterschiede zwischen den Monaten zu beobachten. In 2680 m und 3070 m Höhe war der Anstieg der Regenmenge zwischen April und Juli besonders ausgeprägt. Die Niederschläge in den übrigen Monaten waren aber immer noch so hoch, dass eine ausgeprägte Trockenzeit nicht zu beobachten war. 

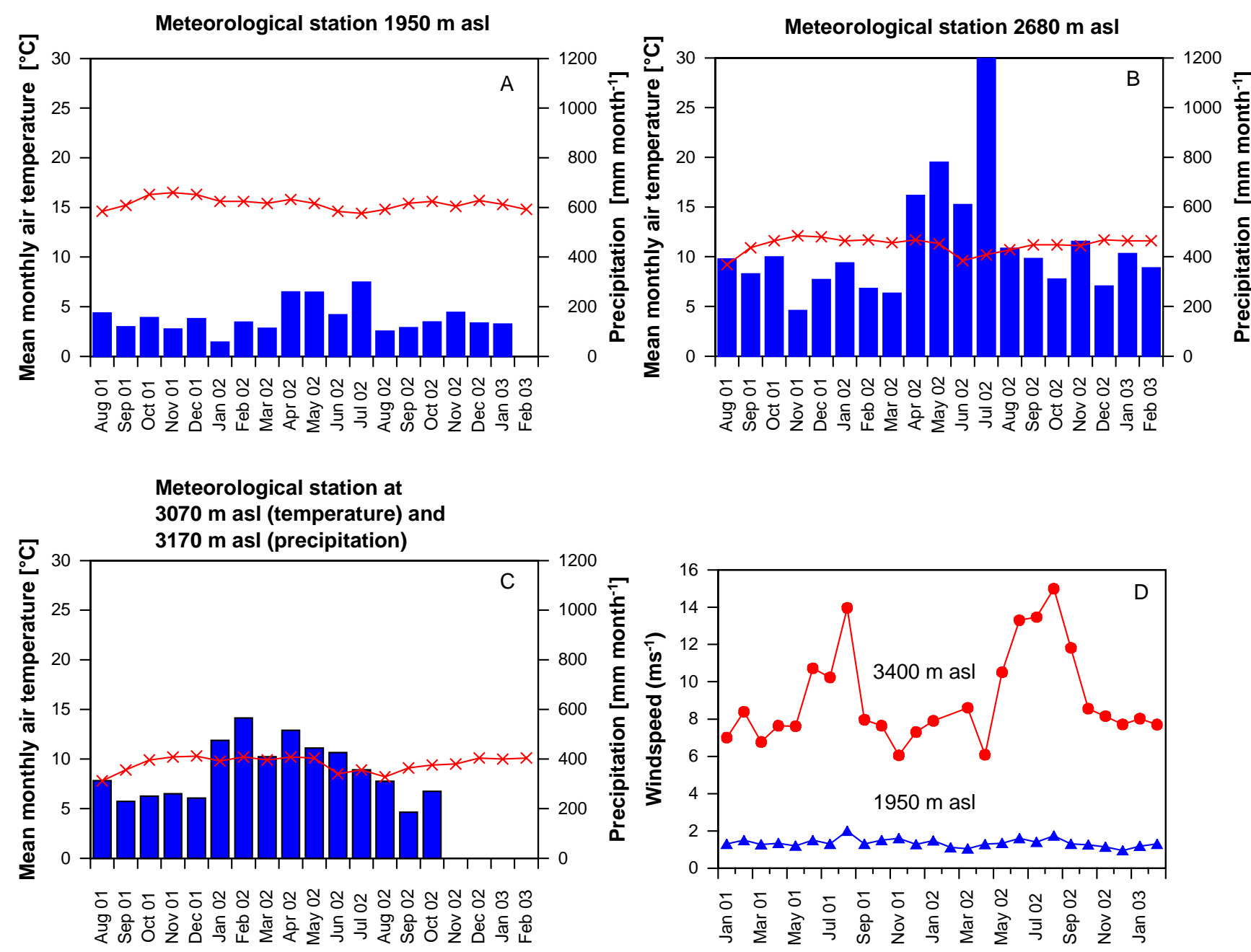

Abb. 2.2 A-C: Monatliche Mitteltemperaturen und Niederschläge A: $1950 \mathrm{~m}$ ü.M. oberhalb der untersten Versuchsfläche $(1890 \mathrm{~m})$; B: $2680 \mathrm{~m}$ ü.M. oberhalb der mittleren Versuchsfläche $(2380 \mathrm{~m})$ und C: mittlere monatliche Temperaturen 3070 m ü.M. und Niederschläge 3170 m ü.M. oberhalb der höchsten Versuchsfläche (3060 m) im Untersuchungszeitraum.

Abb. 2.2 D: mittlere Windgeschwindigkeiten im Páramo bei ca. $3400 \mathrm{~m}$ und auf $1950 \mathrm{~m}$ ü.M. im Stationsgebiet. (Alle Daten von EMCK, unveröffentlicht)

An Hand der Kurven der Windverhältnisse (Abb. 2D) ist zu erkennen, dass im Páramo, also im Baumgrenzbereich, mit $9.12 \mathrm{~m} / \mathrm{s}$ eine fast achtfach höhere Windgeschwindigkeit herrscht als im Gebiet der ESCF (Reserva) mit 1.36 m/s. Auf 1950 m Höhe zeigt sich eine eher ständig gleich bleibende Windgeschwindigkeit. Im Gegensatz dazu zeigen die Messungen in $3400 \mathrm{~m}$ Höhe, eine größere Amplitude. Eine Zunahme der Windgeschwindigkeiten konnte sowohl im Juni/Juli 2001 als auch im selben Zeitraum 2002 beobachtete werden. Die höchsten Windgeschwindigkeiten traten jedoch im August 2002 auf. Die mittlere Höhenstufen von $2680 \mathrm{~m}$ im Untersuchungsgebiet wurde nicht dargestellt, da laut EMCK (persönliche Mitteilung) keinen nennenswerten Unterschiede in der Windgeschwindigkeit zu 3400 m Höhe in Cajanuma bestanden. 


\subsection{Vegetation}

\subsubsection{Höhenzonierung}

Große Flächen der Reserva Biológica und des Podocarpus Nationalparks sind mit Wald bedeckt. Die Bestandesstruktur und die Artenzusammensetzung der Wälder verändert sich mit zunehmender Höhe. Die Waldformationen in neotropischen Hochgebirgen werden in unterschiedliche Klassifizierungen eingeteilt (EllEnBERG 1959, GruBB 1977, HARLING 1979, NeILl 1999, BALSLEV \& ØllgaARD 2002). Im Bereich des Untersuchungsgebietes werden die Höhenstufen von 1500 m bis 2500 m Höhe als immergrüne montane Bergwälder und von $2500 \mathrm{~m}$ bis 3000 (-3500) m Höhe als immergrüner hochmontaner Bergwald angegeben (BALSLEV \& ØLlGAARD 2002). Nach RichTER (2001, 2003) kommt ebenfalls eine Zonierung von „lower orotropical“ (1890 m und 2380 m Höhe) und „upper orotropical forest“ (3060 m Höhe) in Frage. Zwischen 3000 und $3100 \mathrm{~m}$ Höhe erreicht der Bergwald im Untersuchungsgebiet seine obere Grenze. Nach einer Übergangszone folgt nach oben der baumfreie Páramo. Die Baumgrenze befindet sich in Ecuador bei etwa 3250-3400 m (HuECK 1966). Wegen der hohen Niederschläge liegt sie niedriger als in anderen Andenregionen. Nach Richter (2003) bedingt die Andendepression eine niedrige Baumgrenze (bis ca. 3100 m), die in diesem Bereich von sehr starkem Foehn begleitet wird. Nach Richter \& Bussmann (per. Mitteilung) wird die niedrige Baumgrenze u. a. mit Stress durch starke Windereignisse und hohe Bodenfeuchte, niedrigen Temperaturen, möglichen „Gaps“ und Rutschungen begründet.

\subsubsection{Bestandesstruktur}

Der Brusthöhendurchmesser, die Bestandeshöhe und die Stammlänge verringern sich von 1890 m Höhe auf 3060 m Höhe etwa um die Hälfte (Tab. 2.2). Die Basalfläche auf den drei Höhenstufen liegt zwischen 27 und $43 \mathrm{~m}^{2}$ pro Hektar. Die Stammdichte steigt von $1890 \mathrm{~m}$ Höhe auf 3060 m Höhe um das 3.5 fache an und die Holzmasse verringert sich etwa um den Faktor 2.

Die Zahlen zeigen eindeutig, dass Höhe, Länge und Durchmesser der Stämme mit zunehmender Höhe abnehmen. Die Zahl der Bäume pro Flächeneinheit ist in den unteren Höhenstufen deutlich geringer als in 3060 m Höhe, wo viele dünne, verformte Stämme dicht beieinander stehen 
Tab. 2.2: BHD (Brusthöhendurchmesser in $1.30 \mathrm{~m}$ Höhe $(\mathrm{cm})$ ), Basalfläche $\left(\mathrm{m}^{2} \mathrm{ha}^{-1}\right)$, Bestandeshöhe $(\mathrm{m})$, Stammlänge $(\mathrm{m})$, Stammdichte (Bäume $\mathrm{ha}^{-1}$ ) und oberirdische (Baum-) Biomasse ( $\mathrm{t} \mathrm{ha}^{-1}$ ) (Allometrie nach BROWN \& IVERSON (1992)) der drei Untersuchungsflächen (20m x 20 m) des Untersuchungsgebietes. Angegeben sind Mittelwerte und Standardfehler.

\begin{tabular}{ccccc}
\hline & & $1890 \mathrm{~m}$ & $2380 \mathrm{~m}$ & $3060 \mathrm{~m}$ \\
\hline $\begin{array}{c}\mathrm{DBH}(\mathrm{mean}) \\
(>5 \mathrm{~cm})\end{array}$ & $(\mathrm{cm})$ & $12,23 \pm 0,8$ & $9,97 \pm 0,6$ & $7,26 \pm 0,4$ \\
Basal area & $\left(\mathrm{m}^{2} \mathrm{ha}^{-1}\right)$ & 37,05 & 27,20 & 42,61 \\
Canopy height & $(\mathrm{m})$ & 18,9 & 12,0 & 9,0 \\
Stem length (mean) & $(\mathrm{m})$ & $10,04 \pm 0,4$ & $7,38 \pm 0,3$ & $5,22 \pm 0,3$ \\
Stem density & $\left(\right.$ trees ha $\left.{ }^{-1}\right)$ & 2333,72 & 2754,25 & 8314,28 \\
Aboveground tree \\
biomass (mean)
\end{tabular}

\subsubsection{Artenzusammensetzung im Untersuchungsgebiet}

Ecuador weist eine besonders große Anzahl an Gefäßpflanzen auf. Es wird von einer Zahl von inzwischen 17.000 bekannten (UllOA-UlLOA \& NEILL 2005) und wahrscheinlich insgesamt über 20.000 vorkommenden Arten ausgegangen. JøRGENSEN \& LEÓN-YÁNEZ (1999) beziffern die Anzahl der bekannten endemischen Arten an Gefäßpflanzen auf etwa ein Viertel davon. 20 \% der etwa 4000 endemischen Gefäßpflanzen kommen im Podocarpus Nationalpark (VALENCiA et al. 1999).

HomeIER (2004) stellt in seiner Dissertation die bekanntesten Arten für das Untersuchungsgebiet dar. Die prägenden Pflanzenfamilien in der Höhenstufe auf $1890 \mathrm{~m}$ Höhe sind: Graffenrieda emaginata (Melastomaceae), die hier und auf 2380 m Höhe sehr oft vertreten ist und Miconia, Schefflera (Aralieaceae), Prumnopytis und Podocarpus (Podocarpaceae) und Rubiaceen. Auf 2380 m Höhe sind Clusia (Clusiaceae), Graffenrieda (Melastomaceae), Schefflera (Aralieaceae), Podocarpus (Podocarpaceae), Purdiaea nutas (Cyrillaceae), die fast ausschließlich hier vorkommt, und Rubiaceen häufig. Die prägenden Pflanzenfamilien in Cajanuma schließlich auf 3060 m Höhe sind Ilex (Aquifoliaceae), Schefflera (Aralieaceae), Hedyosmum (Chloranthaceae), Weinmannia loxensis (Cunoniaceae), die auf dieser Höhenstufe sehr stark vertreten ist sowie Melastomataceen und Rubiaceen. Im Anhang wird eine ausführliche Tabelle über die vorkommenden Pflanzenarten, meist Baumarten, aufgelistet. So kamen von den 36 unterschiedenen Familien in den beiden unteren Höhenstufen 23, in den obersten dagegen nur 16 vor. 


\section{Material und Methoden}

Die Geländearbeiten fanden in der Zeit von 11.09.01 bis 26.08.02 und vom 24.01.03 bis 18.07.03 im Süden Ecuadors, nahe der Stadt Loja, im Gebiet der ECSF und des Podocarpus Nationalparks statt (Kap. 2, Abb. 2.1).

\subsection{Auswahl der Untersuchungsstellen im Bestand}

$\mathrm{Zu}$ Beginn der Geländearbeiten wurden in der Reserva Biológica und am Rande des Podocapus Nationalparks in drei ausgewählten Höhenstufen (1890 m Höhe, 2380 m Höhe und 3060 m Höhe) jeweils eine Versuchsfläche von $400 \mathrm{~m}^{2}(20$ x $20 \mathrm{~m})$ angelegt. Alle Flächen befanden sich auf steilen, waldbedeckten Hängen. Die Versuchsflächen wurden in Parzellen von $2 \mathrm{~m}$ x $2 \mathrm{~m}$ eingeteilt. Davon wurden 20 zufällig ausgewählt und gekennzeichnet. Diese 20 Parzellen wurden kontinuierlich beprobt.

\subsection{Die Probeentnahmen}

3.2.1 Probenentnahme der Feinwurzelbodenproben - Das sequential coring-Verfahren

Im ersten Jahr wurden im Abstand von sechs Wochen Wurzel- und Blattproben genommen. Mit einem Stechzylinder $(\mathrm{d}=33 \mathrm{~mm}$, Länge ca. $45 \mathrm{~cm})$ wurden im ersten Jahr an acht Probeterminen je Plot jeweils 30 Erdproben aus den 20 gekennzeichneten Parzellen für die Feinwurzelselektionierung im sogenannten sequential coring-Verfahren (PERSSON 1980a, ABER 1985, VogT et al. 1986) entnommen. Zehn dieser Proben wurden für die Bestimmung des Bodenwassergehalts benötigt. Nach der Entnahme wurden die Proben für die Wurzelanalysen in organische Auflage und Mineralboden (bis $20 \mathrm{~cm}$ Tiefe) getrennt. Die Proben wurden beschriftet, in Polyethylenbeutel verpackt und auf der Station in einem Kühlschrank bei $4^{\circ} \mathrm{C}$ bis zur Weiterverarbeitung nach höchstens fünf Wochen gelagert.

\subsubsection{Die Auflagemächtigkeit}

Für die Auflagemächtigkeit wurde an drei Terminen in den drei Höhenstufen die Humusauflage im Bodenhorizont aller 20 Parzellen mit Hilfe eines Zollstocks ermittelt. Durch die Entnahme mit dem Bodenbohrer erfolgt eine Komprimierung der Horizonte, die nachträglich berechnet werden musste. Daher war es wichtig, die ursprüngliche Mächtigkeit der einzelnen Horizonte nachzuvollziehen. 


\subsubsection{Der Bodenwassergehalt}

Zur Bestimmung des Bodenwassergehalts wurden jeweils zehn frische Proben der Humusauflage und des Mineralbodens gewogen, bei $40^{\circ} \mathrm{C}$ bis zur vollständigen Trockenheit getrocknet und rückgewogen. Aus der Differenz von Frisch- und Trockengewicht wurde der Bodenwassergehalt in Prozent des Volumens errechnet.

\subsubsection{Grob- und Feinsortierung der lebenden und toten Feinwurzelmasse}

20 Bodenproben wurden zunächst einzeln mittels Wasser in einem Feinsieb $(0.25 \mathrm{~mm}$ Maschenweite) gewaschen, und die Feinwurzeln größer $1 \mathrm{~cm}$ Länge von Hand ausgelesen und in Petrischalen gesammelt. Unter dem Stereomikroskop wurden diese in Anlehnung an Persson (1978), Murach (1983) und Hertel (1999) nach folgenden Kriterien sortiert: bei den lebenden Feinwurzeln ist der Zentralzylinder meist hell, das Gewebe turgeszent, elastisch, biegsam, dabei kann ein Knirschen zu hören sein und relativ reißfest; Kohäsion zwischen Kortex und Periderm lässt sich feststellen. Die toten Feinwurzeln sind in der Regel starr, spröde und brechen leichter; oft ist das Gewebe des Zentralzylinders dunkler gefärbt, meistens nicht turgeszent, die Rinde löst sich eventuell vom darunter liegenden Gewebe ab.

In einem Trockenschrank wurden die nach Bio- und Nekromasse getrennten Feinwurzeln getrocknet (bei $40^{\circ} \mathrm{C}$ für 72 Stunden) und schließlich mit einer Feinanalysenwaage (Fa. Satorius, Göttingen) nach Trocknung gewogen.

In der Grobsortierung wurde die größte Biomasse an Feinwurzeln gefunden. Da es ebenfalls wichtig war, den großen Anteil an Bio (lebende) - und vor allem Nekromasse (tote Feinwurzeln) in der Feinstfraktionierung zu ermitteln, wurde eine von HERTEL (1999) beschriebene Methode zur Gesamtmassebestimmung herangezogen. Bis auf die von VAN PRAAG et al. (1988) und BAUHUS \& BARTSCH (1996) erwähnten Studien, sind vor allem für tropische Regenwälder bis auf Studien dieser Arbeitsgruppe, keine anderen Studien mit ähnlichem Methodenumfang bekannt.

Nach demselben Prinzip wie bei der Grobsortierung wurde eine Feinsortierung vorgenommen. Von den 20 aussortierten Bodenproben, wurde der Rest des mittlerweile im klaren Wasser verbliebenen Bodenmaterials in 14 Fällen verworfen und in sechs zufällig ausgewählten Proben zur Feinstfraktionierung herangezogen.

Dazu wurde ein Filter (28,5 x $29 \mathrm{~cm})$ in 36 gleich große Quadrate eingeteilt. Auf dieses Filter wurde das übriggebliebene Restmaterial zur Feinfraktionierung gleichmäßig aufgegeben. Nachdem sechs zufällig ausgewählt Quadrate ausgeschnitten worden waren, wurde das Material mit Wasser in eine Petrischale abgespült und ebenfalls unter einem 
Stereomikroskop analysiert. Aus der Petrischale wurden alle identifizierbaren Feinwurzelbestandteile inklusive der Wurzelspitzen aussortiert, ebenfalls lebende und tote Wurzeln nach der beschriebenen Methode voneinander getrennt, das Material bei $40{ }^{\circ} \mathrm{C} 72$ Stunden getrocknet und sein Trockengewicht anschließend durch Wägen bestimmt. Für die verbliebenen 14 Bodenproben wurde die Gesamtmasse anhand des toten Feinwurzelmaterials mittels linearer Regression zwischen der ausgelesenen Nekromasse (größer $1 \mathrm{~mm}$ Länge) und der mittels Verteilungsverfahren bestimmten Nekromasse der sechs quantitativ ausgelesenen Proben ermittelt.

Mit einer Feinanalysenwaage (Fa. Satorius, Göttingen) konnte das Trockengewicht ermittelt werden. Unter Berücksichtigung des Durchmessers des Bohrstockes wurden die bestimmten Mengen der Feinwurzelmasse pro $\mathrm{m}^{2}$ Bodenfläche berechnet. Beim Einschlagen des Bohrstockes konnte es vorkommen, dass der Boden komprimiert wurde. Um Fehler bei der Berechnung zu vermeiden, wurde die tatsächlichen Horizontmächtigkeiten ermittelt (siehe 3.2.2) und ein Korrekturfaktor je Horizont errechnet. Damit wurde ein Ausgleich geschaffen, um die durch den Bohrstock auftretende Komprimierung der Bodenproben mit der tatsächlichen Mächtigkeit des Bodens nachzuvollziehen. So konnte die Feinwurzeldichte pro Bodenvolumen errechnet werden.

Neben den verholzenden Arten gab es nur wenige krautige Arten (z. B. Araceaen) sowie einige Bambus- und Farngewächse auf den Versuchsflächen. Da es zu Beginn nicht möglich war diese Arten voneinander zu unterscheiden, wird im folgenden immer von der Gesamtbio- bzw. nekromasse aller Arten gesprochen, auch wenn es sich vorwiegend um verholzende Arten handelte.

\subsection{Bestimmung der Jahresproduktion, Umsatzrate, Jahresstreuproduktion und Mortalitätsrate von Feinwurzeln der drei Versuchsflächen}

\subsubsection{Die Minimum-Maximum-Methode}

Die Minimum-Maximum Methode ist ein einfaches Verfahren zur Berechnung der Jahresproduktion. Dabei werden kleinere saisonale Schwankungen der Feinwurzelbio- und Nekromasse ignoriert und die Jahresproduktion als Unterschied zwischen dem geringsten (Minimum) und höchsten (Maximum) Wert berechnet (EDWARDS \& HARRIS 1977, MCClaugherty et al. 1982). Für die Berechnung werden (Mittelwerte aus der Summe von Bio- und Nekromasse je Horizont) die Ergebnisse der regelmäßig genommenen Proben (sequential coring) und die Differenz zwischen dem signifikant unterschiedlichen Jahreshöchst- und Jahrestiefstwert als Jahresproduktion gewertet. Die Umsatzrate wurde aus dem Quotient aus jährlicher Feinwurzelproduktion und mittlere Feinwurzelbiomasse berechnet. 
Für die jährliche Feinwurzelmortalität $M$ wurde die Differenz aus Maximum- und Minimumwert der Bio- bzw. nekromasse (Signifikanz!) je Horizont ermittelt und nach den Rechenregeln entsprechend Tab. 3.1 zwischen den jeweils 20 Einzelwerten je Horizont berechnet. Das Mittel dieser Werte ergab die Feinwurzelmortalität. Die Mortalitätsrate der Feinwurzeln ergibt sich als Quotient aus jährlicher Feinwurzelmortalität und mittlerer Feinwurzelbiomasse.

\subsubsection{Die compartmental flow-Methode}

Die compartmental flow Methode ermittelt saisonale Produktionsraten, aus dem Mittel der 20 Einzelwerte der acht Beprobungen je Horizont, die letztlich zur Jahresproduktion addiert werden. Dazu werden die unterschiedlichen Parameter der Biomasse, Nekromasse und die Zersetzungsrate der Wurzelstreu eingesetzt (FAIRLEY \& ALEXANDER, 1985; HERTEL, 1999). Hierbei wurde nicht auf Signifikanz überprüft:

$$
\begin{aligned}
\mathrm{P} & =(\mathrm{B} 2+\mathrm{N} 2)-(\mathrm{B} 1+\mathrm{N} 1)+\mathrm{D} \\
& =(\mathrm{B} 2-\mathrm{B} 1)+(\mathrm{N} 2-\mathrm{N} 1)+\mathrm{D}
\end{aligned}
$$

\section{P: Produktion}

B2, B1: Biomasse zum Zeitpunkt 2 bzw. 1

N2, N1: Nekromasse zum Zeitpunt 2 bzw. 1

D: zersetzte Masse toter Feinwurzeln zwischen den Zeitpunkten 1 und 2

Um die nun aufeinanderfolgenden Messtermine $\mathrm{zu}$ gewichten, wurden nach MCClaugherty et al. (1982) und FAirley \& AleXANDER (1985) beschriebenen Rechenregeln angewendet. Da diese auch bei der Mortalität Anwendung finden, wurde die Berechnung für die Mortalität in Tabelle 3.1 integriert.

Im Falle der Produktion wurde die Veränderung der aufeinanderfolgenden Beprobungen gewichtet. Die Summe der so ermittelten sieben Werte je Horizont wird als Jahresproduktion dargestellt. Die Umsatzrate wurde aus dem Quotient der jährlichen Feinwurzelproduktion und der mittleren Feinwurzelbiomasse berechnet. 
Tab. 3.1: Schema zur Erklärung der Einteilung des Berechnungsverfahren nach MCCLAUGHERTY et al. (1982) und FAIRley \& AleXANDER (1985). B: Biomasse der Feinwurzeln, N: Nekromasse der Feinwurzeln, $\downarrow$ : Abnahme der Feinwurzelmasse, $\uparrow:$ Zunahme der Feinwurzelmasse, $\Delta$ : Betrag der Bio- oder Nekromasse, D: zersetzte Masse toter Feinwurzeln zwischen den Zeitpunkten 1 und 2

\begin{tabular}{|c|c|c|c|}
\hline Produktion & $\begin{array}{c}\text { Veränderung der } \\
\text { Biomasse }\end{array}$ & $\begin{array}{c}\text { Veränderung der } \\
\text { Nekromasse }\end{array}$ & Mortalität \\
\hline 0 & $\mathrm{~B} \downarrow$ & $\mathrm{N} \downarrow$ & $-\Delta \mathrm{B}$ \\
\hline $\begin{array}{c}\text { 1. wenn } \mathrm{B} \downarrow \\
\text { geringer/kleiner als } \\
\mathrm{N} \uparrow=\Delta \mathrm{N}+\Delta \mathrm{B}+\mathrm{D}\end{array}$ & $\mathrm{B} \downarrow$ & $\mathrm{N} \uparrow$ & $\begin{array}{c}\text { 1. wenn } \mathrm{B} \downarrow \\
\text { geringer } / \text { kleiner als } \\
\mathrm{N} \uparrow=\Delta \mathrm{N} \\
2 . \text { wenn B } \downarrow \\
\text { höher/größer als } \\
\mathrm{N} \uparrow=0\end{array}$ \\
\hline$\Delta \mathrm{N}+\Delta \mathrm{B}+\mathrm{D}$ & & & $\begin{array}{c}\text { 2. wenn } \mathrm{B} \downarrow \\
\text { höher/größer als } \\
\mathrm{N} \uparrow=-\Delta \mathrm{B}\end{array}$ \\
\hline$\Delta \mathrm{B}$ & & & $\Delta \mathrm{N}$ \\
\hline
\end{tabular}

Im Falle der Mortalität der Feinwurzeln (MCCLAUGHERTY et al. 1982) wurde ebenfalls überprüft, ob die aufeinanderfolgenden Beprobungen hinsichtlich der Bio- und Nekromasse eine Zunahme, Abnahme oder einen gleichbleibenden Wert zum vorherigen ergeben (Tab. 3.1). Hierbei wurde ebenfalls nicht auf Signifikanz überprüft. Die Summe der sieben Mittelwerte je Horizont ergibt die Mortalität. Die Mortalitätsrate der Feinwurzeln errechnet sich als Quotient aus jährlicher Feinwurzelmortalität und mittlerer Feinwurzelbiomasse.

\subsubsection{Regeneration der Feinwurzeln - Die ingrowth core-Methode}

Die ingrowth core-Methode (BöHM 1979) wurde als dritte Bestimmung für die Jahresproduktion herangezogen. Hierfür wurden auf jeder Höhenstufe 25 Bodenproben aus dem Boden am Rande der bezeichneten Parzellen mit einem Bohrstock $(54 \mathrm{~mm}$ Durchmesser) bis in $20 \mathrm{~cm}$ Bodentiefe des Mineralbodens gezogen. Der Bohrstock konnte mittels einer Schraubvorrichtung vertikal geöffnet werden. So konnten alle Grob- und Feinwurzeln, soweit dies mit der Hand möglich war, aus dem Boden nach Horizonten getrennt ausgelesen werden. Danach wurde dieser Boden entsprechend der Horizontabfolge wieder in das Bodenloch eingefüllt. Konnte nicht genügend Boden in das vorhandene Loch gegeben werden, wurde von einer benachbarten Stelle ebenfalls wurzelbefreiter Boden zur Herstellung der ursprünglichen Horizontmächtigkeit aufgefüllt. Die Stellen wurden mit Holzstäbchen markiert. Nach fünf Monaten wurden je drei der 
Bohrlöcher (ingrowth cores) wiederbeprobt, um zu kontrollieren, ob Wurzeln in den wurzelfreien Raum eingewachsen waren. Nach 500 Tagen wurden die Bohrlöcher beerntet, das Material in das Labor der Station gebracht, gereinigt, getrocknet und gewogen (siehe 3.2.4). Die Feinwurzelmasse wurde in $\mathrm{g}$ pro $\mathrm{m}^{2}$ berechnet.

\subsection{Untersuchungen zum Feinwurzelstreuabbau in litter bags}

Für die Versuche zum Abbau der Feinwurzeln in Feinwurzelstreuzersetzungsbeuteln (litter bags) wurden quadratische Netzbeutel von $10 \mathrm{~cm}$ x $10 \mathrm{~cm}$ Größe mit einer Maschenweite von $0.15 \mathrm{~cm}$ aus Nylongaze genäht. Aus der Humusauflage der drei Versuchsflächen wurden außerhalb der Parzellen frische Wurzeln mit einem Durchmesser kleiner als $2 \mathrm{~mm}$ entnommen, von Erde befreit und ins Labor gebracht. Jeweils $10 \mathrm{~g}$ frische Wurzeln wurden eingewogen, in die Beutelchen eingenäht und am folgenden Tag im Gelände ausgebracht. Sie wurden auf die Humusauflage der jeweiligen Versuchsflächen gelegt und mit Blattstreu abgedeckt. Pro Versuchsfläche wurden zehn Beutelchen ausgelegt. Parallel dazu wurden $10 \mathrm{~g}$ der eingesammelten Wurzeln bei $40^{\circ} \mathrm{C}$ getrocknet und erneut gewogen. Nach etwa 500 Tagen wurden die Beutelchen wieder eingeholt, von frischen Wurzeln und anderen eingewachsenen Pflanzenbestandteilen, wie z. B. Moos, befreit, ebenfalls bei $40^{\circ}$ $\mathrm{C}$ getrocknet und das Trockengewicht bestimmt. Aus der Differenz des Trockengewichts vor und nach dem Auslegen konnte der Gewichtsverlust im Bestand während der Verweildauer errechnet werden (vgl. FAHEY et al. 1988, BLOOMFIELD et al. 1993, LÕHMUS \& IVASK 1995 und ARUNACHALAM et al. 1996). Nach der Berechnung des täglichen Gewichtsverlustes konnten die Werte für die Bestimmung der saisonale Wurzelproduktion eingesetzt werden (Kapitel 3.3.2).

\subsection{Untersuchungen zur Morphologie der Feinwurzeln}

\subsubsection{Wurzelspitzenhäufigkeit}

An jedem Untersuchungstermin wurden aus jeder Probe der Humusauflage und dem Mineralboden vier lebende Feinwurzelstränge zufällig entnommen und unter dem Stereomikroskop die Anzahl lebender Wurzelspitzen gezählt (PERSSON 1980b, KoTTKE \& Agerer 1983, Meyer 1987). Anhand des Gewichts der Feinwurzelstränge und der Anzahl der Spitzen wurde so die Spitzenhäufigkeit ( $\mathrm{n} \mathrm{g}^{-1}$ Trockenmasse) bestimmt.

\subsubsection{Durchmesser und spezifische Oberfläche der Feinwurzeln (specific root area, SRA)}

Die spezifische Oberfläche der Feinwurzeln wurde mit Hilfe des Computerprogramms WinRHIZO (Fa. Régent Instruments Inc., Canada) ermittelt. Von jeder Probe der Feinwurzelbiomasse wurden vier Wurzelstränge in einer mit Wasser befüllten Petrischale mittels eines Flachbettscanners unter Aufsichtbeleuchtung abgetastet. Aus den digitalen 
Bildern konnte die Gesamtoberfläche und der Durchmesser der einzelnen Feinwurzelstränge sowie der Anteil der unterschiedlichen Wurzeldurchmesserklassen der Gesamtoberfläche bestimmt werden. Nach der Trocknung bei $70^{\circ} \mathrm{C}$ und Wägung konnte die spezifische Oberfläche, SRA (der Quotient aus der Feinwurzeloberfläche zum Feinwurzelgewicht, $\mathrm{cm}^{2}$ pro $\mathrm{g}$ Trockenmasse) berechnet werden.

3.6 Bestandesspitzenzahl und Wurzelflächenindex (RAI)

\subsubsection{Bestandesspitzenzahl und -dichte}

Bezogen auf die ermittelte Gesamtbiomasse an Feinwurzeln wurde die Gesamtzahl an Wurzelspitzen (siehe 3.5.1) in einem Quadratmeter Boden $\left(\mathrm{n} \cdot 10^{4}\right.$ pro $\mathrm{m}^{2}$ ) und die Dichte pro Bodenvolumen (n pro $100 \mathrm{~mL}$ ) errechnet.

\subsubsection{Wurzelflächenindex (root area index, RAI)}

Der Wurzelflächenindex stellt die Wurzeloberfläche bezogen auf den $\mathrm{m}^{2}$ Boden dar und gibt damit ein Maß für die Durchwurzelung des Boden an. Um den RAI zu erhalten wird die spezifische Wurzeloberfläche $\left(\mathrm{cm}^{2}\right.$ pro g) (siehe 3.5.2) mit der mittleren Feinwurzelbiomasse der beiden untersuchten Horizonte multipliziert. Das Produkt aus beiden wird in $\mathrm{m}^{2}$ pro $\mathrm{m}^{2}$ dargestellt.

\subsection{Bestimmung der Kohlenstoff- und Stickstoffkonzentrationen der Feinwurzeln}

Alle Feinwurzeln wurden sortiert, getrocknet und zur Bestimmung des C/N-Verhältnisses in einer Scheiben-Schwing-Mühle (Siebtechnik) zu feinem Staub zermahlen. Die Bestimmung der Stickstoff- bzw. Kohlenstoffkonzentrationen fand mit Hilfe eines C/NAnalysers (Vario EL 3, Fa. Elementar, Hanau) in Göttingen statt. In diesem Analyseverfahren werden unter Verbrennung und gaschromatischer Trennung (Trägergas: Helium) die Gase $\mathrm{N}_{2}$ und $\mathrm{CO}_{2}$ bestimmt (nach Hertel 1999, Vario EL, Anleitung). Anhand der Einwaagemenge (ca. $5 \mathrm{mg}$ ), und den Ergebnissen der Blindprobe wurden zunächst die absoluten Mengen an $\mathrm{N}$ bzw. $\mathrm{C}$ berechnet. Um diese Werte mit in der Literatur angegebenen Werten vergleichen zu können, wurden sie in mmol pro mmol C bzw. mmol pro mmol $\mathrm{N}$ und das Verhältnis von $\mathrm{C}$ zu N angegeben. 


\subsection{Blattstreuproduktion}

3.8.1 Probenahmen der Blätter, saisonaler Verlauf und Blattstreuproduktion

Auf jeder der drei Versuchsflächen wurden 12 Streufänger aus einer hölzernen Rahmenkonstruktion von etwa 45 x $45 \mathrm{~cm}$ Größe ca. $50 \mathrm{~cm}$ oberhalb des Bodens aufgestellt. Die Streufänger wurden mit Nylongaze (Maschenweite $0.15 \mathrm{~cm}$ ) bespannt und zeitgleich zur Wurzelprobeentnahme geleert. Die Blätter, ebenso wenige sehr kleine Blüten und Früchte, wurden ausgelesen, getrocknet (bei $40{ }^{\circ} \mathrm{C}$ für 72 Stunden) und bilanziert. Große Blüten, Früchte und Aststücke wurden verworfen. Um die erhaltene Blattstreu zu bestimmen, wurde die Grundfläche der Fänger auf $\mathrm{m}^{2}$ umgerechnet und mit dem Trockengewicht der Blätter multipliziert. Die sechswöchigen Beprobungen wurden schließlich über Tageswerte in Monatswerte umgerechnet. Pro Fänger und Versuchsfläche konnte so der saisonale Verlauf aufgetragen und aus der Summe die Jahresblattstreuproduktion ( $\mathrm{g} \mathrm{m}^{-2} \mathrm{Jahr}$ ) berechnet werden.

\subsubsection{Spezifische Oberfläche der Blätter (specific leaf area, SLA)}

Die spezifische Oberfläche der Blätter wurde mit Hilfe des Computerprogramms WinFOLIA (Fa. Régent Insturments Inc., Canada) untersucht.

Dazu wurden alle (max. 35) Blätter aus einem Streufänger mit einem Flachbettscanner eingelesen. Aus den digital erhaltenen Bildern wurde mit Hilfe von WinFOLIA die Gesamtoberfläche und der Blattdurchmesser bestimmt. Löcher, die in den Blättern vorhanden waren, wurden separat erfasst, und flossen nicht in die Berechnung der Gesamtoberfläche ein. Die spezifische Blattoberfläche (SLA) wurde als Quotient aus Blattoberfläche und Blattgewicht ( $\mathrm{cm}^{2}$ pro g Trockenmasse) ausgewertet. Zusätzlich wurde die jährliche Blattstreufläche (leaf aera fallen, LAF) in $\mathrm{m}^{2}$ pro $\mathrm{m}^{2}$ aus dem Produkt von SLA und der Summe des mittleren Jahresblattfalls (g pro $\mathrm{m}$ ) errechnet.

\subsubsection{Bestimmung der Kohlenstoff- und Stickstoffkonzentrationen der Blätter}

Aus jedem Streufänger wurde ein Mischung der darin vorhandenen Blattproben ausgewählt, sortiert und im selben Verfahren wie bei der Feinwurzeln bestimmt (siehe 3.7). Die Werte wurden ebenfalls in mmol pro mmol $\mathrm{C}$ bzw. mmol pro $\mathrm{mmol} \mathrm{N}$ angegeben und das Verhältnis von $\mathrm{C}$ zu N berechnet.

\subsection{Statistische Auswertung}

Es wurden mit Microsoft Excel Mittelwerte und Standardfehler für alle Daten berechnet. Für statistische Berechnungen wurde das Programm SAS (Cary, NC, USA) benutzt. 
Zuerst wurde untersucht, ob die erhaltenen Werte normalverteilt sind (SHAPIRO \& WILK Test, $\mathrm{p}<0.05)$. In den meisten Fällen traten nicht-normalverteilte Werte auf. Für die Ermittlung auf signifikante Unterschiede wurden daraufhin nichtparametrische, verteilungsunabhängige Testverfahren für mehrere Stichproben, meist WILCOXON-U-Tests (MANN \& WHITNEY) für unbalancierte, unabhängige Werte angewendet. Für normalverteilte Daten wurde zur Ermittlung der signifikanten Unterschiede der Test nach SCHEFFÉ durchgeführt. Weiterhin wurden lineare Regressionen zur Berechnung der Korrelationskoeffizienten und des Signifikanzniveaus zwischen unterschiedlichen Parametern mit dem Computerprogramm Xact (Fa. SciLab, Hamburg) untersucht. Mit diesem Programm wurden Grafiken und lineare Zusammenhänge dargestellt. 


\section{Ergebnisse}

\subsection{Auflagemächtigkeit}

Die Humusauflage zeigt unterschiedliche Auflagemächtigkeiten, die hier unkomprimiert und ohne Hohlräume angegeben wurden. Sie liegt bei 1890 m um 18 cm, auf 2380 m um 16 cm und steigt mit der Höhe auf $24 \mathrm{~cm}$ an; auf $3060 \mathrm{~m}$ ist die Auflage ca. 41 \% mächtiger als auf den beiden anderen Beprobungsflächen (Abb. 4.1). Auf dieser Höhenstufe befinden sich zwischen der Humusauflage und dem Quarzgestein teilweise große Hohlräume und kaum Mineralboden.

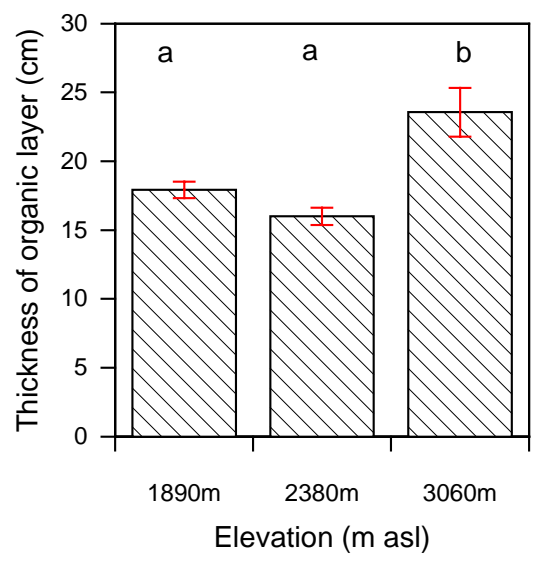

Abb. 4.1: Mächtigkeit der organischen Auflage (cm) der Waldflächen auf den drei Höhenstufen. Angegeben sind Mittelwerte und Standardfehler $(\mathrm{n}=3)$. Unterschiedliche Buchstaben kennzeichnen signifikante Unterschiede zwischen den drei Höhenstufen, U-Test nach Mann \& Whitney $(\mathrm{p}<0.05)$.

\subsection{Bodenwassergehalt}

Der Mittelwert des volumetrischen Bodenwassergehalts wurde aus der Summe aller Bodenfeuchtebestimmungen von Humusauflage und Mineralboden gebildet. Er beträgt für die Fläche auf $1890 \mathrm{~m} \mathrm{Vol.} 19$ \% und ist damit deutlich niedriger als die Mittelwerte der beiden anderen Flächen, die jeweils eine mittlere Bodenfeuchte von etwa 30 Vol. \% aufweisen und damit um einen Faktor von 1.6 höher liegen (Abb. 4.2A).

Die Variationskoeffizienten für die Daten des Bodenwassergehalts zeigen, dass sehr große Schwankungen zwischen den einzelnen Höhen und Horizonten vorhanden sind. So liegt der Variationskoeffizient in der Humusauflage auf 1890 m Höhe bei 47, auf 2380 m Höhe bei 60 und auf 3060 m Höhe bei 34 \%. Im Mineralboden liegen die Werte etwas näher beieinander. Auf 1890 m Höhe ergibt sich hier ein Variationskoeffizient von 41, auf $2380 \mathrm{~m}$ Höhe von 29 und auf 3060 m Höhe von 39 \%. Sehr inhomogen sind die Werte zwischen Humusauflage auf 2380 m Höhe und dessen Mineralboden, hier liegt die Differenz bei 31 $\%$. 
Im Jahresverlauf weist die Humusauflage in 3060 m Höhe den höchsten, die in 1890 m Höhe den niedrigsten Wassergehalt auf (Abb. 4.2B). Auf 1890m Höhe liegt das Maximum des Bodenwassergehalts im Februar 02, das Minimum im August 02. Die mittlere Höhenstufe (2380 m Höhe) weist ihr Maximum im Januar 02 und das Minimum im April 02 auf. Auf der höchsten Fläche, auf 3060 m Höhe wird der höchste Bodenwassergehalt im Februar 02 und der geringste im Juli 02 gemessen. Die größten Schwankungen im Jahresverlauf des vol. Bodenwassergehaltes, zwischen 25 und 45 Vol. \%, treten auf der höchsten Untersuchungsfläche auf 3060 m Höhe auf.

Der Jahresverlauf im Mineralboden hingegen zeigt ein anderes Bild. Die mittlere Fläche auf 2380 m Höhe zeigt fast ständig die höchsten Bodenwassergehalte und hat ihr Maximum im Mai 02, welches sich mit 50 Vol. \% deutlich höher liegt als die anderen Werte. Das Minimum liegt im Dezember 01. Auf 1890 m Höhe befindet sich das Maximum im August 02, das Minimum im Januar 02. Die höchste Fläche auf 3060 m Höhe liegt im mittleren Bereich, maximale Werte erreichen im Oktober 01 etwa $40 \mathrm{Vol}$. \%, während die geringsten Bodenwassergehalte im April 02 bei etwa 20 Vol. \% liegen. Allgemein sind die Unterschiede im Bodenwassergehalt zwischen den Untersuchungsflächen in der Humusauflage größer als im Mineralboden.

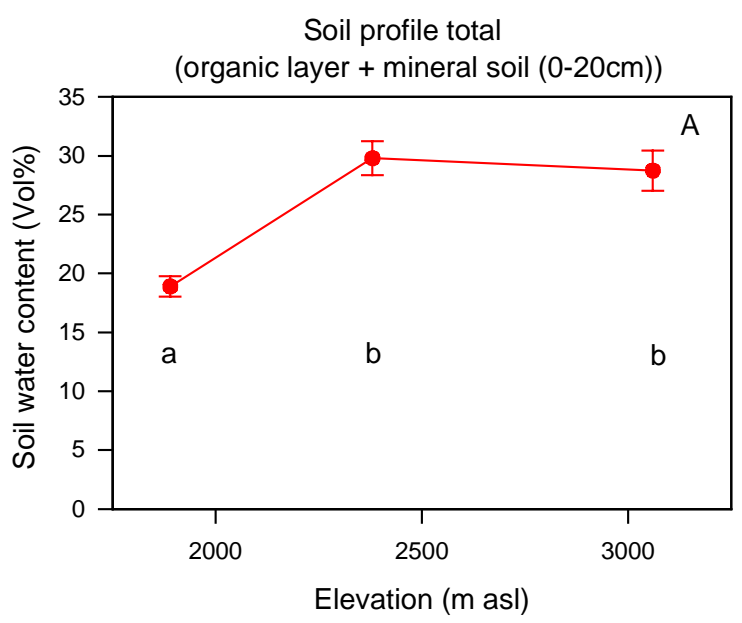

Abb. 4.2 A: Bodenwassergehalt (Vol. \%) im Bodenprofil (total) (A). Unterschiedliche Buchstaben für Abb. 4.2A kennzeichnen signifikante Unterschiede zwischen den drei Höhenstufen, U-Test nach Mann \& Whitney $(\mathrm{p}<0.05)$. Angegeben sind Mittelwerte und Standardfehler $(\mathrm{n}=10)$. 

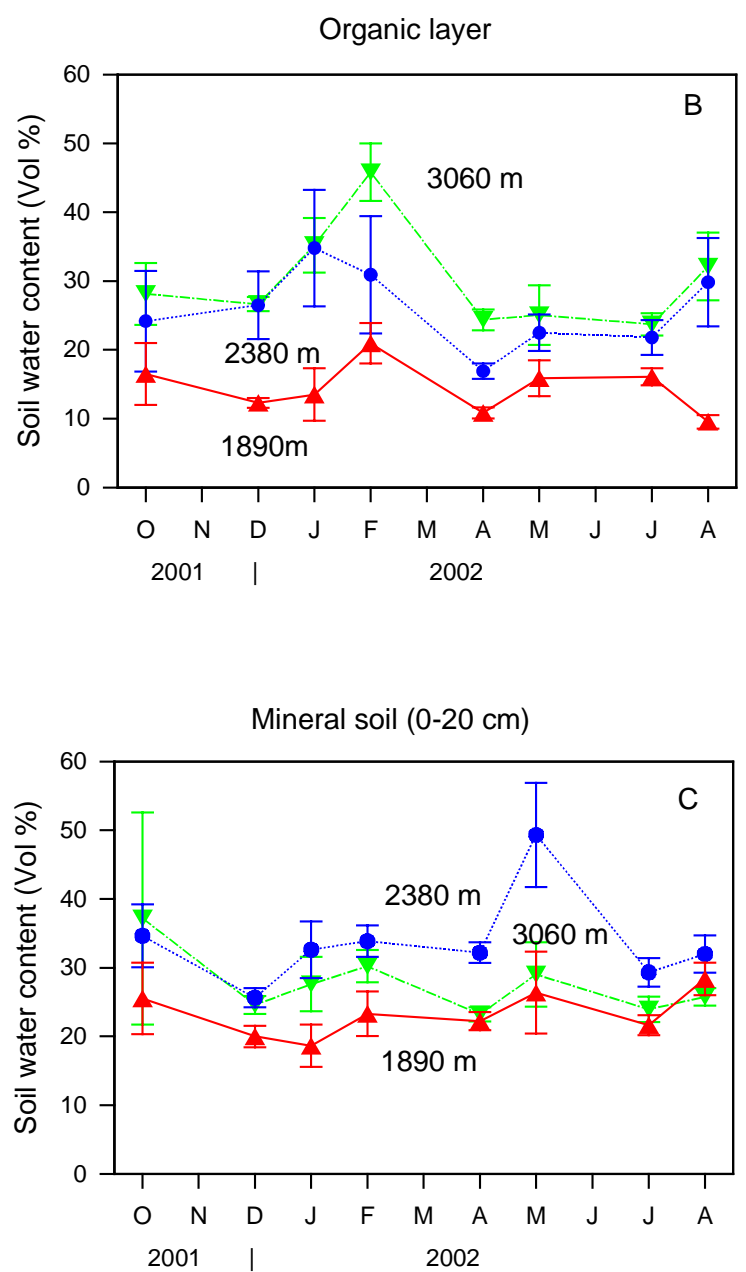

Abb. 4.2 B-C: Saisonale Veränderung des Bodenwassergehalts (Vol. \%) im Untersuchungszeitraum (B und C). Angegeben sind Mittelwerte und Standardfehler $(\mathrm{n}=10)$.

4.3 Mittlere Feinwurzelbio und -nekromasse

4.3.1 Mittlere Feinwurzelbio und -nekromasse (bis $20 \mathrm{~cm}$ Mineralboden)

Die größte Masse an Feinwurzeln findet sich in der Humusauflage auf 3060 m Höhe mit durchschnittlich etwa $645 \mathrm{~g} \mathrm{~m}^{-2}$ (Abb. 4.3A-B). Es folgt die mittlere Fläche auf $2380 \mathrm{~m}$ Höhe mit $361 \mathrm{~g} \mathrm{~m}^{-2}$ und schließlich die unterste Fläche auf $1890 \mathrm{~m}$ Höhe mit $244 \mathrm{~g} \mathrm{~m}^{-2}$. Die Biomasse nimmt von der höchst gelegenen Fläche zur untersten Fläche etwa um den Faktor 2.64 ab. Im Mineralboden in 3060 m Höhe erreichen die lebenden Feinwurzeln einen durchschnittlichen Wert von $333 \mathrm{~g} \mathrm{~m}^{-2}$; auf $2380 \mathrm{~m}$ Höhe sind es noch $178 \mathrm{~g} \mathrm{~m}^{-2}$ und auf 1890 m Höhe $150 \mathrm{~g} \mathrm{~m}^{-2}$. Im Mineralboden zeigt sich nur eine Abnahme um die Hälfte der Biomasse von der obersten zur untersten Fläche. Für die Biomasse insgesamt gilt, dass in der Humusauflage etwa die doppelte Menge an Feinwurzeln vorhanden ist wie im Mineralboden.

Auf der obersten Fläche auf $3060 \mathrm{~m}$ beträgt die Nekromasse in der Humusauflage durchschnittlich $1178 \mathrm{~g} \mathrm{~m}^{-2}$. Auf $2380 \mathrm{~m}$ Höhe ergibt sich im Mittel eine Masse von $609 \mathrm{~g}$ $\mathrm{m}^{-2}$. Mit $470 \mathrm{~g} \mathrm{~m}^{-2}$ ist die Feinwurzelnekromasse in der Humusauflage in $1890 \mathrm{~m}$ Höhe am 
geringsten. Dies bedeutet, dass die Nekromasse von der obersten zur untersten Versuchsfläche um den Faktor 2.5 an Masse abnimmt. Es zeigt sich, dass vor allem die Feinwurzelnekromasse im Mineralboden auf 3060 m Höhe hohe Werte aufweist. Die durchschnittliche Masse an toten Feinwurzeln beträgt für $3060 \mathrm{~m} 1220 \mathrm{~g} \mathrm{~m}^{-2}$, für $2380 \mathrm{~m}$

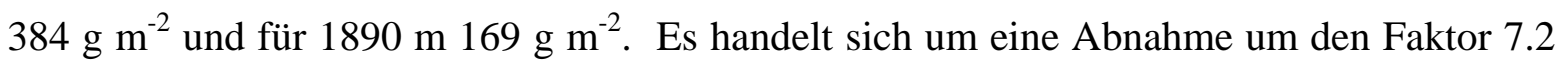
von der obersten zur untersten Fläche.

\subsubsection{Feinwurzelmassen inklusive des Mineralbodens von 20-40 cm}

Der Jahresdurchschnitt aller Mittelwerte der Feinwurzelmasse zeigt eine dem Höhengradienten folgend steigende Tendenz, sowohl in der Biomasse beider Horizonte als auch in den beiden Mineralbodenhorizonten.

Die Feinwurzelbiomasse beträgt, dem Höhengradienten nach oben folgend, $535 \mathrm{~g} \mathrm{~m}^{-2}, 588 \mathrm{~g}$ $\mathrm{m}^{-2}$ und $1073 \mathrm{~g} \mathrm{~m}^{-2}$. Für die Nekromasse liegen die Werte, ebenfalls dem Höhengradienten folgend bei $730 \mathrm{~g} \mathrm{~m}^{-2}, 1040 \mathrm{~g} \mathrm{~m}^{-2}$ und $2733 \mathrm{~g} \mathrm{~m}^{-2}$. Damit ergibt sich eine Steigerung um das Doppelte für die Feinwurzelbiomasse, während die Nekromasse entsprechend um den Faktor 3.7 zunimmt.
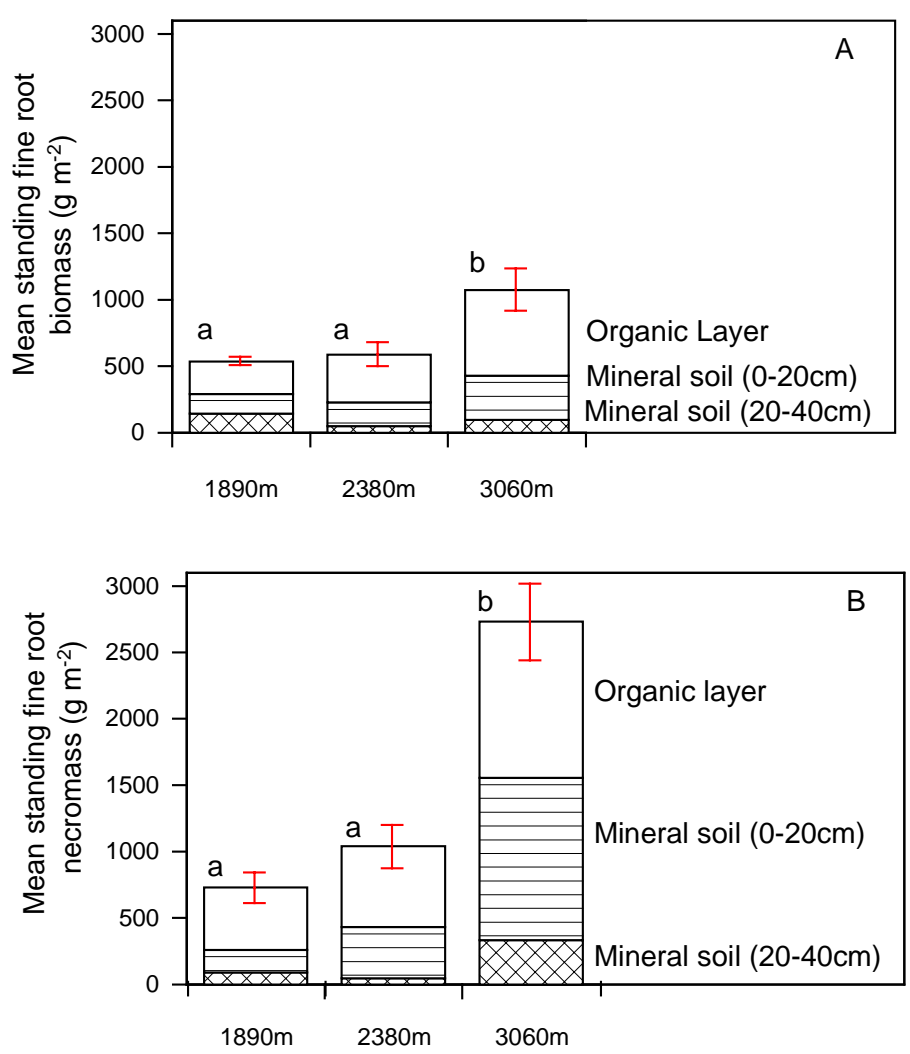

Abb. 4.3 A-B: Mittlere Bestandesmasse an lebenden und toten Feinwurzeln $\left(\mathrm{g} \mathrm{m}^{-2}\right)$ der Untersuchungsflächen auf drei Höhenstufen in der Humusauflage und den beiden darunter liegenden Mineralbodentiefen $(0-20 \mathrm{~cm}$ und 20-40 cm Tiefe) im Untersuchungszeitraum (Okt. 01 - Aug. 02). Die Daten der Wurzelmasse Mineralboden 20-40 cm wurden von BERTSCH (2003) ermittelt, U-Test nach Mann \& Whitney (p $<0.05$ ). Angegeben ist der Standardfehler $(n=8)$ der Gesamtfeinwurzelmasse je Horizont. 


\subsubsection{Das Bio- Nekromassenverhältnis}

Das Verhältnis von Biomasse zu Nekromasse auf den drei Höhenstufen sinkt im Durchschnitt von 0.73 bei 1890 m Höhe über 0.61 bei 2380 m Höhe auf 0.43 bei $3060 \mathrm{~m}$ Höhe, insgesamt um den Faktor 1.7, ab (Tab. 4.1). Die im Verlauf der einzelnen Beprobungen bestimmten Werte für das Verhältnis schwanken sehr stark. Deutlich wird vor allem, dass der besonders hohe Anteil an Nekromasse in 3060 m Höhe (siehe Abb. 4.3B) zu einem besonders niedrigen Verhältnis führt.

Tab. 4.1: Das Verhältnis von Biomasse zur Nekromasse an acht Terminen im Beprobungszeitraum (Humusauflage und Mineralboden $(0-20 \mathrm{~cm}$ Tiefe) getrennt) auf drei Höhenstufen. Unterschiedliche Buchstaben kennzeichnen signifikante Unterschiede zwischen den drei Höhenstufen, Scheffé Test $(p<0.05)$. Angegeben sind Mittelwerte $(n=8)$.

\begin{tabular}{|c|c|c|c|c|c|c|}
\hline \multirow[b]{3}{*}{ Samples } & \multicolumn{5}{|c|}{$\begin{array}{l}\text { Bio/necromass ratio in } \\
\text { elevation (m asl) }\end{array}$} & \multirow[b]{2}{*}{$3060 \mathrm{~m}$} \\
\hline & $1890 \mathrm{~m}$ & $1890 \mathrm{~m}$ & $2380 \mathrm{~m}$ & $2380 \mathrm{~m}$ & $3060 \mathrm{~m}$ & \\
\hline & Organic layer & $\begin{array}{l}\text { Mineral } \\
\text { soil }\end{array}$ & Organic layer & $\begin{array}{c}\text { Mineral } \\
\text { soil }\end{array}$ & Organic layer & $\begin{array}{c}\text { Minera } \\
\text { soil }\end{array}$ \\
\hline 1 & 0.55 & 0.68 & 0.98 & 0.84 & 0.69 & 0.37 \\
\hline 2 & 0.57 & 0.84 & 0.31 & 0.54 & 0.57 & 0.20 \\
\hline 3 & 0.53 & 0.76 & 0.69 & 1.12 & 0.44 & 0.22 \\
\hline 4 & 0.40 & 1.63 & 0.42 & 0.40 & 0.40 & 0.45 \\
\hline 5 & 0.65 & 0.82 & 0.79 & 0.57 & 0.55 & 0.42 \\
\hline 6 & 0.67 & 1.34 & 0.89 & 0.61 & 0.69 & 0.28 \\
\hline 7 & 0.49 & 0.59 & 0.70 & 0.24 & 0.69 & 0.16 \\
\hline 8 & 0.37 & 0.86 & 0.46 & 0.19 & 0.54 & 0.27 \\
\hline total & $0.53^{a}$ & $0.94^{\mathrm{A}}$ & $0.65^{a}$ & $0.56^{\mathrm{B}}$ & $0.57^{\mathrm{a}}$ & $0.29^{\mathrm{B}}$ \\
\hline
\end{tabular}

\subsection{Feinwurzeldichte}

\subsubsection{Vertikalverteilung der Feinwurzeldichte}

Wie bei der Feinwurzelbiomasse und -nekromasse zeigt sich auch bei der Feinwurzeldichte (g Trockensubstanz pro L) eine Zunahme mit zunehmender Höhe (Abb. 4.6A-B). Entlang des Höhengradienten nimmt die Feinwurzeldichte in der Humusauflage von $3.03 \mathrm{~g} \mathrm{~L}^{-1}$ in 3060 m Höhe auf $1.59 \mathrm{~g} \mathrm{~L}^{-1}$ in 1890 m Höhe, ungefähr um die Hälfte ab (Abb. 4.4A). Ähnlich verhält sich die Feinwurzeldichte im Mineralboden bis 20 cm. Von 3060 m Höhe verringert sich die Dichte um $1.63 \mathrm{~g} \mathrm{~L}^{-1}$ auf $0.67 \mathrm{~g} \mathrm{~L}^{-1}$, um den Faktor 2.4. Abweichend davon sind die Werte im Mineralboden in 20-40 cm Tiefe zwischen den Höhenstufen. Hier zeigt die tiefst gelegene Höhenstufe 1890 m Höhe den höchsten Wert mit $1.1 \mathrm{~g} \mathrm{~L}^{-1}$ und die 
mittlere Höhenstufe auf 2380 m Höhe den geringsten Wert der Feinwurzeldichte von 0.36 g $\mathrm{L}^{-1}$ (Faktor 3.1).

Sehr viel deutlicher zeigt sich der Unterschied im Höhengradienten bei der Auftragung der Dichte der toten Feinwurzeln (Abb. 4.4B). Die am höchsten gelegene Untersuchungsfläche weist in den drei untersuchten Bodentiefen jeweils die größten Dichten an toten Feinwurzeln auf. Maximale Werte wurden hier auf $3060 \mathrm{~m}$ Höhe mit $6.26 \mathrm{~g} \mathrm{~L}^{-1}$ in einer Mineralbodentiefe von 0-20 cm gefunden. In der organischen Auflage sinken die Werte von $5.54 \mathrm{~g} \mathrm{~L}^{-1}$ auf $3060 \mathrm{~m}$ Höhe um den Faktor 1.7 auf $3.21 \mathrm{~g} \mathrm{~L}^{-1}$ auf $1890 \mathrm{~m}$ Höhe ab. Dagegen ist der Unterschied im Mineralboden 0-20 cm deutlicher. Von $6.26 \mathrm{~g} \mathrm{~L}^{-1}$ auf $3060 \mathrm{~m}$ Höhe verringert sich die Dichte der toten Feinwurzeln um den Faktor 8.1 auf $0.77 \mathrm{~g} \mathrm{~L}^{-1}$ auf 1890 m Höhe. Im Mineralboden von 20-40 cm Tiefe nimmt die Dichte von $2.7 \mathrm{~g} \mathrm{~L}^{-1}$ (3060 m Höhe) um den Faktor 6.7 auf $0.4 \mathrm{~g} \mathrm{~L}^{-1}$ auf 2380 m Höhe ab. Hier zeigt sich, dass die Dichte der toten Feinwurzeln der untersten Fläche auf $1890 \mathrm{~m}$ mit $0.64 \mathrm{~g} \mathrm{~L}^{-1}$ minimal höher liegt, als die der mittleren (2380 m Höhe) mit $0.4 \mathrm{~g} \mathrm{~L}^{-1}$.

Betrachtet man die Vertikalverteilung der lebenden Feinwurzeldichte, zeigen die Flächen auf 3060 m Höhe und 2380 m Höhe eine deutliche Abnahme mit der Bodentiefe. Bei 3060 m Höhe sinken die Werte um den Faktor 4.2, bei 2380 m Höhe um den Faktor 6.2. Lediglich die Fläche auf $1890 \mathrm{~m}$ Höhe verzeichnet zuerst ein Abnahme zum Bereich des Mineralbodens 0-20 cm, danach eine Zunahme (Mineralboden 20-40 cm). Insgesamt verringert sich damit die Feinwurzeldichte nur um den Faktor 1.5 (HumusauflageMineralboden 20-40 cm).

Ähnliches lässt sich für die Dichte der toten Feinwurzeln beobachten. Hier nehmen die Dichten auf den Flächen 2380 m Höhe und 1890 m Höhe mit zunehmender Tiefe des Bodens ab. Auf 3060 m Höhe dagegen steigt die Dichte von der Humusauflage zum Mineralboden 0-20 cm um $0.72 \mathrm{~g} \mathrm{~L}^{-1}$ an. Mit zunehmender Tiefe, im Bereich des Mineralbodens 20-40 cm sinkt sie stark ab, so dass ebenfalls von einer Abnahme (Humusauflage-Mineralboden 20-40 cm) um den Faktor 2.1 gesprochen werden kann. 


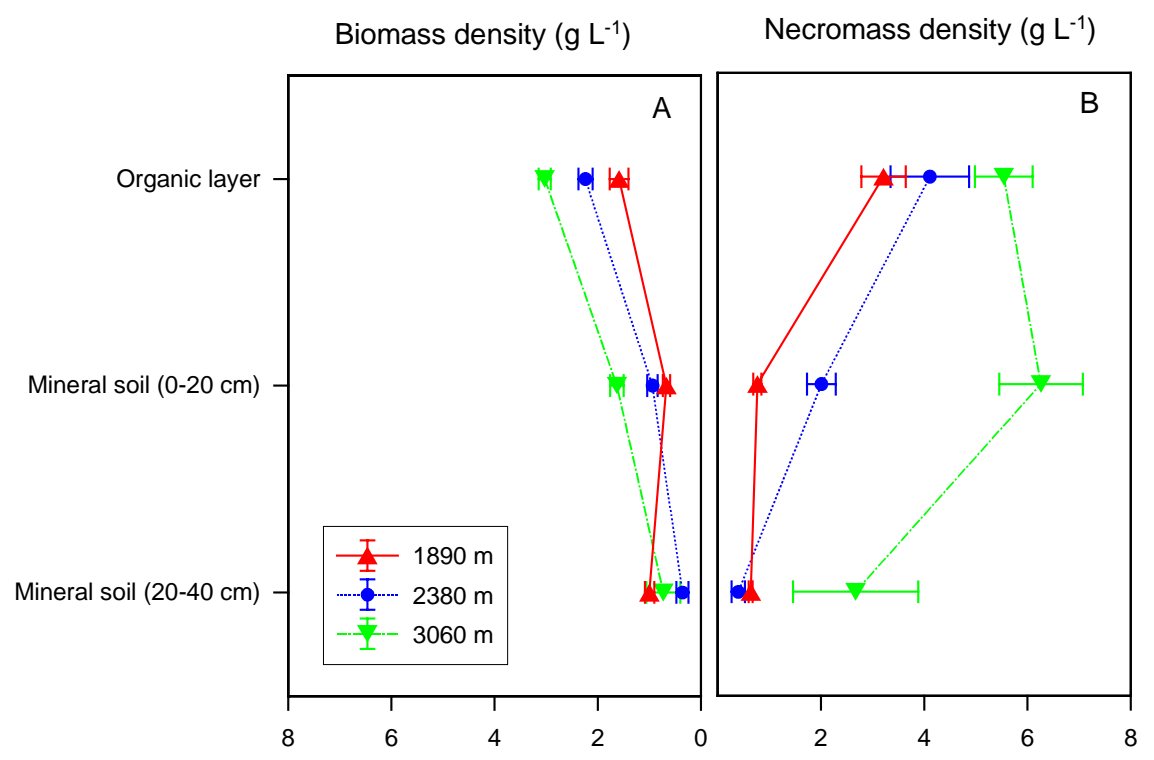

Abb. 4.4 A-B: Vertikale Verteilung der Feinwurzeldichte auf den drei Höhenstufen im Untersuchungszeitraum. Es sind Mittelwerte und Standardfehler $(\mathrm{n}=8)$ der drei Beprobungsflächen, in Humusauflage, Mineralboden 0-20 cm und 20-40 cm dargestellt. Links ist die Dichte der lebenden, rechts die Dichte der toten Feinwurzeln $\left(\mathrm{g} \mathrm{L}^{-1}\right)$ aufgetragen. Die Daten der Wurzelmasse im Mineralboden 20-40 cm wurden von BERTSCH (2003) ermittelt.

\subsection{Feinwurzeldynamik}

4.5.1 Saisonale Veränderung von lebender und toter Feinwurzelmasse

Die Feinwurzelbiomasse in der organischen Auflage (Abb. 4.5A) zeigt im Jahresverlauf für alle drei Höhenstufen eine abnehmende Tendenz. So zeigen Maxima für alle drei Höhenstufen etwa zu Beginn der Untersuchungen und die Minima am Ende des Untersuchungszeitraums. Im Mineralboden ist insgesamt weniger Feinwurzelbiomasse vorhanden (Abb. 4.5B). Auf der obersten Fläche auf 3060 m Höhe liegt das Maximum im April 02 und das Minimum im Juli 02. Die mittlere Fläche auf $2380 \mathrm{~m}$ hat parallel zu der untersten Fläche ihr Maximum an Feinwurzeln im Mai 02 und ihr Minimum im August 02. Auf $2380 \mathrm{~m}$ Höhe (128 $\mathrm{g} \mathrm{m}^{-2}$ ) ist geringfügig weniger Feinwurzelbiomasse als auf $1890 \mathrm{~m}$ Höhe $\left(121 \mathrm{~g} \mathrm{~m}^{-2}\right)$ zu erkennen. Bemerkenswert ist der weitgehend parallele Jahresgang.

Insgesamt gibt es mehr Feinwurzelnekromasse als Feinwurzelbiomasse, sowohl in der Humusauflage, als auch im Mineralboden. Es ist kein jahreszeitlich einheitlicher Trend für alle drei Höhenstufen zu beobachten. Auf der obersten Fläche auf 3060 m Höhe sinkt die Nekromasse in der Humusauflage nach einem Anstieg in der trockneren Jahreszeit zwischen Oktober 01 und Februar 02 in der feuchteren Jahreszeit ab (Abb. 4.5C). Ihr Maximum liegt im Februar 02 und ihr Minimum im Juli 02. Diese Fläche zeigt sowohl die größten Massen als auch die größten Schwankungen im Untersuchungszeitraum. Die mittlere Fläche auf 2380 m lässt im Dezember 01 und im Februar 02 zwei Spitzen erkennen, wobei das Maximum im Dezember 01 liegt. Das Minimum ist auf dieser Fläche im Juli 02. Bei den 
Feinwurzelnekromassen auf 2380 m Höhe und 1890 m Höhe liegen die Werte während des Jahresverlaufs ebenfalls näher beieinander als im Vergleich zu 3060 m Höhe, auch wenn der Verlauf zwischen ihnen nicht gleichsinnig ist.

Auf der untersten Fläche auf 1890 m Höhe liegt das Maximum ebenfalls im Februar 02 und das Minimum der Feinwurzelnekromasse in der Humusauflage im Juli 02. Damit liegt das Minimum auf allen drei Höhenstufen im Juli 02. Der Mineralboden der Feinwurzelnekromasse zeigen sich auf 3060 m Höhe zwei eindeutige Spitzenwerte im Dezember 01 und im Juli 01, wobei der Dezemberwert das Maximum darstellt (Abb. 4.5D). Das Minimum liegt auf dieser Fläche im Februar 02. Auf der mittleren Fläche auf $2380 \mathrm{~m}$ Höhe steigt die Nekromasse ab Januar 02, hier hat sie ihr Minimum, stetig bis zum Maximum im August 02 hin an. Die unterste Fläche, auf 1890 m Höhe scheint eher ausgeglichen, das Maximum ist im Juli 02 und das Minimum im Februar 02.
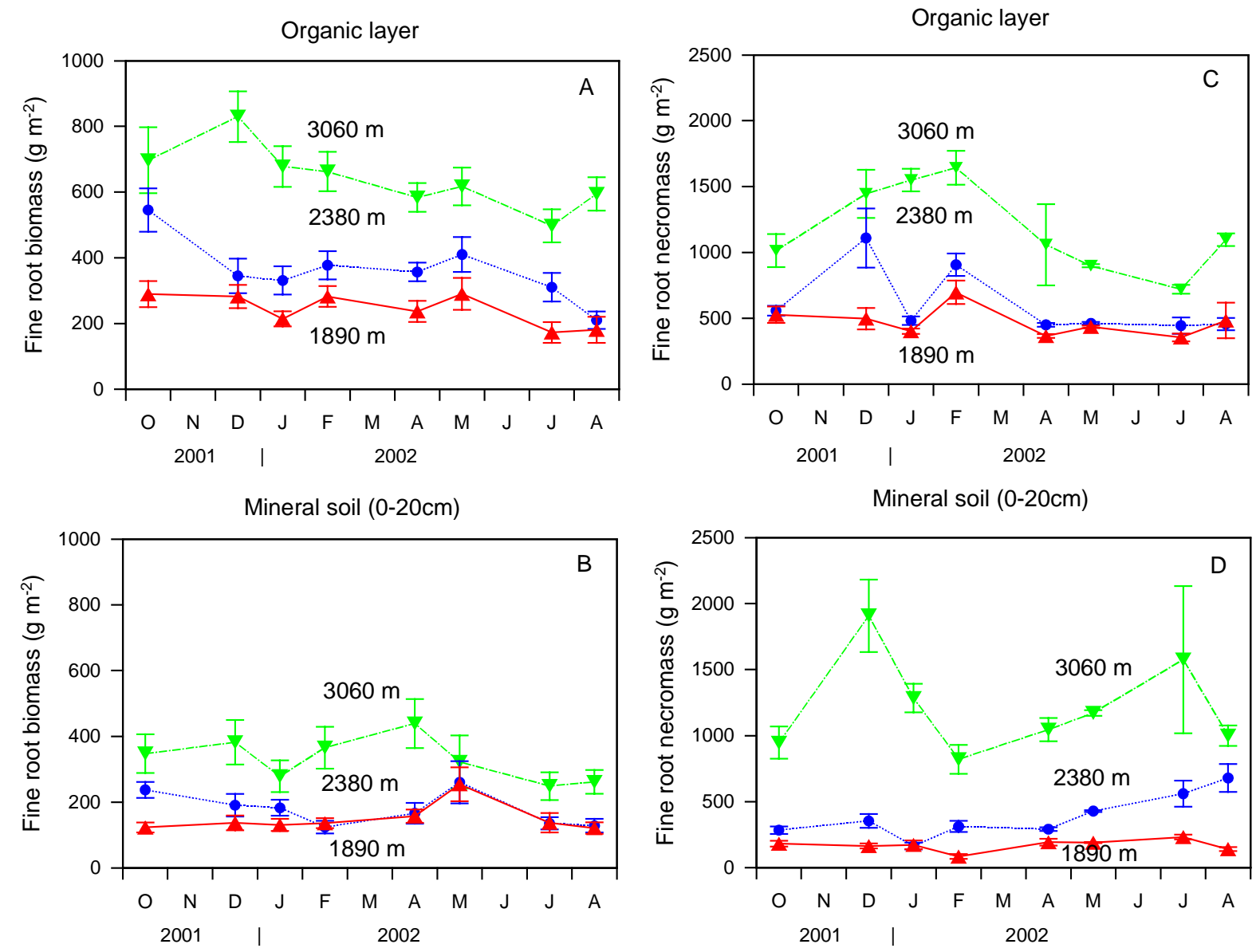

Abb. 4.5 A-D: Saisonale Veränderung der Feinwurzelbio- und nekromasse in Humusauflage und Mineralboden (0-20 cm) der drei Höhenstufen im Untersuchungszeitraum (Oktober 2001 bis August 2002). A und $\mathbf{B}$ stellen die Feinwurzelbiomasse, $\mathbf{C}$ und $\mathbf{D}$ die Feinwurzelnekromasse dar. Angegeben sind Mittelwerte und Standardfehler $(n=20)$. 


\subsubsection{Die unterschiedenen Methoden}

\subsubsection{Die Minimum-Maximum-Methode}

Aus den saisonalen Veränderungen der Feinwurzelbio- und nekromasse als Gesamtfeinwurzelmasse wird u.a. die Jahresproduktion der Feinwurzeln nach der Minimum-Maximum-Methode (siehe Kap. 3.3.1) ermittelt.

Unterscheidet man Humusauflage und Mineralboden, zeigt sich eine signifikante Abhängigkeit der Produktion von der Meereshöhe (Abb. 4.6). Die Gesamtproduktion an Feinwurzeln steigt von 1890 m Höhe auf 2380 m Höhe um den Faktor 1.9. Eine ähnliche Zunahme geht mit der Produktion von 2380 m Höhe auf 3060 m Höhe um den Faktor 1.8 einher. Insgesamt entspricht dies einer Erhöhung der Produktion von der untersten zur obersten Fläche um den Faktor 3.2.

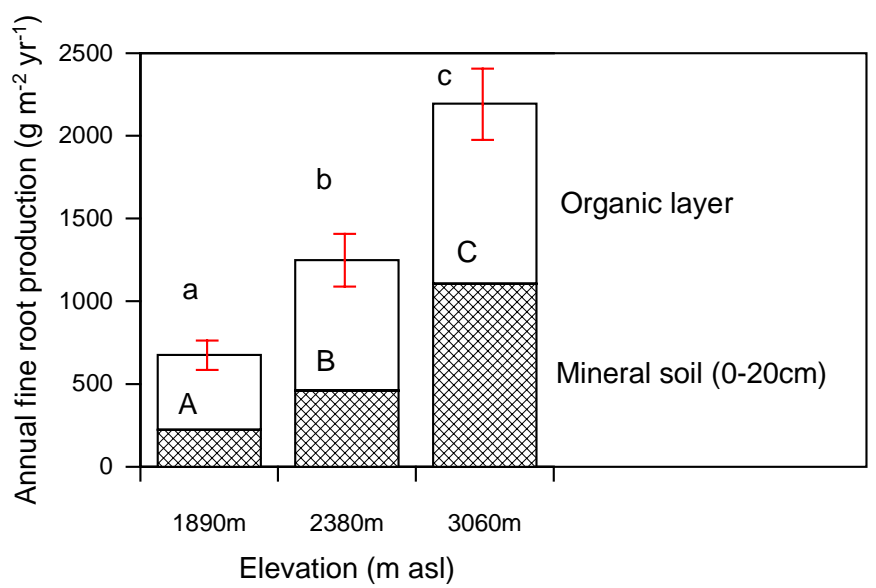

Abb. 4.6: Produktion der Feinwurzeln (Humusauflage und Mineralboden $(0-20 \mathrm{~cm})$ getrennt dargestellt) nach der Minimum-Maximum-Methode auf den drei Höhenstufen für den Untersuchungszeitraum. Unterschiedliche Buchstaben kennzeichnen signifikante Unterschiede zwischen den einzelnen Höhenstufen, U-Test nach Mann \& Whitney $(\mathrm{p}<0.05)$. Angegeben sind Mittelwerte und Standardfehler $(\mathrm{n}=8)$.

\subsubsection{Die compartmental flow-Methode}

Bei der compartmental flow-Methode wird zwischen den Veränderungen der Bio- und Nekromasse aufeinanderfolgender Zeiträume unterschieden (Abb. 4.7A-B). Für die Berechnung der Produktion, wurde zusätzlich die Zersetzung der toten Feinwurzeln mitberücksichtigt (Kap. 4.6). Im Vergleich zur Minimum-Maximum-Methode werden stark erhöhte Werte sichtbar (Tab. 4.2). Es ist kein gleichsinniger Verlauf in beiden Horizonten auf den drei Höhenstufen sichtbar (Abb. 4.7A-B). Die Werte in der Humusauflage liegen näher beieinander, obwohl auf 3060 m Höhe weiterhin die größten Massen zu finden sind. Die Schwankungen vor allem auf $3060 \mathrm{~m}$ Höhe sind im Mineralboden $(0-20 \mathrm{~cm})$ größer als in der Humusauflage. Hingegen sind die Schwankungen im Mineralboden $(0-20 \mathrm{~cm})$ auf den beiden unteren Höhenstufen geringer. 

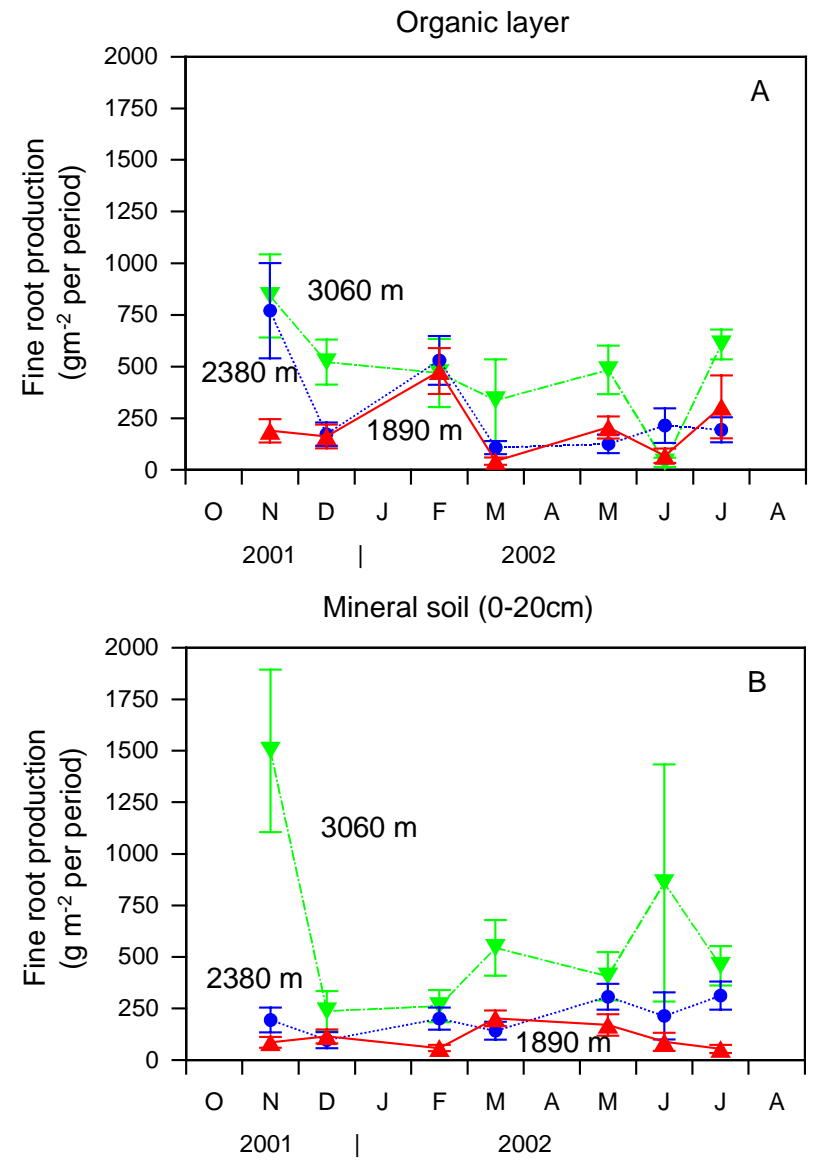

Abb. 4.7 A-B: Saisonaler Verlauf der Feinwurzelproduktion der Humusauflage A und des Mineralbodens B der drei Höhenstufen im Untersuchungszeitraum. Berechnung nach der compartmental flow-Methode. Die Probenahme erfolgte etwa alle sechs Wochen. Angegeben sind Mittelwerte und Standardfehler $(n=20)$.

4.5.2.3 Vergleich von Minimum-Maximum-Methode mit compartmental flow- und der ingrowth core-Methode

Die Minimum-Maximum-Methode und die compartmental flow-Methode gehen aus den Daten des sequential coring hervor. Die ingrowth core-Methode wurde zusätzlich angewandt und ausgewertet (siehe Kap. 3.3.3). Diese Methode geht im Gegensatz zu den beiden anderen Methoden von ursprünglich wurzelbefreitem Boden aus. Dieser Versuch war für einen Zeitraum von 500 Tagen angelegt. In der vorgegebenen Zeit zeigt sich ein viel geringeres Wachstum als es im Gegensatz zu den beiden anderen Methoden errechnet wurde.

Sowohl bei der Minimum-Maximum-Methode als auch bei der compartmental flowMethode verdoppeln sich in etwa die Werte von der untersten zur höchsten Fläche (Tab. 4. 2). Auf $3060 \mathrm{~m}$ Höhe ist fast vier Mal mehr Feinwurzelmasse als auf $1890 \mathrm{~m}$ Höhe 
vorhanden. Allerdings konnten mit der compartmental flow-Methode dreifach höhere Werte der Biomasse errechnet werden als mit der Minimum-Maximum-Methode.

Im Vergleich von ingrowth core-Methode und compartmental flow-Methode liegt der Wert sogar um ein elf- (1890 m) bis 52faches (3060 m) höher. Unterschiedlich hohe Werte der Produktion lieferten ebenfalls ingrowth core- und Minimum-Maximum-Methode. So wurden anhand der Minimum-Maximum-Methode bis zu 15fach höhere Werte für die Feinwurzelproduktion errechnet.

Tab. 4.2: Vergleich der unterschiedlichen Ergebnisse von drei Methoden zur Feinwurzelproduktionsberechnung ( $\mathrm{g} / \mathrm{m}^{2} \mathrm{Jahr}$ ). Gesamtwerte und Werte je Horizont getrennt nach Humusauflage und Mineralboden $(0-20 \mathrm{~cm})$ der Höhenstufe im Untersuchungszeitraum. Unterschiedliche Buchstaben kennzeichnen signifikante Unterschiede zwischen den drei Höhenstufen, wobei jeder Horizont für sich gewertet wird. U-Test nach Mann \& Whitney $(\mathrm{p}<0.05)$ Angegeben sind Mittelwerte und Standardfehler $(\mathrm{n}=20)$. nd (not determined), keine Proben vorhanden

\begin{tabular}{|c|c|c|c|c|c|}
\hline Site & $\begin{array}{c}\text { Elevation } \\
\text { (m asl) }\end{array}$ & & $\begin{array}{c}\text { Annual } \\
\text { fine root } \\
\text { production } \\
\text { Ingrowth core }\end{array}$ & $\begin{array}{l}\text { Annual fine root } \\
\text { production } \\
\text { min-max } \\
\text { calculation }\end{array}$ & $\begin{array}{l}\text { Annual fine root } \\
\text { production } \\
\text { compartmental } \\
\text { flow calculation }\end{array}$ \\
\hline \multirow[t]{2}{*}{1} & 1890 & Profile total & & $676 \pm 35^{a}$ & $2219 \pm 46^{a}$ \\
\hline & & $\begin{array}{c}\text { Organic layer } \\
\text { Mineral soil }(0-20 \mathrm{~cm})\end{array}$ & $\begin{array}{l}196 \pm 26^{\text {a }} \\
\text { nd }\end{array}$ & $\begin{array}{l}452 \pm 51^{\mathrm{a}} \\
224 \pm 24^{\mathrm{a}}\end{array}$ & $\begin{array}{l}1449 \pm 56^{\mathrm{a}} \\
770 \pm 21^{\mathrm{a}}\end{array}$ \\
\hline \multirow[t]{2}{*}{2} & 2380 & Profile total & & $1250 \pm 77^{b}$ & $3578 \pm 97^{b}$ \\
\hline & & $\begin{array}{c}\text { Organic layer } \\
\text { Mineral soil }(0-20 \mathrm{~cm})\end{array}$ & $\begin{array}{l}87 \pm 13^{b} \\
\text { nd }\end{array}$ & $\begin{array}{l}789 \pm 99^{b} \\
461 \pm 55^{b}\end{array}$ & $\begin{array}{l}2114 \pm 95^{\mathrm{a}} \\
1464 \pm 30^{\mathrm{b}}\end{array}$ \\
\hline \multirow[t]{2}{*}{3} & 3060 & Profile total & & $2193 \pm 135^{c}$ & $7560 \pm 214^{c}$ \\
\hline & & $\begin{array}{c}\text { Organic layer } \\
\text { Mineral soil }(0-20 \mathrm{~cm})\end{array}$ & $\begin{array}{c}144 \pm 22^{\mathrm{a}} \\
\text { nd }\end{array}$ & $\begin{array}{l}1087 \pm 142^{\mathrm{c}} \\
1106 \pm 127^{\mathrm{c}}\end{array}$ & $\begin{array}{l}3298 \pm 93^{b} \\
4262 \pm 168^{c}\end{array}$ \\
\hline
\end{tabular}

\subsubsection{Feinwurzelmortalität und -umsatz}

\subsubsection{Die Minimum-Maximum-Methode}

Ausgehend von der Minimum-Maximum-Methode werden entsprechend zur Produktion im jahreszeitliche Verlauf der Gesamtfeinwurzelmasse die signifikanten Minimum- und Maximumwerte für die Berechnung der Mortalität ermittelt (Kap. 3.3.1). Die mit Sternchen gekennzeichneten Werte gingen in die Berechnung der Mortalität ein (Abb. 4.8 A-B). 

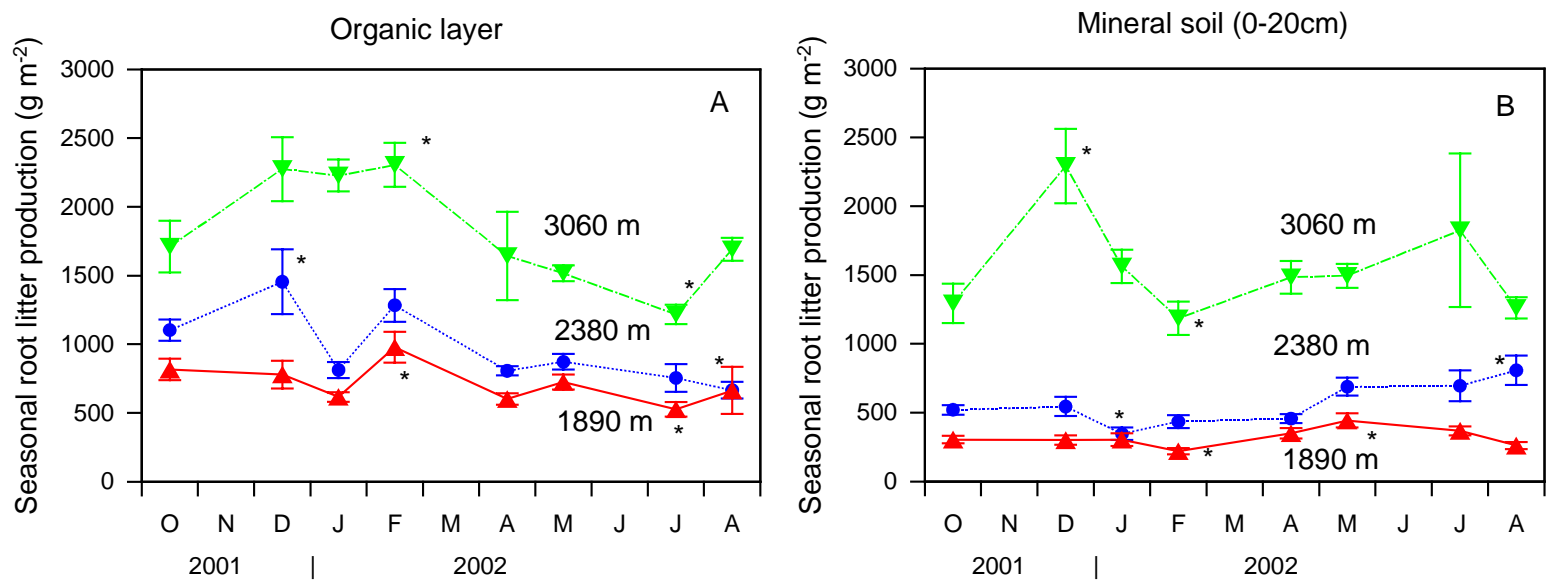

Abb. 4.8 A-B: Saisonaler Verlauf der Gesamtfeinwurzelmasse als Ausgangspunkt für die Berechnung der Wurzelstreuproduktion nach der Minimum-Maximum-Methode: Humusauflage A und Mineralboden $(0-20 \mathrm{~cm})$ B auf den drei Höhenstufen. Sternchen kennzeichnen die signifikanten Mini- bzw. Maxima innerhalb des Untersuchungszeitraums. Die Probenahme erfolgte etwa alle sechs Wochen. Angegeben sind Mittelwerte und Standardfehler $(n=40)$.

\subsubsection{Feinwurzelmortalität}

Die Feinwurzelmortalität steigt mit der Höhe (Abb. 4.9, Tab. 4.4). Ein eindeutig linearer Zusammenhang ist $\mathrm{zu}$ erkennen ( $\left.\mathrm{p}=0.012, \mathrm{r}^{2}=0.99\right)$. Alle drei Höhenstufen sind signifikant unterschiedlich zueinander hinsichtlich der Feinwurzelmortalität. Insgesamt steigt die Feinwurzelmortalität entlang des Höhengradienten um den Faktor 4.

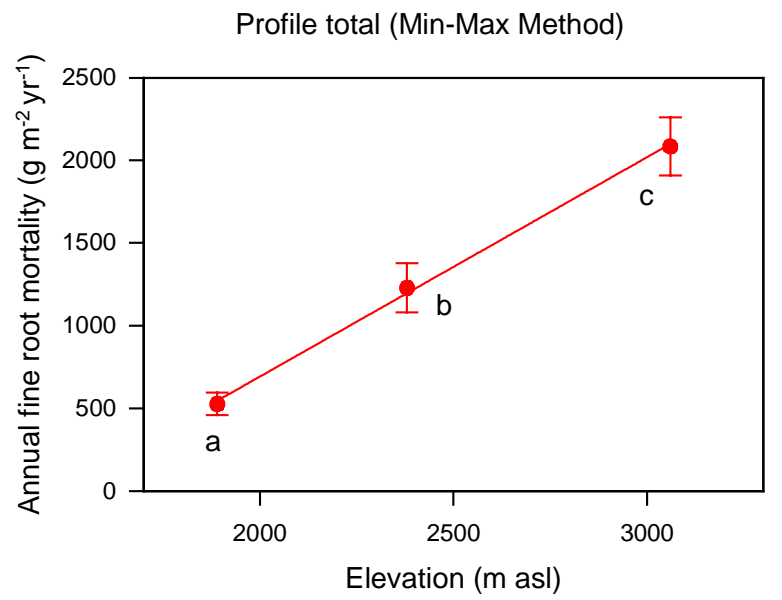

Abb. 4.9: Feinwurzelmortalität nach der Minimum-Maximum-Methode auf den drei Höhenstufen für den Untersuchungszeitraum. Angegeben sind Mittelwerte und Standardfehler. Unterschiedliche Buchstaben kennzeichnen signifikante Unterschiede zwischen den einzelnen Höhenstufen, U-Test nach Mann \& Whitney $(\mathrm{p}<0.05)$.

\subsubsection{Compartmental flow-Methode}

Die Mortalität in der Humusauflage nimmt auf allen drei Flächen vom Beginn der Untersuchung hin zum Ende des Untersuchungszeitraums diskontinuierlich ab. Im Vergleich 
zur Minimum-Maximum-Methode werden hier ebenfalls stark erhöhte Werte (Tab. 4.3) und kein gleichsinniger Verlauf in beiden Horizonten auf den drei Höhenstufen sichtbar (Abb. 4.10 A-B). Alle Werte in der Humusauflage liegen näher beieinander, obwohl auf $3060 \mathrm{~m}$ Höhe die größten Massen zu finden sind. Im Mineralboden zeigen sich für die beiden unteren Flächen relativ ausgeglichene Werte unter $250 \mathrm{~g} \mathrm{~m}^{-2}$, für die oberste Fläche auf $3060 \mathrm{~m}$ hingegen große Schwankungen im Untersuchungszeitraum. Produktion und Mortalität zeigen sehr identische Verläufe (Abb. 4.7 A-B und Abb. 4.10 A-B).
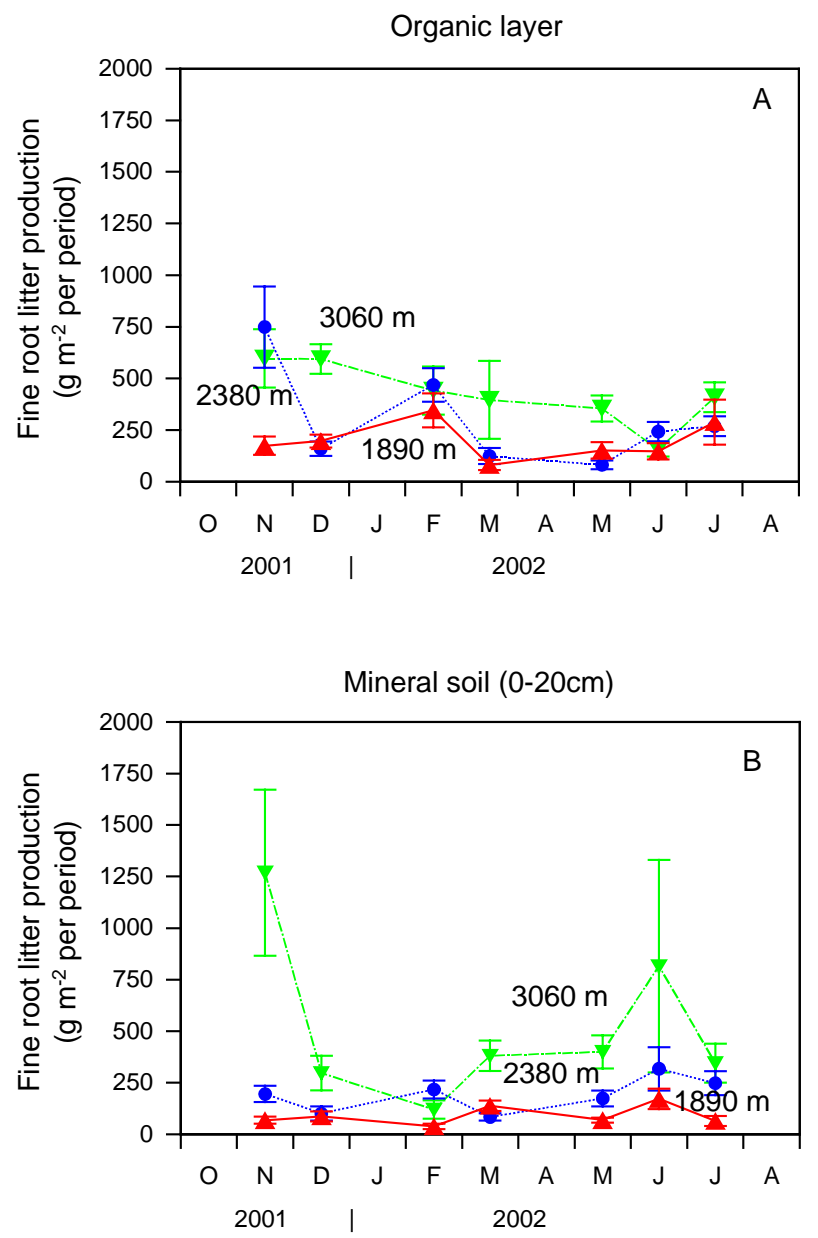

Abb. 4.10 A-B: Saisonaler Verlauf der Feinwurzelstreuproduktion (Mortalität) der Humusauflage A und des Mineralbodens B der drei Höhenstufen im Untersuchungszeitraum. Berechnung nach der compartmental flowMethode. Die Probenahme erfolgte etwa alle sechs Wochen. Angegeben sind Mittelwerte und Standardfehler $(\mathrm{n}=20)$.

\subsubsection{Vergleich der angewendeten Methoden}

Die Ergebnisse der Feinwurzelstreuproduktion (Feinwurzelmortalität) (Tab. 4.3) lassen erkennen, dass ein großer Unterschied in den Feinwurzelmassen zwischen den Berechnungen mittels Minimum-Maximum-Methode und compartmental flow-Methode besteht. Die compartmental flow-Methode zeigt in diesem Falle eine dreifach höhere Masse an Feinwurzelstreu als die Minimum-Maximum-Methode. Das gilt für alle Bodenhorizonte 
und schlägt sich somit in der Gesamtbilanz nieder. Für die ingrowth core-Methode gibt es nach der herkömmlichen Anwendung keine Möglichkeit, die Mortalität der Feinwurzeln zu bestimmen. Man kann lediglich anmerken, dass tote Wurzeln vorhanden waren.

Tab. 4.3: Vergleich der nach zwei Methoden errechneten Feinwurzelstreuproduktion (Feinwurzelmortalität), Gesamtwerte und Werte je Horizont getrennt nach Humusauflage und Mineralboden $(0-20 \mathrm{~cm})$ der Höhenstufen im Untersuchungszeitraum. Unterschiedliche Buchstaben kennzeichnen signifikante Unterschiede zwischen den drei Höhenstufen, wobei jeder Horizont für sich gewertet wird. U-Test nach Mann \& Whitney $(\mathrm{p}<0.05)$ Angegeben sind Mittelwerte und Standardfehler $(n=8)$.

\begin{tabular}{|c|c|c|c|c|}
\hline Site & $\begin{array}{c}\text { Elevation } \\
\text { (m asl) }\end{array}$ & & $\begin{array}{l}\text { Annual fine root } \\
\text { litter production } \\
\text { min-max calculation }\end{array}$ & $\begin{array}{l}\text { Annual fine root } \\
\text { litter production } \\
\text { compartmental flow } \\
\text { calculation }\end{array}$ \\
\hline \multirow[t]{2}{*}{1} & 1890 & Profile total & $527 \pm 68^{\mathrm{a}}$ & $2015 \pm 25^{\mathrm{a}}$ \\
\hline & & $\begin{array}{c}\text { Organic layer } \\
\text { Mineral soil }(0-20 \mathrm{~cm})\end{array}$ & $\begin{array}{l}393 \pm 77^{\mathrm{a}} \\
134 \pm 58^{\mathrm{a}}\end{array}$ & $\begin{array}{l}1382 \pm 34^{\mathrm{a}} \\
633 \pm 18^{\mathrm{a}}\end{array}$ \\
\hline \multirow[t]{2}{*}{2} & 2380 & Profile total & $1229 \pm 149^{b}$ & $3424 \pm 103^{b}$ \\
\hline & & $\begin{array}{c}\text { Organic layer } \\
\text { Mineral soil }(0-20 \mathrm{~cm})\end{array}$ & $\begin{array}{l}694 \pm 201^{\mathrm{a}} \\
535 \pm 96^{\mathrm{b}}\end{array}$ & $\begin{array}{l}2091 \pm 89^{b} \\
1333 \pm 31^{b}\end{array}$ \\
\hline \multirow[t]{2}{*}{3} & 3060 & Profile total & $2085 \pm 176^{c}$ & $6567 \pm 162^{c}$ \\
\hline & & $\begin{array}{c}\text { Organic layer } \\
\text { Mineral soil }(0-20 \mathrm{~cm})\end{array}$ & $\begin{array}{l}922 \pm 125^{b} \\
1163 \pm 227^{c}\end{array}$ & $\begin{array}{c}2944 \pm 57^{\mathrm{c}} \\
3623 \pm 148^{\mathrm{c}}\end{array}$ \\
\hline
\end{tabular}

\subsubsection{Umsatz- und Mortalitätsrate der Feinwurzeln}

Beispielhaft wird die Berechnung für die Umsatzrate und die Mortalitätsrate anhand der Minimum-Maximum-Methode dargestellt (Tab. 4.4), da die compartmental flow-Methode und die Daten zu der ingrowth core-Produktion (beides Tab. 4.2) identisch berechnet werden.

Bei der Minimum-Maximum-Methode beträgt die Umsatzrate auf der am höchsten gelegenen Fläche (3060 m Höhe) 2.24. Der Umsatz auf der mittleren Fläche in $2380 \mathrm{~m}$ Höhe steigt leicht auf 2.32 an. Die unterste Fläche hingegen in $1890 \mathrm{~m}$ Höhe, hat Umsatzrate von 1.72.

Ein vergleichbares Bild zeigt sich bei Mortalitätsrate auf den drei Höhenstufen. Von 2.13 (3060 m Höhe) erhöht sich diese in 2.28 bei 2380 m Höhe und sinkt auf 1.34 auf der niedrigsten Fläche auf 1890 m ab. 
Tab. 4.4: Berechnung der Umsatzrate und der Mortalitätsrate mit der Minimum-Maximum-Methode, Humusauflage und Mineralboden $(0-20 \mathrm{~cm})$ je Höhenstufe im Untersuchungszeitraum. Aus der signifikanten Differenz des Mini- bzw. Maximum erhält man die Produktion getrennt für beide Horizonte und als Gesamtwert. Die Summe der Produktion aus Humusauflage und Mineralboden wird durch den Mittelwert der Feinwurzelbiomasse dividiert. Der Quotient ist die Umsatzrate. Die Mortalitätsrate ist der Quotient aus der Summe der Feinwurzelstreuproduktion und dem Mittelwert der Feinwurzelbiomasse. Signifikante Unterschiede zwischen den drei Höhenstufen, wobei jeder Horizont für sich gewertet wird, werden durch einen Stern gekennzeichnet, Scheffé $(<0.05)$.

\begin{tabular}{|c|c|c|c|c|c|c|c|c|c|c|}
\hline Site & $\begin{array}{l}\text { Eleva } \\
\text { tion } \\
\text { (m asl) }\end{array}$ & Horizon & $\begin{array}{l}\text { MinMax } \\
\text { fine root } \\
\text { mass } \\
\text { max } \\
\mathrm{g} \mathrm{m}^{-2}\end{array}$ & $\begin{array}{c}\text { MinMax } \\
\text { fine root } \\
\text { mass } \\
\text { min } \\
\mathrm{g} \mathrm{m}^{-2}\end{array}$ & $\begin{array}{c}\text { Signi } \\
\text { ficane } \\
\text { of } \\
\text { diffe } \\
\text { rence }\end{array}$ & $\begin{array}{c}\text { Produc } \\
\text { tion } \\
\mathrm{g} \mathrm{m}^{-2}\end{array}$ & $\begin{array}{c}\text { Mean } \\
\text { of bio } \\
\text { masse } \\
\mathrm{g} \mathrm{m}^{-2}\end{array}$ & $\begin{array}{l}\text { Turn } \\
\text { over } \\
\text { ratio }\end{array}$ & $\begin{array}{l}\text { MinMax } \\
\text { annual fine } \\
\text { root } \\
\text { mortality } \\
\mathrm{g} \mathrm{m}^{-2} \mathrm{yr}^{-1}\end{array}$ & $\begin{array}{l}\text { Mor } \\
\text { tality } \\
\text { ratio }\end{array}$ \\
\hline \multirow[t]{2}{*}{1} & 1890 & $\begin{array}{c}\text { Organic } \\
\text { layer }\end{array}$ & 979.16 & 527.16 & * & 452.00 & 393 & 1.72 & 393 & 1.34 \\
\hline & & $\begin{array}{c}\text { Mineral } \\
\text { soil }\end{array}$ & 443.31 & 219.66 & * & 223.65 & & & 134 & \\
\hline \multirow[t]{2}{*}{2} & 2380 & $\begin{array}{c}\text { Organic } \\
\text { layer }\end{array}$ & 1454.70 & 666.06 & * & 788.64 & 539 & 2.32 & 694 & 2.28 \\
\hline & & $\begin{array}{c}\text { Mineral } \\
\text { soil }\end{array}$ & 807.10 & 346.39 & * & 460.71 & & & 535 & \\
\hline \multirow[t]{2}{*}{3} & 3060 & $\begin{array}{c}\text { Organic } \\
\text { layer }\end{array}$ & 2304.73 & 1217.43 & $*$ & 1087.31 & 978 & 2.24 & 922 & 2.13 \\
\hline & & $\begin{array}{c}\text { Mineral } \\
\text { soil }\end{array}$ & 2291.73 & 1186.13 & * & 1105.60 & & & 1163 & \\
\hline
\end{tabular}

Die mit der ingrowth core-Methode berechnete Umsatzrate sinkt mit der Höhe. Das bedeutet, dass sich die Feinwurzelbiomasse auf den beiden oberen Flächen sehr langsam umsetzt. Die Lebensdauer der Feinwurzeln wäre auf den beiden obersten Flächen mehr als sechs Jahre. Dagegen steigt die Umsatzrate bei der Berechnung nach der compartmental flow-Methode mit der Meereshöhe an. Dies deutet auf genau das Gegenteil hin, eine sehr schnelle Umsetzung der Feinwurzeln, die sich in den oberen Untersuchungsflächen bis zu acht Mal im Jahr umsetzen, also einer Lebensdauer der Feinwurzeln von etwa sechs Wochen entsprechen würde. Die Umsatzrate, berechnet nach der Minimum-Maximum-Methode, ergibt einen höchsten Wert auf der mittleren Versuchsfläche auf 2380 m Höhe. Sie ist im Vergleich mit dem compartmental flow-Ansatz um ein dreifaches niedriger (Tab. 4.5). Die Lebenserwartung einer Feinwurzel würde in diesem Fall ein halbes Jahr betragen.

Die Mortalitätsrate nach der compartmental flow-Methode steigt mit zunehmender Höhe an. Im Vergleich mit den Ergebnissen der Minimum-Maximum-Methode ist sie um ein dreifaches höher. Dies ist schon durch die vorherrschenden Produktionswerte (Tab. 4.2) vorgegeben. 
Tab. 4.5: Vergleich der Umsatz- und Mortalitätsraten aller drei bzw. zwei Methoden, je Höhenstufe im Untersuchungszeitraum.

\begin{tabular}{cccccccc}
\hline Site & $\begin{array}{c}\text { Elevation } \\
\text { (m asl) }\end{array}$ & Horizon & $\begin{array}{c}\text { Turnover } \\
\text { ratio } \\
\text { ingrowth } \\
\text { core (only } \\
\text { organic } \\
\text { layer) }\end{array}$ & $\begin{array}{c}\text { Turnover } \\
\text { ratio } \\
\text { MinMax }\end{array}$ & $\begin{array}{c}\text { Turnover } \\
\text { ratio } \\
\text { compart } \\
\text { mental } \\
\text { flow }\end{array}$ & $\begin{array}{c}\text { Mortality } \\
\text { ratio } \\
\text { MinMax }\end{array}$ & $\begin{array}{c}\text { Mortality } \\
\text { ratio } \\
\text { compart } \\
\text { mental } \\
\text { flow }\end{array}$ \\
\hline 1 & 1890 & total & 0.50 & 1.72 & 5.65 & 1.34 & 5.13 \\
2 & 2380 & total & 0.16 & 2.32 & 6.64 & 2.28 & 6.35 \\
3 & 3060 & total & 0.15 & 2.24 & 7.73 & 2.13 & 6.71 \\
\hline
\end{tabular}

\subsection{Abbau der Feinwurzeln in litter bags}

In einem Versuch mit litter bags (Testbeuteln zur Streuzersetzung) wurde die Zersetzung der Wurzeln in der Humusauflage der drei Versuchsflächen untersucht. Die Ergebnisse des Versuchs zeigen, dass eine klare, signifikante Beziehung zwischen der Abbaugeschwindigkeit und der Höhenstufe besteht $\left(p=0.023, r^{2}=0.99\right)$ (Abb. 4.11). Die Höhenstufen sind ebenfalls signifikant unterschiedlich zueinander. Die Werte für den Abbau betragen auf der am tiefst gelegenen Fläche 60 \%. Die Untersuchungsfläche der Höhenstufe 2380 m verzeichnet 41 \% nimmt weiterhin ab auf 21 \% (3060m Höhe). Damit nimmt der Verlust von Feinwurzelmasse entgegen dem Höhengradienten von der untersten Fläche auf 1890 m Höhe zur höchsten auf 3060 m Höhe um je 20 \% Punkte ab. Auf der untersten Versuchfläche zersetzt sich die Feinwurzelmasse drei Mal schneller als in der Nähe der Baumgrenze.

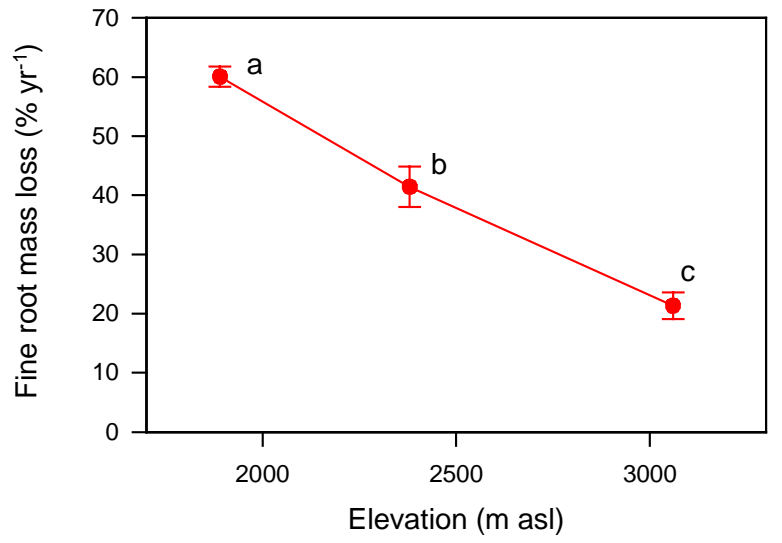

Abb. 4.11: Massenverlust an Feinwurzeln ( $<2 \mathrm{~mm}$ Durchmesser) in einem Abbauexperiment mit litter bags. Dargestellt sind Mittelwerte und Standardfehler $(n=10)$ der jährlichen Massenverluste auf den drei Höhenstufen im Untersuchungszeitraum (ca. 500 Tage). Die Buchstaben kennzeichnen signifikante Unterschiede zwischen den drei Höhenstufen, Scheffé ( $\mathrm{p}<0.001)$. 


\subsection{Wurzelmorphologie}

\subsubsection{Durchmesser der Feinwurzeln}

Auf 1890 m Höhe liegt der mittlere Durchmesser der untersuchten Feinwurzeln bei 0.72 mm, bei $2380 \mathrm{~m}$ Höhe bei $0.79 \mathrm{~mm}$ und auf $3060 \mathrm{~m}$ Höhe bei $0.76 \mathrm{~mm}$ (Abb. 4.12A). In Abb. 4.12B ist in der Humusauflage auf $2380 \mathrm{~m}$ Höhe ein größerer Wert $(0.83 \mathrm{~mm})$ deutlich zu erkennen. Die Feinwurzeln der Humusschicht auf 1890 m Höhe und 3060 m Höhe haben mittlere Durchmesser von 0.72 mm. Der Durchmesser der Feinwurzeln im Mineralboden wird dagegen mit der Höhe größer. Von 1890 m Höhe an steigt der durchschnittliche Durchmesser der Feinwurzeln von $0.72 \mathrm{~mm}$ auf $0.75 \mathrm{~mm}$ in $2380 \mathrm{~m}$ Höhe und auf $0.79 \mathrm{~mm}$ in $3060 \mathrm{~m}$ Höhe an.
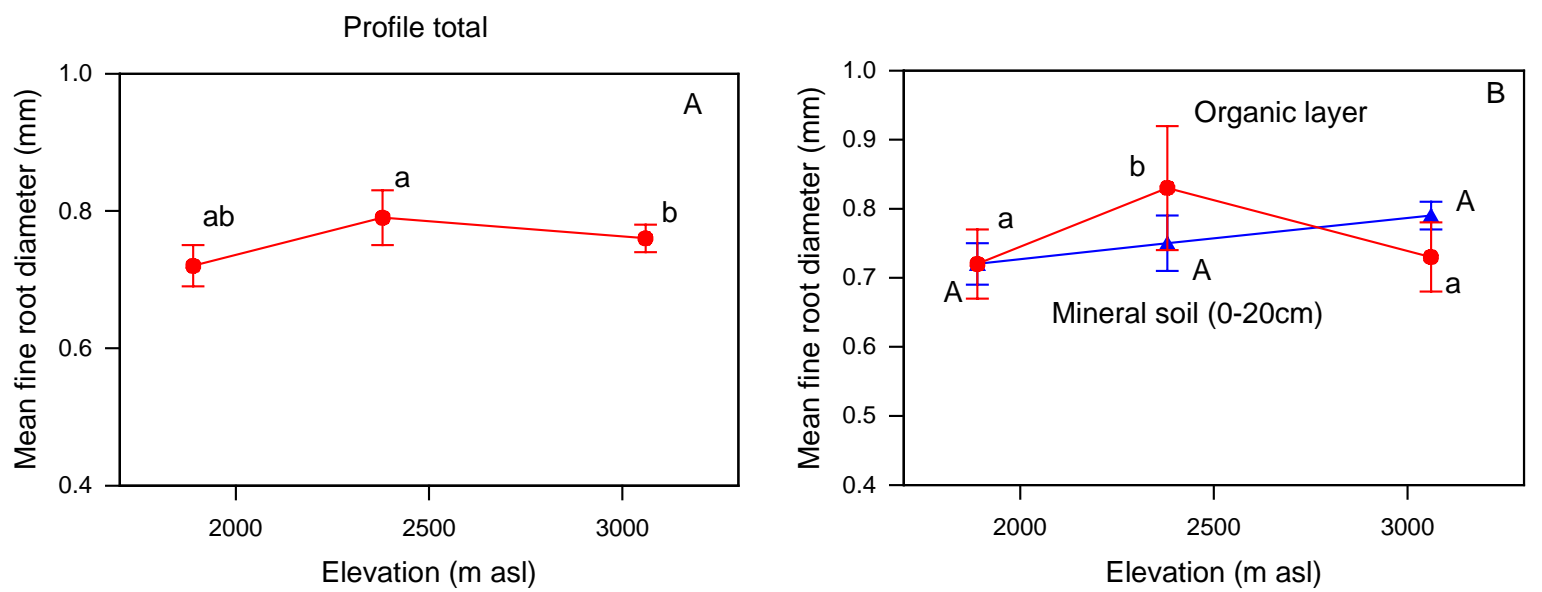

Abb. 4.12 A-B: Mittlerer Durchmesser der Feinwurzeln insgesamt (A) und in Humusauflage und Mineralboden $(0-20 \mathrm{~cm})$ getrennt (B) auf den drei Höhenstufen. Unterschiedliche Buchstaben kennzeichnen signifikante Unterschiede zwischen den drei Höhenstufen, U-Test nach Mann \& Whitney (p < 0.05). Angegeben sind Mittelwerte und Standardfehler $(\mathrm{n}=80)$.

\subsubsection{Spezifische Wurzeloberfläche (specific root area, SRA)}

Die spezifische Wurzeloberfläche (SRA) gibt Aufschluss über das Verhältnis zwischen der Wurzeloberfläche und dem Trockengewicht der Wurzeln. Die SRA nimmt signifikant mit steigender Höhe ab (Abb. 4.8A-B). Dies spricht für ein höheres Gewicht und eine geringere Oberfläche der Feinwurzeln in höheren Regionen. Die Höhenstufen zeigen einen linearen Höhentrend ( $\left.\mathrm{p}=0.068, \mathrm{r}^{2}=0.99\right)$. Die SRA fällt von $227 \mathrm{~cm}^{2} \mathrm{~g}^{-1}$ (1890 m Höhe) zunächst um den Faktor 1.2 auf $192 \mathrm{~cm}^{2} \mathrm{~g}^{-1}$ (2380 m Höhe) und schließlich auf $152 \mathrm{~cm}^{2} \mathrm{~g}^{-1}$ in $1890 \mathrm{~m}$ Höhe) (Faktor 1.3) (Abb. 4.13A). Insgesamt nimmt die spezifische Wurzeloberfläche somit um das 1.5 fache mit der Höhe ab.

Trennt man den Boden in Humusauflage und Mineralboden, so zeigt sich in beiden Fällen ein abnehmender Trend (Abb. 4.13B). In der Humusauflage sinkt die SRA von $236 \mathrm{~cm}^{2} \mathrm{~g}^{-1}$ 
in $1890 \mathrm{~m}$ Höhe über $175 \mathrm{~cm}^{2} \mathrm{~g}^{-1}$ (Faktor 1.4) in 2380m Höhe auf $151 \mathrm{~cm}^{2} \mathrm{~g}^{-1}$ (Faktor 1.2) in 3060 m Höhe. Von der untersten zur obersten Fläche bedeutet das eine Abnahme in der Humusauflage um 1.6fache. Die spezifische Wurzeloberfläche im Mineralboden nimmt von $213 \mathrm{~cm}^{2} \mathrm{~g}^{-1}$ in $1890 \mathrm{~m}$ Höhe über $209 \mathrm{~cm}^{2} \mathrm{~g}^{-1}$ in $2380 \mathrm{~m}$ Höhe auf $154 \mathrm{~cm}^{2} \mathrm{~g}^{-1}$ in $3060 \mathrm{~m}$ Höhe ab. Dies entspricht einer Abnahme im Mineralboden um den Faktor 1.4 von der höchsten zur tiefst gelegenen Fläche.
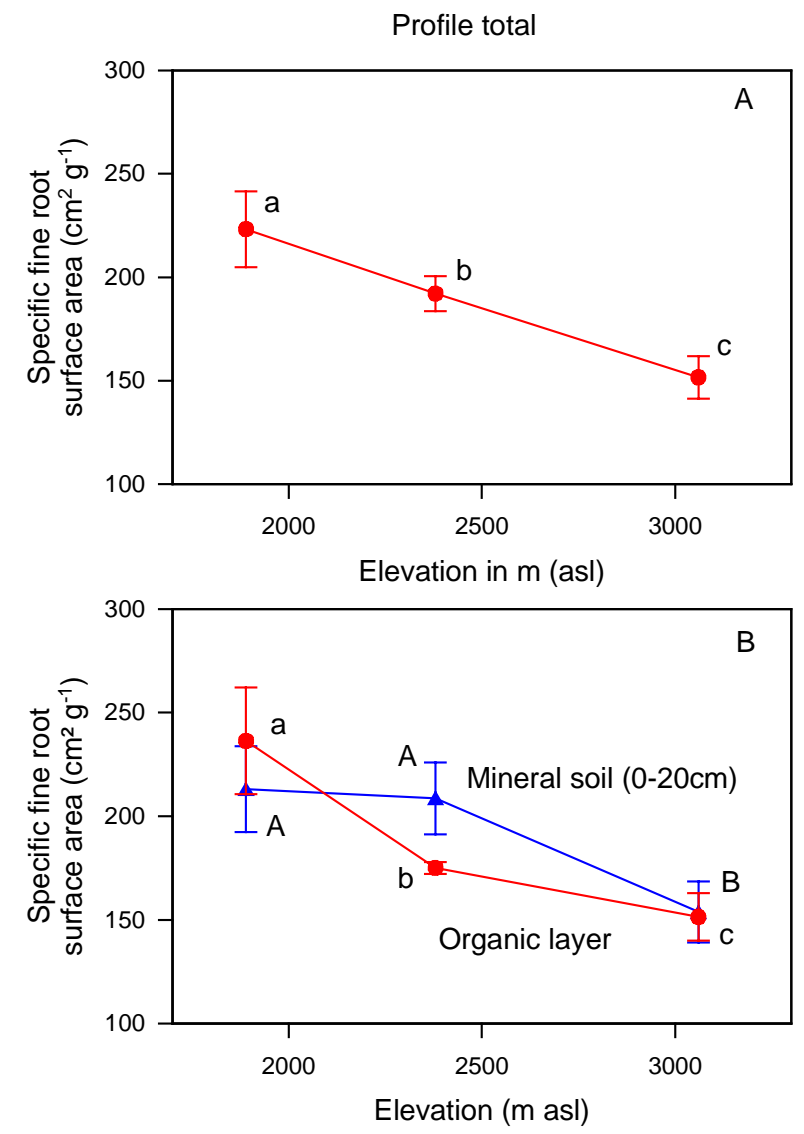

Abb. 4.13 A-B: Mittelwert der spezifischen Oberfläche der Feinwurzeln des gesamten Profils A und in Humusauflage und Mineralboden $(0-20 \mathrm{~cm})$ getrennt $\mathbf{B}$ auf den drei Höhenstufen. Unterschiedliche Buchstaben kennzeichnen signifikante Unterschiede zwischen den drei Höhenstufen, U-Test nach Mann \& Whitney ( $\mathrm{p}<$ 0.05). Angegeben sind Mittelwerte und Standardfehler $(\mathrm{n}=80)$.

\subsubsection{Spezifische Wurzelspitzenhäufigkeit}

Es zeigt sich, dass im Beprobungszeitraum die mittlere Höhenstufe im Durchschnitt mehr Wurzelspitzen aufweist als die beiden anderen Höhenstufen (Abb. 4.14). In 2380 m Höhe wurde mit 167 Wurzelspitzen $\mathrm{g}^{-1}$ Trockenmasse die höchste Anzahl in der Humusauflage und mit 76 Wurzelspitzen $\mathrm{g}^{-1} \mathrm{TM}$ auch im Mineralboden gefunden. Mit 144 Wurzelspitzen $\mathrm{g}^{-1} \mathrm{TM}$ in der Humusauflage bzw. 68 Spitzen $\mathrm{g}^{-1} \mathrm{TM}$ im Mineralboden, hat die Fläche auf 3060 m Höhe weniger Wurzelspitzen. Auf der Fläche in 1890 m Höhe wurden mit 105 Wurzelspitzen $\mathrm{g}^{-1} \mathrm{TM}$ in der Humusauflage und 60 Spitzen $\mathrm{g}^{-1} \mathrm{TM}$ im Mineralboden die 
niedrigsten Werte gemessen. Insgesamt erhöht sich damit die spezifische Spitzenhäufigkeit nicht kontinuierlich.

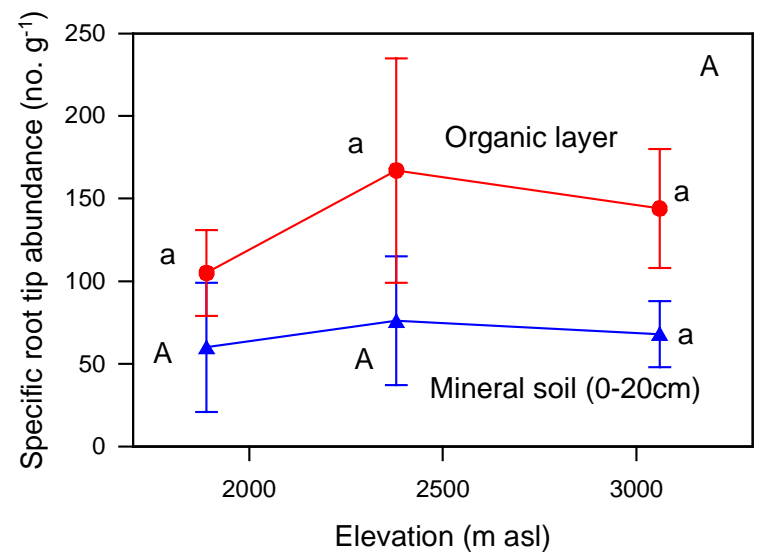

Abb. 4.14: Spezifische Spitzenhäufigkeit der Feinwurzeln auf den drei Höhenstufen im Untersuchungszeitraum. Es sind die Werte der Humusauflage und des Mineralbodens $(0-20 \mathrm{~cm}$ Tiefe $)$ dargestellt. Unterschiedliche Buchstaben kennzeichnen signifikante Unterschiede zwischen den drei Höhenstufen, U-Test nach Mann \& Whitney $(\mathrm{p}<0.05)$. Angegeben sind Mittelwerte und Standardfehler $(\mathrm{n}=$ 80).

4.8 Bestandesspitzenanzahl, Spitzendichte und Wurzelflächenindex

\subsubsection{Bestandesspitzenanzahl und Spitzendichte der Feinwurzeln}

Die Anzahl der Wurzelspitzen pro Flächeneinheit steigt mit zunehmender Höhenstufe an (Abb. 4.15 A-B). Von 1890 m Höhe ausgehend erhöht sich die Anzahl der Wurzelspitzen von $26035 \mathrm{~m}^{-2}$ in der Humusauflage und $7746 \mathrm{~m}^{-2}$ im Mineralboden auf $63528 \mathrm{~m}^{-2}$ (Faktor 2.4) bzw. $15187 \mathrm{~m}^{-2}$ im Mineralboden (Faktor 2) auf 2380 m Höhe. Die höchsten Werte werden mit 85731 Spitzen $\mathrm{m}^{-2}$ in der Humusauflage und 19900 Spitzen $\mathrm{m}^{-2}$ im Mineralboden auf 3060 m Höhe erreicht. Dies entspricht einer Steigerung von 1.4 gegenüber der Humusauflage auf 2380 m Höhe bzw. von 1.3 im untersuchten Mineralbodenhorizont. Von der untersten zur obersten Fläche nimmt damit die Anzahl an Wurzelspitzen in der Humusauflage um den Faktor 3.3 und im Mineralboden um den Faktor 2.6 zu.

In der Humusauflage zeigt sich eine starke Erhöhung der Wurzelspitzendichte von 1890 m auf 2380 m Höhe (Abb. 4.15B). Zwischen 2380 m und 3060 m Höhe verändert sich diese Dichte jedoch kaum.

Die Dichte der Wurzelspitzen in der Humusauflage verdoppelt sich von 20 pro $100 \mathrm{~mL}$ auf 1890 m Höhe auf 43 pro 100 mL (2380 m Höhe) und bleibt mit 41 pro 100 mL auf der Fläche in 3060 m Höhe konstant. Im Mineralboden hingegen kann einen Höhentrend beobachtet werden. Dort befinden sich auf 1890 m Höhe nur 4 Wurzelspitzen in $100 \mathrm{~mL}$ Boden. In 2380 m Höhe verdoppelt sich die Dichte auf 8 Wurzelspitzen pro $100 \mathrm{~mL}$ Boden. Eine weitere Steigerung um das 1.5fache auf 12 Spitzen pro $100 \mathrm{~mL}$ Boden kann auf der 
obersten Fläche auf 3060 m Höhe gemessen werden. Damit erhöht sich die Wurzelspitzendichte im Mineralboden mit zunehmender Höhe um das Dreifache.
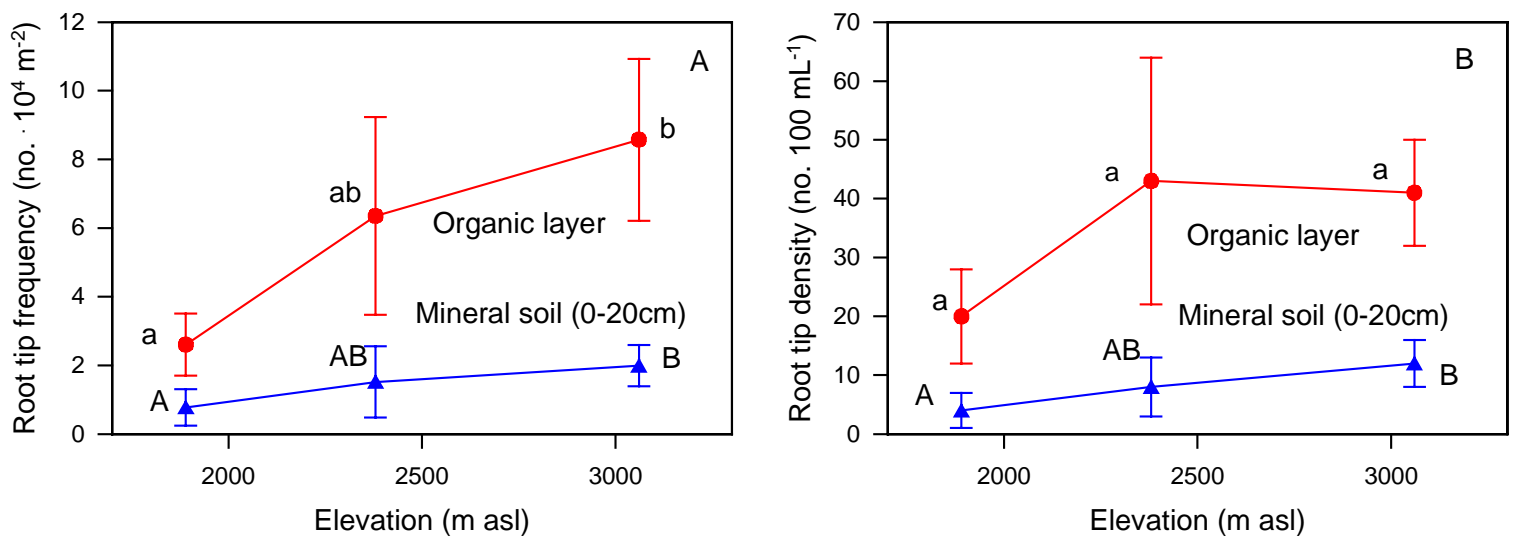

Abb. 4.15 A-B: Bestandesspitzenzahl und Spitzendichte der Feinwurzeln auf den drei Höhenstufen im Untersuchungszeitraum. Es sind Werte aus Humusauflage und Mineralboden $(0-20 \mathrm{~cm}$ Tiefe) dargestellt. Grafik A zeigt Anzahl der Wurzelspitzen pro m², Grafik B die Anzahl der Wurzelspitzen pro 100mL Boden. Unterschiedliche Buchstaben kennzeichnen signifikante Unterschiede zwischen den drei Höhenstufen, U-Test nach Mann \& Whitney $(\mathrm{p}<0.05)$. Angegeben sind Mittelwerte und Standardfehler $(\mathrm{n}=80)$.

\subsubsection{Der Wurzelflächenindex (root area index, RAI)}

Der Wurzelflächenindex (RAI) stellt die Wurzeloberfläche bezogen auf eine Flächeneinheit dar. Von der tiefsten zur höchsten Untersuchungsfläche nimmt die Durchwurzelung um 41 \% zu. Der RAI liegt auf $1890 \mathrm{~m}$ Höhe bei $8.8 \mathrm{~m}^{2} \mathrm{~m}^{-2}$, steigt auf $10.3 \mathrm{~m}^{2} \mathrm{~m}^{-2}$ in $2380 \mathrm{~m}$ Höhe und erreicht auf $3060 \mathrm{~m}$ Höhe $14.8 \mathrm{~m}^{2} \mathrm{~m}^{-2}$ (Abb. 4.16).

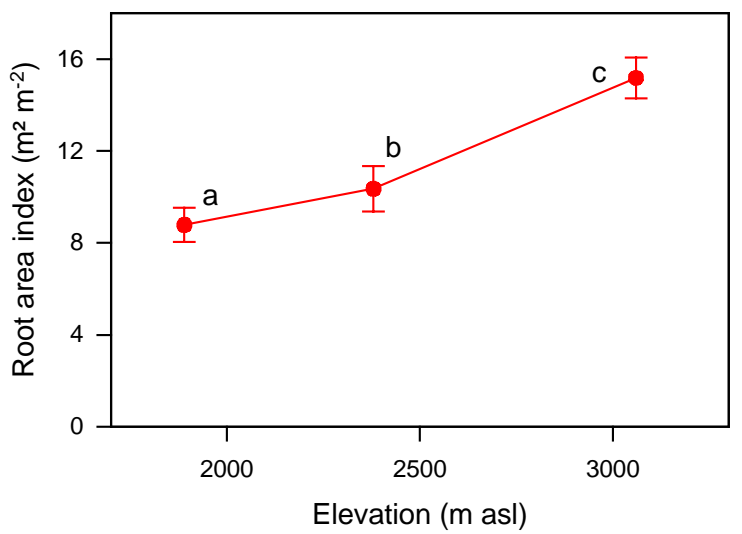

Abb. 4.16: Mittlerer Wurzelflächenindex der Feinwurzeln (Humusauflage und Mineralboden (0-20 cm Tiefe)) in den drei Höhenstufen. Unterschiedliche Buchstaben kennzeichnen signifikante Unterschiede zwischen den drei Höhenstufen, U-Test nach Mann \& Whitney ( $<$ 0.05). Angegeben sind Mittelwerte und Standardfehler $(n=80)$. 


\subsection{C- und N-Gehalte der Feinwurzeln}

\subsubsection{Das Kohlenstoff-Stickstoffverhältnis von Feinwurzeln}

Der Kohlenstoffgehalt der Feinwurzeln ist für die zwei untersuchten Bodenhorizonte in 1890 m Höhe jeweils am niedrigsten (39.09 mmol g ${ }^{-1}$ Humusauflage; 36.75 mmol g ${ }^{-1}$ Mineralboden). Er steigt mit zunehmender Höhe an (2380 m Höhe: $41.41 \mathrm{mmol} \mathrm{g}^{-1}$ Humusauflage; $38.79 \mathrm{mmol} \mathrm{g}^{-1}$ Mineralboden), wobei die Werte sich in $3060 \mathrm{~m}$ Höhe annähern (42.24 mmol g ${ }^{-1}$ Humusauflage; $41.09 \mathrm{mmol} \mathrm{g}^{-1}$ Mineralboden) (Abb. 4.17A). Insgesamt nimmt der C-Gehalt der Feinwurzeln in der Humusauflage im Gradienten von $1890 \mathrm{~m}$ auf $3060 \mathrm{~m}$ um den Faktor 1.1, bzw. im Mineralboden ebenfalls um den Faktor 1.1 $\mathrm{zu}$.

Der Stickstoffgehalt der Feinwurzeln sinkt dagegen mit zunehmender Meereshöhe durchschnittlich um den Faktor 1.6 (Abb. 4.17B). Als Folge des gegenläufigen Verhaltens der Kohlenstoff- und Stickstoffkonzentrationen der Feinwurzeln steigt das C/N-Verhältnis mit zunehmender Höhe etwa um den Faktor 1.9 an. Bemerkenswert sind die sehr ähnlichen Werte des C/N-Verhältnisses der Feinwurzeln aus Humusauflage und Mineralboden. Für die Auflage liegen diese zwischen 38 und 76, für den Mineralboden zwischen 42 und 73.
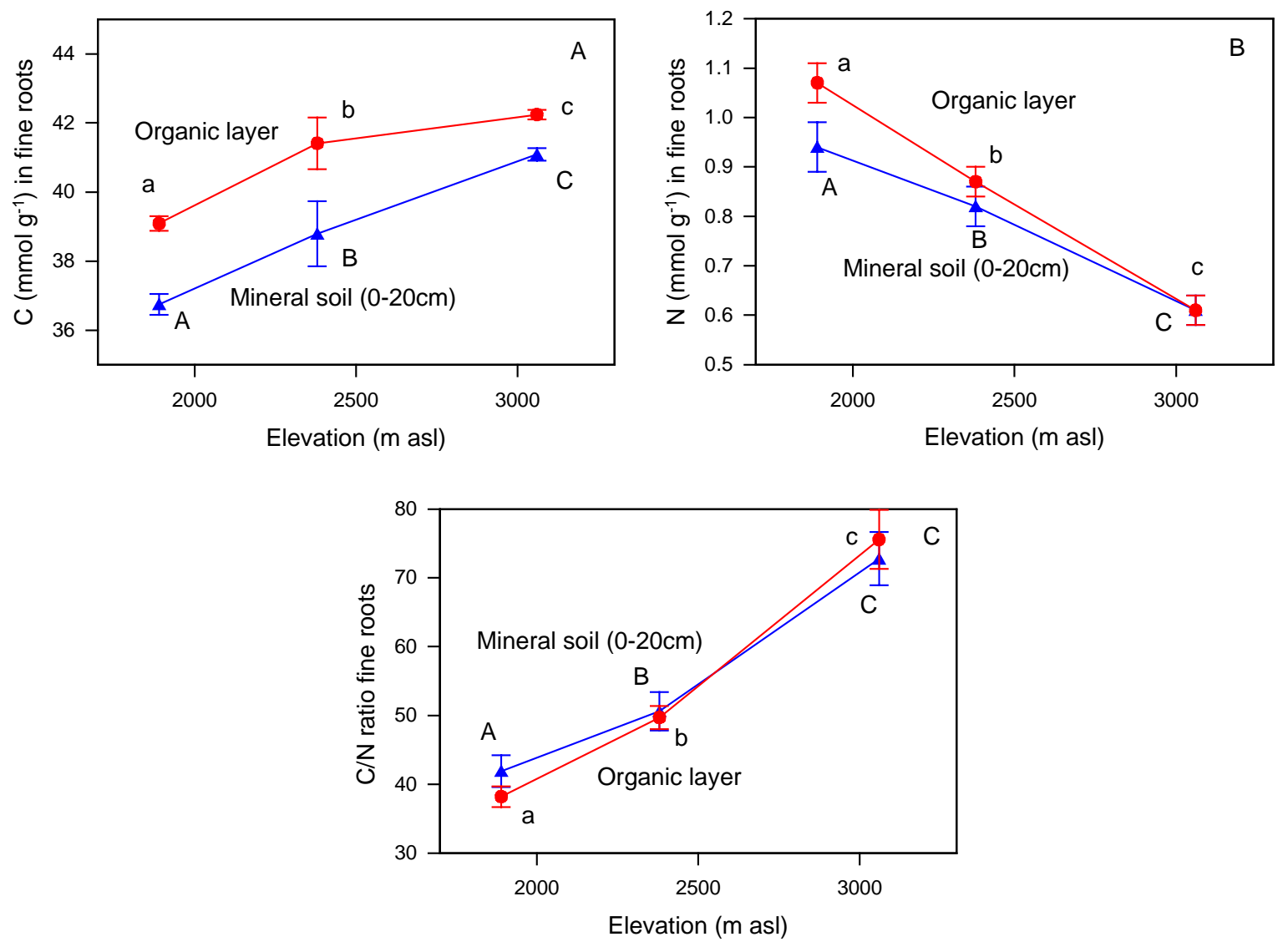

Abb. 4.17 A-C Kohlenstoffgehalt ( $\mathrm{mmol} \mathrm{g}^{-1}$ ), Stickstoffgehalt ( $\mathrm{mmol} \mathrm{g}^{-1}$ ) und das Verhältnis von C/N (mmol $\mathrm{mmol}^{-1}$ ), auf drei Höhenstufen im Untersuchungszeitraum. Es werden Humusauflage und Mineralboden (0-20 $\mathrm{cm}$ Tiefe) unterschieden. Angegeben sind Mittelwerte und Standardfehler $(\mathrm{n}=20)$. Unterschiedliche Buchstaben kennzeichnen signifikante Unterschiede zwischen den drei Höhenstufen, U-Test nach Mann \& Whitney $(\mathrm{p}<0.05)$. 


\subsection{Blattstreuproduktion}

\subsubsection{Saisonale Blattstreuproduktion}

Die Mittelwerte des Blattstreufalls zeigen deutliche Unterschiede in der Höhe des Streufalls zwischen den drei untersuchten Höhenstufen (Abb. 4.18). Beim Betrachten des saisonalen Verlaufs des Blattstreufalls fällt eine Parallelität auf allen drei Höhenstufen auf, mit jeweils einer Verringerung des Streufalls Anfang 2002 und einem Anstieg im Juni auf maximale Werte. Am Ende des Jahres sinkt der Blattstreufall wieder. Am deutlichsten zu erkennen ist diese Saisonalität des Streufalls auf der untersten Versuchsfläche bei 1890 m, welche die höchsten Werte aufweist. Hier verändert sich der Wert in Spitzenzeiten (November 01 und Juni 02) um jeweils $60 \mathrm{~g} \mathrm{~m}^{-2}$. Dagegen sind die Änderungen in der Menge der Blattstreu auf den Flächen auf $2380 \mathrm{~m}$ und 3060 m Höhe mit $24 \mathrm{~g} \mathrm{~m}^{-2}$ bzw. $18 \mathrm{~g} \mathrm{~m}^{-2}$ nicht so deutlich ausgeprägt.

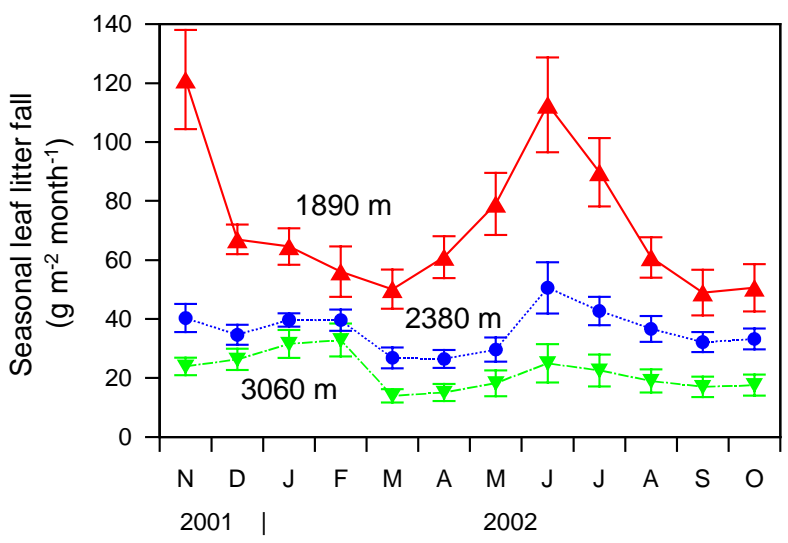

Abb. 4.18: Der saisonale Verlauf des Blattstreufalls pro Monat auf den drei Höhenstufen im Untersuchungszeitraum. Angegeben sind Mittelwerte und Standardfehler $(n=12)$.

\subsubsection{Jahressumme des Blattstreufalls}

Die Mittelwerte des Blattstreufalls zeigen deutliche Unterschiede zwischen den drei untersuchten Höhenstufen (Abb. 4.19). Die Jahressumme sinkt mit steigender Höhe von 862 $\mathrm{g} \mathrm{m}^{-2}$ Jahr auf $1890 \mathrm{~m}$ Höhe um etwa die Hälfte auf $433 \mathrm{~g} \mathrm{~m}^{-2}$ Jahr (2380 m Höhe). Der Unterschied zur Fläche auf $3060 \mathrm{~m}$ Höhe beträgt $39 \%$ (263 g m${ }^{-2} \mathrm{Jahr}$ ). Insgesamt verringert sich damit der Blattstreufall von der obersten Fläche auf 3060 m Höhe um 69.5 \% (Faktor 3.28) zur untersten Fläche auf 1890 m Höhe. 


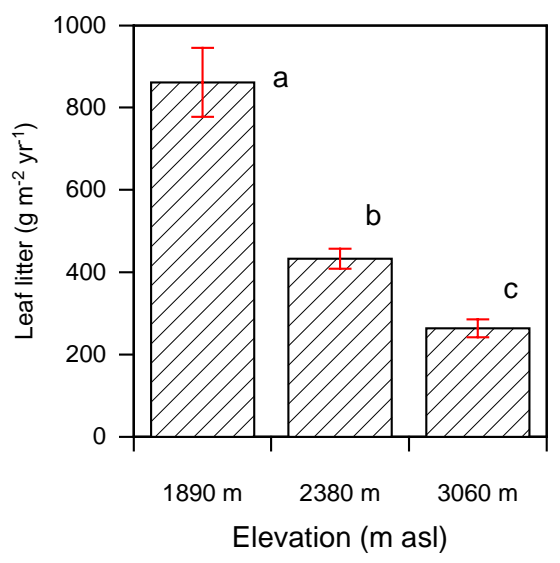

Abb. 4.19: Die Mittelwerte der Summen des Blattstreufalls pro Jahr auf den drei untersuchten Höhenstufen im Untersuchungszeitraum. Angegeben sind Mittelwerte und Standardfehler $(n=12)$. Buchstaben kennzeichnen signifikante Unterschiede zwischen den drei Höhenstufen, U-Test nach Mann \& Whitney (p < 0.05).

\subsection{Spezifische Blattoberfläche (specific leaf area, SLA)}

Die spezifische Blattoberfläche ist, analog zum RAI, ein Maß für die Beziehung zwischen der Blattoberfläche und dem Gewicht von Blättern. Je höher der SLA Wert, desto größer ist die Blattfläche und desto leichter ist das Blatt.

Die Blätter der Bäume auf den drei Höhenstufen unterscheiden sich morphologisch. Auf 1890 m Höhe lassen sich viele Arten mit großen Blättern finden. Die größten im Streufänger gefundenen Blätter waren dort Graffenrieda emarginata. Auf 3060 m Höhe dagegen haben die meisten Bäume kleine, skleromorphe Blätter. Entsprechend unterscheiden sich die Mittelwerte der spezifischen Blattoberfläche, wie in Abb. 4.20 dargestellt ist. Die SLA sinkt von $72 \mathrm{~cm}^{-2} \mathrm{~g}^{-1}(1890 \mathrm{~m})$ um den Faktor 1.3 auf $57 \mathrm{~cm}^{-2} \mathrm{~g}^{-1}(2380 \mathrm{~m})$ und von dieser Höhenstufe um den Faktor 1.1 auf $52 \mathrm{~cm}^{-2} \mathrm{~g}^{-1}$ (3060 m). Dies bedeutet eine Verringerung der SLA von 28 \% zwischen den Flächen auf 1890 m Höhe und 3060 m Höhe.

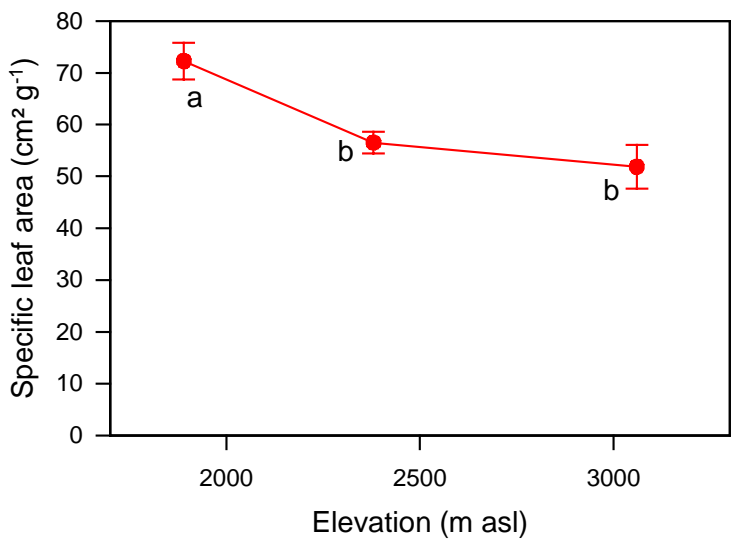

Abb. 4.20: Mittlere spezifische Blattoberfläche (SLA) der Blattstreu auf den drei Höhenstufen im Untersuchungszeitraum. Angegeben sind Mittelwerte und Standardfehler. Buchstaben kennzeichnen signifikante Unterschiede zwischen den drei Höhenstufen, U-Test nach Mann \& Whitney (p < 0.05). 


\subsubsection{Die jährliche Blattstreufläche (leaf area fallen, LAF)}

Die Blattstreufläche errechnet sich aus der Summe des mittleren Jahresblattfalls multipliziert mit dem Mittel der SLA der jeweiligen Höhenstufe. Sie zeigt eine ebenfalls mit der Höhenstufe sinkende Tendenz (Abb. 4.21). Die Werte für die Höhenstufen sind signifikant voneinander unterschiedlich. In $1890 \mathrm{~m}$ Höhe ergibt sich eine Blattstreufläche von $75 \mathrm{~m}^{2} \mathrm{~m}^{-}$ 2. $29 \mathrm{~m}^{2} \mathrm{~m}^{-2}$ werden auf der Untersuchungsfläche auf $2380 \mathrm{~m}$ Höhe ermittelt, und auf der obersten Fläche auf $3060 \mathrm{~m}$ Höhe sinkt die Blattstreufläche auf $16 \mathrm{~m}^{2} \mathrm{~m}^{-2}$. Damit ist ein Rückgang von insgesamt 79 \% von der höchsten zur tiefst gelegenen Fläche zu verzeichnen, was einem Faktor von 4.7 entspricht.

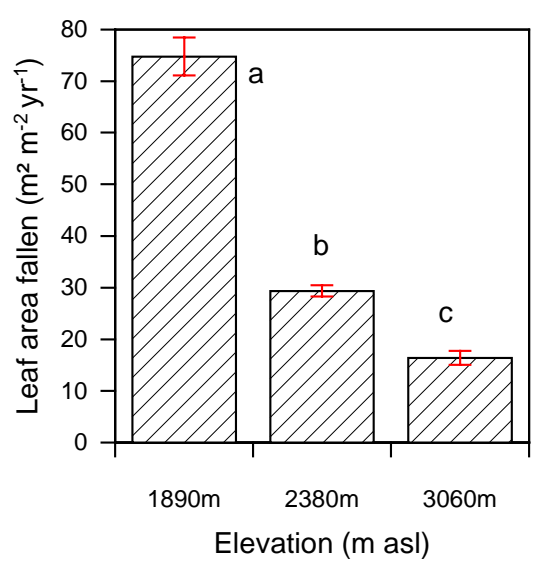

Abb. 4.21: Blattstreuflächen $\left(\mathrm{m}^{2} \mathrm{~m}^{-2}\right)$ auf den drei Höhenstufen im Untersuchungszeitraum. Angegeben sind Mittelwerte und Standardfehler $(n=30)$. Buchstaben kennzeichnen signifikante Unterschiede zwischen den drei Höhenstufen, U-Test nach Mann \& Whitney $(\mathrm{p}<0.05)$.

\subsection{Das Kohlenstoff- Stickstoffverhältnis der abgefallenen Blätter}

Der Kohlenstoffgehalt zeigt einen auf allen Höhenstufen ähnlichen Wert um $39 \mathrm{mmol} \mathrm{g}^{-1}$ (Abb. 4.22A). Lediglich auf $2380 \mathrm{~m}$ Höhe enthalten die Blätter mit $38.72 \mathrm{mmol} \mathrm{g}^{-1}$ weniger Kohlenstoff. Der Stickstoffgehalt sinkt mit zunehmender Meereshöhe: auf $1890 \mathrm{~m}$ Höhe beträgt er $0.89 \mathrm{mmol} \mathrm{g}^{-1}$, geht auf der mittleren Fläche auf $0.7 \mathrm{mmol} \mathrm{g}^{-1}$ zurück und weist auf der höchst gelegenen Versuchfläche nur noch $0.67 \mathrm{mmol} \mathrm{g}^{-1}$ auf (Abb. 4.22B).

Dies entspricht einem Rückgang des Stickstoffgehalts um den Faktor 1.3 von der untersten zur obersten Höhenstufe.

Das Kohlenstoff-Stickstoffverhältnis der Blätter zeigt ein ähnliches Bild wie das C/NVerhältnis der Feinwurzeln (Abb. 4.22C). Mit der Höhenstufe (1890 m 46; 2380 m 60; 3060 m Höhe 65) steigt das C/N-Verhältnis an. Von der untersten zur höchsten Fläche ergibt sich so eine Zunahme um den Faktor 1.4. 

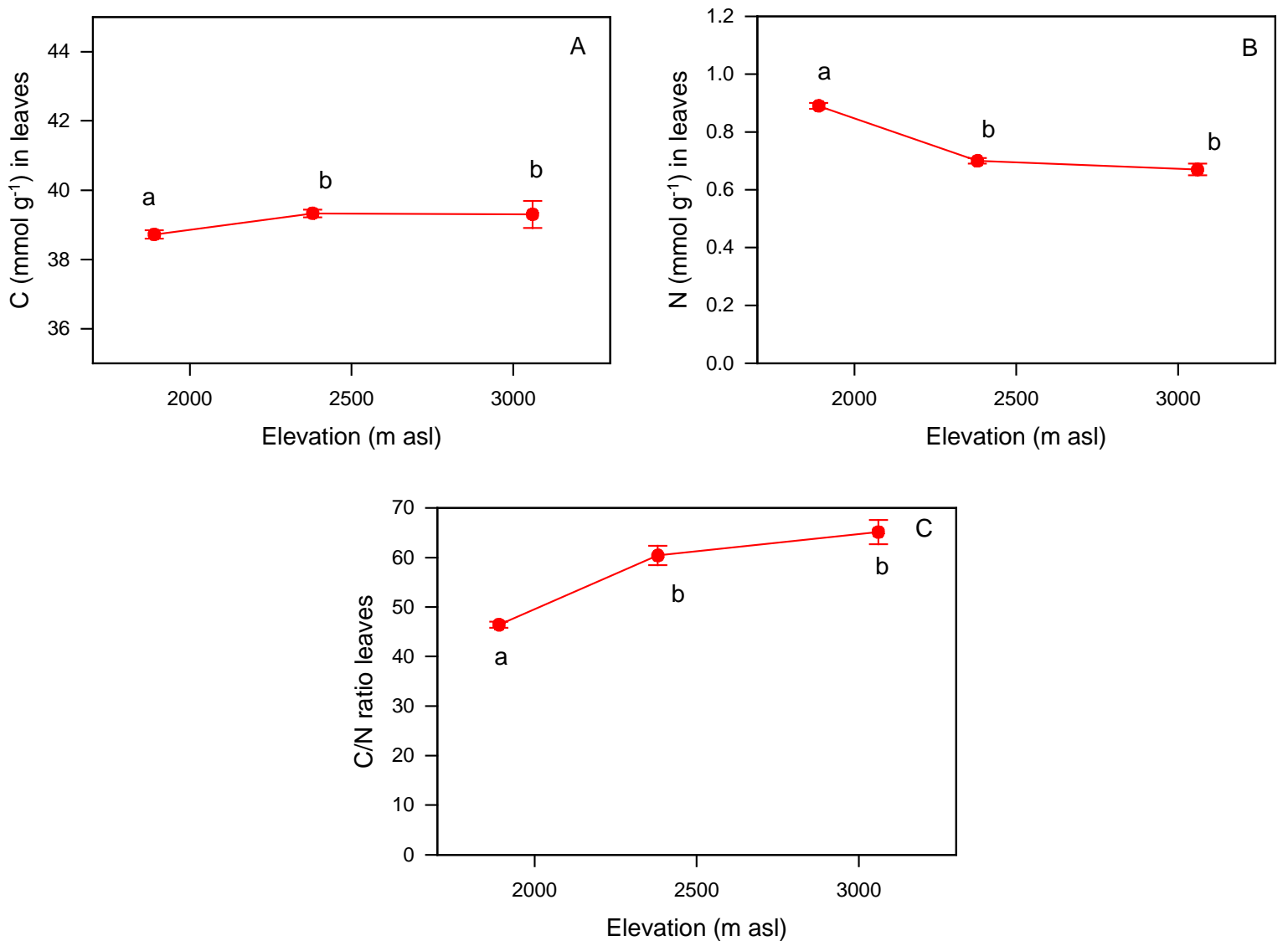

Abb. 4.22 A-C: Kohlenstoffgehalt ( $\left.\mathrm{mmol} \mathrm{g}^{-1}\right)$, Stickstoffgehalt $\left(\mathrm{mmol} \mathrm{g}^{-1}\right)$ und das Verhältnis von C/N (mmol $\mathrm{mmol}^{-1}$ ) der Blattstreu auf den drei Höhenstufen im Untersuchungszeitraum. Angegeben sind Mittelwerte und Standardfehler $(\mathrm{n}=12)$. Buchstaben kennzeichnen signifikante Unterschiede zwischen den drei Höhenstufen, U-Test nach Mann \& Whitney (p < 0.05). 


\section{Diskussion}

5.1 Der Einfluss der Meereshöhe auf Masse, Morphologie und räumliche Verteilung der Feinwurzeln von tropischen Bergwäldern

5.1.1 Unterschiede in den Feinwurzelmassen in unterschiedlicher Meereshöhe

\subsubsection{Bio- und Nekromassen der Feinwurzeln}

In der vorliegenden Arbeit ist eine positive Korrelation zwischen der Masse an Feinwurzeln und der Meereshöhe gefunden worden. Entlang des ecuadorianischen Höhengradienten verdoppelt sich die Feinwurzelbiomasse von $535 \mathrm{~g} \mathrm{~m}^{-2}$ (1890 m) auf $1073 \mathrm{~g} \mathrm{~m}^{-2}$ (3060 m). Die Feinwurzelnekromasse erhöht sich sogar um den Faktor vier von $730 \mathrm{~g} \mathrm{~m}^{-2}$ auf $2733 \mathrm{~g} \mathrm{~m}^{-2}$.

In einer globalen Übersicht beschreiben JACKSON et al. (1996) Werte von Feinwurzelbiomassen unterschiedlicher Biome, die in einer Spanne von 200-5000 g m liegen. In Wäldern gemäßigter Breiten werden Bio- bzw. Nekromassen von Feinwurzeln zwischen 28 und $1500 \mathrm{~g} \mathrm{~m}^{-2}$, bzw. zwischen 5 und $2955 \mathrm{~g} \mathrm{~m}^{-2}$ gefunden (LEUSCHNER \& HeRTEl 2003). Für montane Bergwälder in Costa Rica (2900 m) ermitteln HERTEL et al. (2003) Feinwurzelbiomassen zwischen 200 und $1300 \mathrm{~g} \mathrm{~m}^{-2}$ und Feinwurzelnekromassen zwischen 100 und $550 \mathrm{~g} \mathrm{~m}^{-2}$. In einer aktuellen Übersicht der Feinwurzelmassen tropischer Regenwälder wird gezeigt, dass sowohl die Bio- als auch die Nekromassen sehr stark zwischen den verschiedenen Beständen variieren (HERTEL \& LEUSCHNER 2006). Die gesammelten Daten zur Feinwurzelbiomasse und -nekromasse aus dieser Literaturzusammenstellung liegen zwischen 8 und $1440 \mathrm{~g} \mathrm{~m}^{-2}$, bzw. 34 und $2398 \mathrm{~g} \mathrm{~m}^{-2}$.

Die in Ecuador ermittelten Feinwurzelmassen liegen innerhalb der oben beschriebenen Spektren und sind deutlich höher als die von HERTEL et al. (2003) gefundenen Werte.

Für hochmontane Regenwälder stehen wenige Literaturangaben zur Verfügung. In der folgenden Übersicht (Tab. 5.1) sind Daten aufgeführt, die in vergleichbaren Höhenstufen aufgenommen wurden. In der Tabelle sind Werte für die Feinwurzelbiomasse tropisch montaner Bergregenwälder dargestellt, die starke Schwankungen zwischen $400 \mathrm{~g} \mathrm{~m}^{-2}$ und $1440 \mathrm{~g} \mathrm{~m}^{-2}$ aufweisen. Auch die Ergebnisse von KITAYAMA \& AIBA (2002) entlang eines Höhengradienten von 1860 bis 3050 m Meereshöhe am Mt. Kinabalu (Malaysia) haben darüber hinaus einen deutlichen Anstieg der Feinwurzelbiomasse mit zunehmender Meereshöhe zu verzeichnen.

Jedoch zeigt die Literaturübersicht der Feinwurzelmassen tropischer Regenwälder von HERTEL \& LEUSCHNER (2006), dass diese Werte eine hohe Variabilität aufweisen, da hohe Massen sowohl im Tiefland- als auch in Bergregenwäldern vorkommen können und somit eine Zunahme der Feinwurzelmassen nicht immer durch die Meereshöhe bedingt wird, sondern auch edaphische Ursachen haben kann. 
Tab. 5.1: Literaturangaben zur Feinwurzelbiomasse tropischer Wälder auf unterschiedlichen Höhenstufen. Feinwurzelbiomasse-Angaben bei RöDERSTEIN et al. (2005) Mineralboden bis $20 \mathrm{~cm}$, P Angaben von Soethe (per. Mitt.). ECSF = Estación Científica San Francisco und PNP = Podocapus National Park, Ecuador; Daten in Klammern sind Gesamtfeinwurzelmassen.

\begin{tabular}{|c|c|c|c|c|c|}
\hline Location & $\begin{array}{l}\text { Elevation } \\
\text { in } \mathbf{m}\end{array}$ & $\begin{array}{l}\text { Precipitation } \\
\text { in } \mathrm{mm} \mathrm{y}^{-1}\end{array}$ & $\begin{array}{l}\text { Fine root } \\
\text { biomass in } g \\
\operatorname{dm~m}^{-2} \mathrm{yr}^{-1}\end{array}$ & $\begin{array}{l}\text { Nutrient- } \\
\text { poor/rich area }\end{array}$ & \\
\hline $\begin{array}{l}\text { Mt. Kinabalu } \\
\text { Malaysia }\end{array}$ & 1860 & ca. 2400 & 900 & poor $\mathrm{P}$ and $\mathrm{N}$ & $\begin{array}{l}\text { KITAYAMA \& AIBA } \\
2002\end{array}$ \\
\hline $\begin{array}{l}\text { Mt. Kinabalu } \\
\text { Malaysia }\end{array}$ & 2700 & 2200 & 960 & poor $\mathrm{P}$ and $\mathrm{N}$ & $\begin{array}{l}\text { KITAYAMA \& AIBA } \\
2002\end{array}$ \\
\hline $\begin{array}{l}\text { Mt. Kinabalu } \\
\text { Malaysia }\end{array}$ & 3050 & 2100 & 1440 & poor $\mathrm{P}$ and $\mathrm{N}$ & $\begin{array}{l}\text { KITAYAMA \& AIBA } \\
2002\end{array}$ \\
\hline $\begin{array}{l}\text { La Planada } \\
\text { (Mature) } \\
\text { Colombia }\end{array}$ & 1800 & 3750 & (1169) & poor $\mathrm{P}$, high $\mathrm{N}$ & $\begin{array}{l}\text { CAVELIER et al. } \\
1996\end{array}$ \\
\hline $\begin{array}{l}\text { Mt. Kerigomna } \\
\text { New Guinea }\end{array}$ & 2500 & 4000 & $(950)$ & $\begin{array}{l}\text { poor } \mathrm{P}, \\
\text { medium } \mathrm{N}\end{array}$ & $\begin{array}{l}\text { EDWARDS \& GRUBB } \\
1977 / 82\end{array}$ \\
\hline $\begin{array}{l}\text { Cordillera de } \\
\text { Talamanca } \\
\text { (Mature) } \\
\text { Costa Rica }\end{array}$ & 2900 & 2700 & $1329(1866)$ & poor $\mathrm{P}$ and $\mathrm{N}$ & HERTEL et al. 2003 \\
\hline $\begin{array}{l}\text { ECSF } \\
\text { Ecuador }\end{array}$ & 1890 & 1930 & $393(1033)$ & poor $\mathrm{N}$ (poor $\mathrm{P}$ ) & $\begin{array}{l}\text { RÖDERSTEIN et al. } \\
2005\end{array}$ \\
\hline $\begin{array}{l}\text { ECSF } \\
\text { Ecuador }\end{array}$ & 2380 & ca. 5790 & $539(1531)$ & poor $\mathrm{N}$ (poor $\mathrm{P}$ ) & $\begin{array}{l}\text { RÖDERSTEIN et al. } \\
2005\end{array}$ \\
\hline $\begin{array}{l}\text { ECSF (PNP) } \\
\text { Ecuador }\end{array}$ & 3060 & 4480 & $978(3376)$ & poor $\mathrm{N}$ (poor $\mathrm{P}$ ) & $\begin{array}{l}\text { RÖDERSTEIN et al. } \\
2005\end{array}$ \\
\hline
\end{tabular}

5.1.1.2 Die Beziehung zwischen Feinwurzelbiomasse und der oberirdischen Pflanzenbiomasse

Verschiedene Autoren (u.a. VogT et al. 1987, Vogt et al. 1996, CAIRns et al. 1997, BROWN 1997) haben den Zusammenhang zwischen der oberirdischen und der unterirdischen Biomasse in Wäldern untersucht. VoGT et al. (1987) weisen nach, dass in einem sehr produktiven Koniferenwald eine hohe Feinwurzelbiomasse mit einer geringen Basalfläche verbunden ist. In der vorliegenden Arbeit konnten signifikante Beziehungen nur zwischen dem mittleren Brusthöhendurchmesser und der Feinwurzelbiomasse ( $p=$ $\left.0.01, r^{2}=0.99\right)$ der einzelnen Waldbestände gefunden werden sowie zwischen der mittleren Stammlänge und der Feinwurzelbiomasse $\left(p=0.049, r^{2}=0.97\right)$. SANTANTONIO et al. (1977) beschreiben ebenfalls einen direkten Zusammenhang zwischen Feinwurzelbiomasse und Brusthöhendurchmesser. Für andere (Kap. 2, Tab. 2.2) oberirdische Bestandesparameter wurden keine signifikanten Korrelationen ermittelt. Drexhage \& Colin (2001) sowie Bolte et al. (2004) unternehmen den Versuch, eine Schätzung der Wurzelmasse bzw. Grobwurzelmasse für Wälder der gemäßigten Breiten anhand des BHD vorzunehmen. Sie fanden dabei eine enge Beziehung zwischen diesen beiden Parametern. Diese Verfahrensweise wurde in der vorliegenden Arbeit für die 
Schätzung des Gesamtwurzelsystems sowie für die Feinwurzelbiomasse und den BHD angewandt. Um die Daten besser vergleichen zu können, wurden sie logarithmiert. Für die Gesamtwurzelbiomasse und die Feinwurzelbiomasse liegen die dargestellten Werte innerhalb des Bereiches, den DREXHAGE \& COLIN (2001) für Wälder des gemäßigten Klimas ermittelt haben.
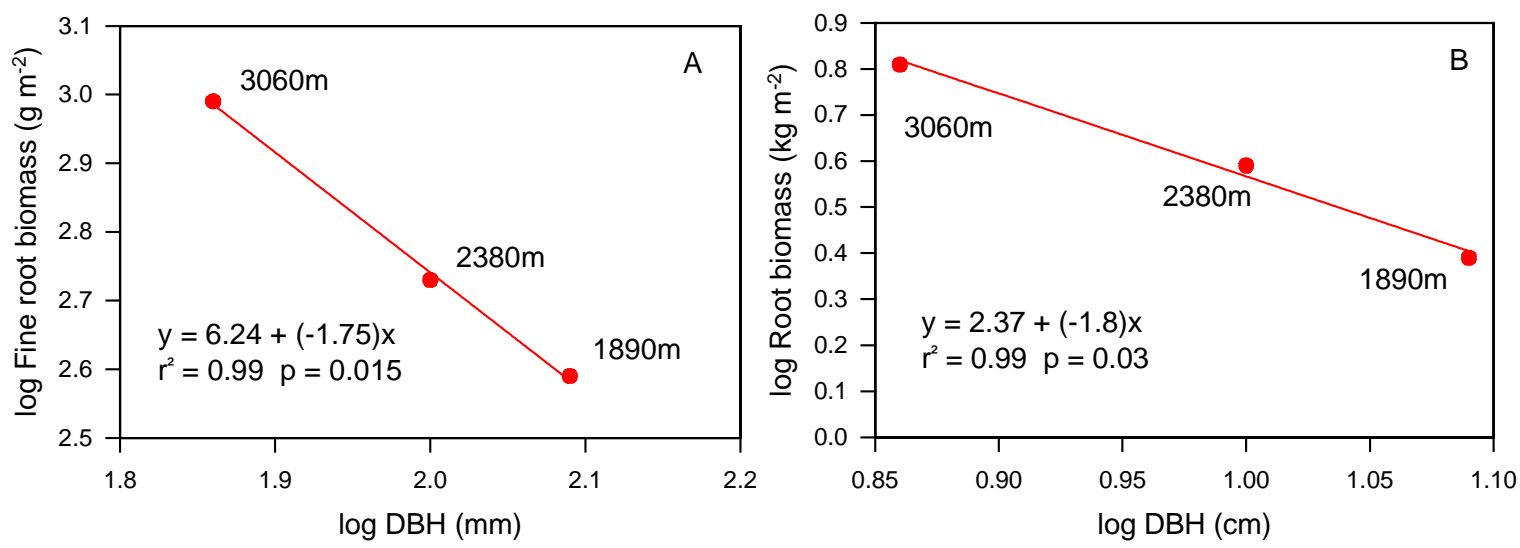

Abb. 5.1 A und B: Logarithmierte Feinwurzelbiomasse $\left(\mathrm{g} \mathrm{m}^{-2}\right)$ (A) und die logarithmierte Gesamtwurzelbiomasse $\left(\mathrm{kg} \mathrm{m}^{-2}\right)$ (B) (Grobwurzeldaten stammen von SoETHE, pers. Mitt.) gegen den logarithmierten mittleren Brusthöhendurchmesser $(\mathrm{cm})$ auf den drei Untersuchungsflächen (lineare Regressionsanalysen). 
Die Verteilung der Biomassen auf den drei Höhenstufen zeigt, dass die oberirdische Biomasse mit der Höhe abnimmt, die unterirdische Biomasse gleichzeitig zunimmt und somit der Feinwurzelbiomassenanteil mit der Höhe steigt.
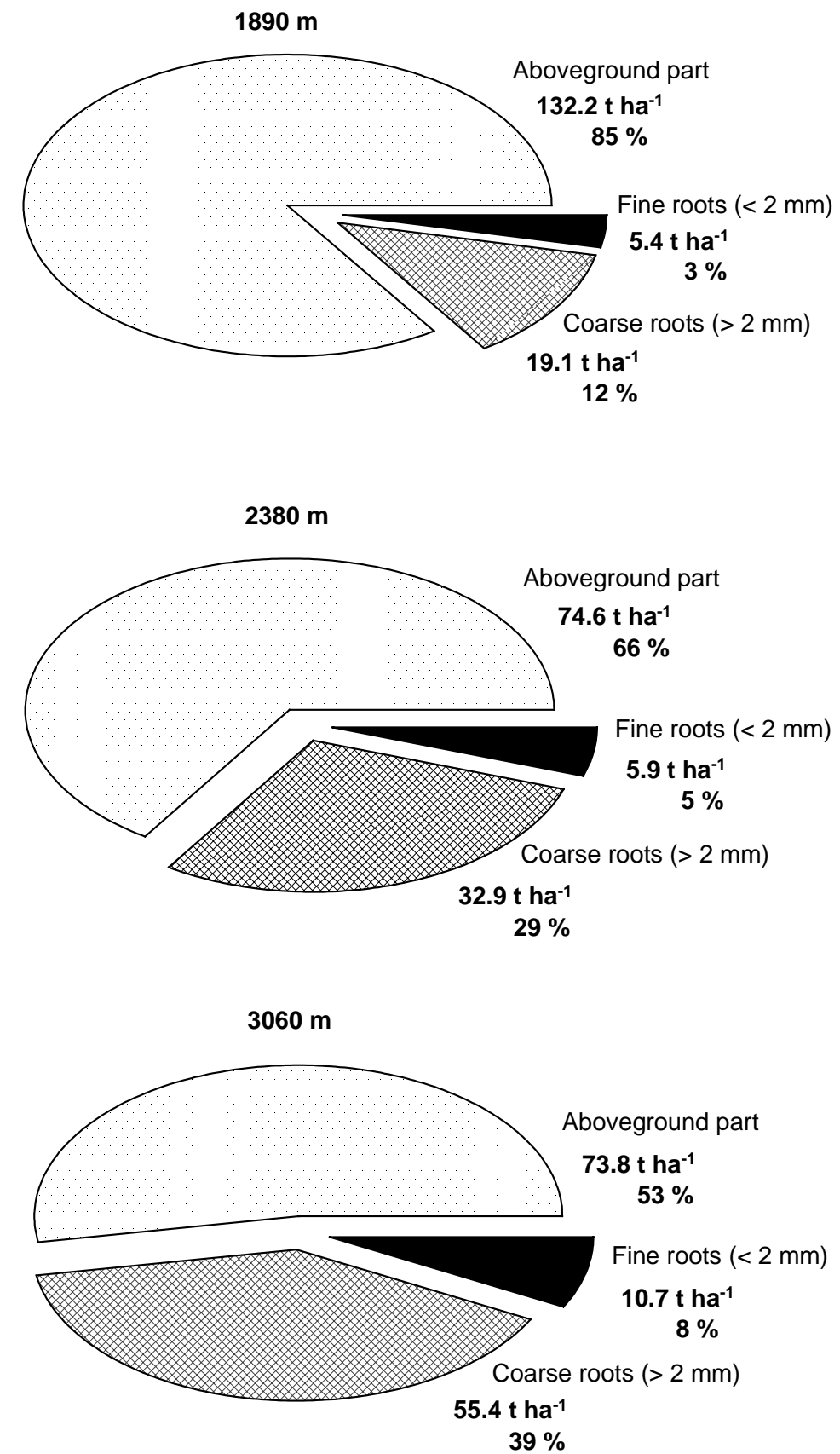

Abb. 5.2: Die Verteilung der ober- und unterirdischen Biomasse auf den drei Untersuchungsflächen. Die oberirdische Biomasse wurde für 80 Bäume pro Bestand nach der allometrischen Beziehung (ln y $=-3.375+$ $\left.0.948 \ln \left(\mathrm{BHD}^{2} \cdot \mathrm{H}\right)\right)$ zwischen BHD und Stammlänge H von BrOwN \& IvERSON (1992) geschätzt. Die Daten für die Grobwurzelbiomasse wurden von SOETHE (unveröffentlicht) zur Verfügung gestellt. (y $=\mathrm{TM} \mathrm{g} \mathrm{m}^{2}$; $\mathrm{BHD}=\mathrm{cm} ; \mathrm{H}=\mathrm{m}$; umgerechnet in $\mathrm{t} / \mathrm{ha})$ 
5.1.1.3 Der Einfluss der Umweltfaktoren auf die Feinwurzelmassen im Höhengradienten Mit steigender Meereshöhe sinken im allgemeinen die Boden- und Lufttemperaturen (CAVElier 1996, MCGROdDY \& SILVER 2000). Im ecuadorianischen Höhengradienten nimmt die Temperatur ebenfalls mit steigender Höhe $\mathrm{ab}\left(\mathrm{r}^{2}=0.99, \mathrm{p}=0.04\right)$. Zwischen der Zunahme der Feinwurzelmasse und der abnehmenden Lufttemperatur besteht jedoch keine signifikante Beziehung $(\mathrm{p}=0.1)$. CAVELIER (1996) sieht niedrige Boden- und Lufttemperaturen und hohen Bodenwassergehalt als Ursachen für die langsame Zersetzung des organischen Materials. Dieser verzögerte Abbau der organischen Substanz führt zu einer geringeren Nährstoffverfügbarkeit im Boden, was eine verstärkte Konkurrenz der Pflanzen um die limitierten Nährelemente bewirkt (TANNER et al. 1998), und die Ausbildung eines dichteren Feinwurzelsystems zur Folge haben kann. Auch andere Autoren erachten in tropischen Gebieten vor allem die Temperatur als wichtigen steuernden Faktor für die mikrobielle Umsetzung (BENNER et al. 2006) und den Stickstoffumsatz (BREUER et al. 2002, 2005).

VOGT et al. (1996) zeigen in einem Literaturüberblick, dass klimatische Faktoren sowie die Bodenart nicht grundsätzlich mit der Feinwurzelmasse von Waldbeständen korrelieren. Allerdings belegen die Autoren dieser Studie für tropisch immergrüne Wälder den signifikanten Einfluss der Temperatur auf die Feinwurzelmasse.

In der vorliegenden Arbeit sinkt die Temperatur um $5 \mathrm{~K}$ pro km im Höhengradienten (Kap. 2, Tab. 2.1). Der durch die Temperaturabnahme verlangsamte Abbau der Wurzelstreu ist vermutlich für die hohen Feinwurzelnekromassen gerade auf der höchst gelegenen Versuchsfläche verantwortlich.

In der Arbeit von VANGuELOVA et al. (2005) besteht ein positiver Zusammenhang zwischen dem Bodenwassergehalt und der Feinwurzelbiomasse in einem Kiefernbestand. MCGRoddy \& SILVER (2000) finden für einen Höhengradienten in einem Tieflandregenwald (Puerto Rico) ebenfalls eine signifikante, positive Korrelation zwischen der Wurzelbiomasse und dem Bodenwassergehalt. GREEN et al. (2005) zeigen in ihrer Untersuchung in Malaysia, dass das Vorhandensein von Wasser einen größeren Einfluss auf die Feinwurzelbiomasse hat als die Nährstoffverfügbarkeit. Ein weiteres Ergebnis ihrer Untersuchungen ist die direkte Beeinflussung des Niederschlags und des resultierenden Bodenwassergehaltes sowohl auf die Wurzelbiomasse als auch auf den Abbau der toten Wurzeln. BAKER et al. (2001) dokumentieren hingegen, dass in einem Feuchtwald in South Carolina auf der besser entwässerten Fläche eine höhere Feinwurzelbiomasse erreicht wurde als auf der stark vernässten.

In der vorliegenden Arbeit wurde keine direkte Einwirkung des Niederschlags bzw. des Bodenwassergehaltes auf die Bio- und Nekromasse der Feinwurzeln gefunden. Allerdings ließ sich ein signifikanter Einfluss des mittleren Bodenwassergehaltes auf die Lebensdauer der Feinwurzeln (Niederschlag: $\mathrm{r}^{2}=0.99, \mathrm{p}=0.022$; mittlerer Bodenwassergehalt: $\mathrm{r}^{2}=1$, 
$p=0.004$ ) sowie den Feinwurzelumsatz (Niederschlag: $r^{2}=0.99, p=0.011 ;$ mittlerer Bodenwassergehalt: $\left.r^{2}=0.99, p=0.013\right)$ feststellen. Der hohe Bodenwassergehalt in vielen tropisch montanen Wäldern dürfte die Sauerstoffversorgung der Bodenmikroorganismen deutlich verschlechtern (ODUM 1970, HETSCH \& HOHEISEL 1976, VITOUSEK \& SANFORD 1986) mit der Folge eines verminderten Abbaus der organischen Substanz (CAVELIER 1996). Es kommt zu einer Akkumulation toter organischer Substanz und zur Bildung mächtiger organischer Auflagen unter hochmontanen Bedingungen, die einen torfähnlichen und stark sauren Oberboden bilden (BRUIJNZEEL \& PROCTOR 1995) und zu einer schlechten Nährstoffverfügbarkeit im Boden führen (TANNER et al. 1998).

TANNER et al. (1998), HAFKENSCHEID (2000) und WiLCKE et al. (2002) finden in ihren Untersuchungen in tropisch montanen Wäldern ähnlich mächtige organische Auflagen, wie in der vorliegenden Arbeit. Die Auflagemächtigkeit liegt bei den zwei tiefer gelegenen Untersuchungsflächen bei $17 \mathrm{~cm}$ und steigt auf $24 \mathrm{~cm}$ (eigene Messung) bzw. $30 \mathrm{~cm}$ (SoETHE, pers. Mitt.) auf der höchst gelegenen Fläche an. Neben der Topographie (STADTMÜller 1987, Silver et al. 1994) bestimmen vor allem die Hangneigung, mögliche Plateaueffekte oder Lücken im Bestand (OSTERTAG 1998, HAFKENSCHEID, 2000) die Höhe der Auflagemächtigkeit. Ebenso können Bewölkung und Niederschlag (BRuijnzeEl 2004, RollenBeck et al. 2005, Bendix et al. 2006), Stürme und die Zusammensetzung der Baumarten (CuEvas et al. 1991, LAL et al. 1995) zur Erhöhung der organischen Auflage beitragen. Für temperate Wälder zeigen VoGT et al. (1981), SunDARPANDIAN \& SWAMY (1996) und HERTEL (1999), dass besonders im Bezug auf die Feinwurzelnekromasse ein negativer Zusammenhang zwischen der Mächtigkeit der organischen Auflage und der Nährstoffverfügbarkeit der Standorte vorhanden ist. Allerdings konnte in der vorliegenden Untersuchung keine signifikante Korrelation zwischen der Auflagemächtigkeit und den Feinwurzelmassen entlang des Höhengradienten festgestellt werden, da nur drei Untersuchungsflächen beprobt wurden.

Zwischen der Höhe der organischen Auflage und dem pH-Wert wurde im ecuadorianischen Höhengradienten kein signifikanter Zusammenhang gefunden. Allerdings konnte eine starke Abhängigkeit der Feinwurzelbiomasse vom $\mathrm{pH}-$ Wert des Bodens $\left(r^{2}=0.99, p=0.008\right)$ sowie der Feinwurzelnekromasse vom $\mathrm{pH}\left(\mathrm{r}^{2}=0.99, \mathrm{p}=\right.$ $0.01)$ nachgewiesen werden.

BERG \& LASKOWSKI (2006) belegen, dass hohe Konzentrationen von $\mathrm{H}^{+}$- und $\mathrm{Al}^{3+}$-Ionen in Böden mit niedriger Nährstoffverfügbarkeit die Destruenten negativ beeinflussen und zusätzlich die Zersetzung hemmen. VANGUELOVA et al. (2005) stellen fest, dass bei niedrigem $\mathrm{pH}$-Wert $(<4.2)$ und hoher Al-Konzentration $\left(>3-10 \mathrm{mg}^{-1}\right)$ ein direkter negativer Effekt auf das Wurzelwachstum ausgeübt wird, welcher sich in Form von steigender Wurzelmortalität äußert. Aber nicht alle Baumarten nehmen Aluminium auf. 
CUENCA et al. (1987, 1990) zählen zu den Familien, die Aluminium anreichern (Aluminium-Accumulatoren) u. a. Euphorbiaceae, Melastomataceae, Myrtaceae und Rubiaceae, die alle im Untersuchungsgebiet vorkommen. Aluminium-Ionen, die die Blätter über den Xylemsaftfluss erreichen, können in die Chloroplasten gelangen und Schäden am Photosyntheseapparat hervorrufen. SOETHE (pers. Mitt.) stellt fest, dass auf der höchsten Untersuchungsfläche im ecuadorianischen Höhentransekt vor allem der Anteil an für Pflanzen verfügbarem Phosphor im Boden sehr gering ist, nicht aber die Gesamtmenge des im Boden enthaltenen Phosphors.

SILVER \& MiYA (2001) zeigen in einer Studie über Zersetzungsraten von Wurzeln in Wäldern der gemäßigten Breiten, dass eine negative Korrelation zwischen dem C/NVerhältnis und dem Abbau besteht; je höher das C/N-Verhältnis ist, desto schlechter wird die Wurzelmasse zersetzt. Dies konnte in der vorliegenden Arbeit bestätigt werden (Abb. 5.3). Dies erklärt zu einem Teil die mächtige organische Auflage mit zunehmender Meereshöhe.

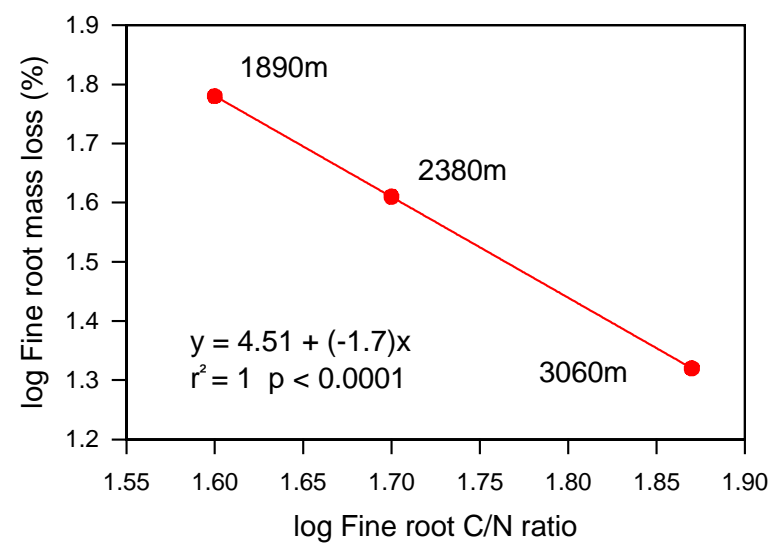

Abb. 5.3: Beziehung zwischen logarithmierter zersetzter Feinwurzelmasse (\%) und dem logarithmierten C/N-Verhältnis der Feinwurzeln auf den drei Höhenstufen. Lineare Regressionsanalyse, Irrtumswahrscheinlichkeit $\mathrm{p}$ und das Bestimmtheitsmaß $\mathrm{r}^{2}$.

In der vorliegenden Untersuchung steigt das $\mathrm{C} / \mathrm{N}-$ Verhältnis nicht nur in den Feinwurzeln und Blättern, sondern ebenfalls im Boden (SoETHE, pers. Mitt.) mit der Meereshöhe. Das $\mathrm{C} / \mathrm{N}-$ Verhältnis der Feinwurzeln steigt mit der Meereshöhe in Ecuador von 40 auf 74 an und erreicht damit sehr hohe Werte. Das bedeutet, dass der Wurzelabbau mit der Höhe zunehmend durch N-Mangel limitiert wird. Die C/N-Werte der Feinwurzeln liegen etwa in derselben Höhe wie die der Blätter. Einen signifikanten Zusammenhang auf das $\mathrm{C} / \mathrm{N}$ Verhältnis der Feinwurzeln hat sowohl die Höhe $\left(p=0.046, r^{2}=0.98\right)$, der Temperatur $(p$ $\left.=0.048, \mathrm{r}^{2}=0.98\right)$, dem RAI $\left(\mathrm{p}=0.015, \mathrm{r}^{2}=0.99\right)$ als auch der $\mathrm{pH}-$ Wert $\left(\mathrm{p}=0.024, \mathrm{r}^{2}=\right.$ $0.99)$. 
Das ungünstige C/N-Verhältnis der Streu verlangsamt zusätzlich zur schlechten Sauerstoffversorgung der Mikroorganismen die Zersetzung (CAVELIER 1996) und verstärkt die Streuakkumulation nahe der Waldgrenze in Südecuador. In einer Studie im südecuadorianischen Untersuchungsgebiet wird festgestellt, dass die Abundanz von primären Destruenten im Oberboden verhältnismäßig gering ist (ILLIG et al. 2005), und dies zu einer weiteren Verminderung der Zersetzungsraten führt.

VoGT et al. (1996) finden, dass in einigen Ökosystemen mehr Stickstoff durch die Feinwurzelzersetzung dem Boden zurückgeführt wird als durch die restliche Streu. Nach diesen Autoren hat die Temperatur einen größeren Einfluss auf den Abbau von Feinwurzeln als auf die Zersetzung von Blättern (SILVER \& MIYA, 2001). OsTERTAG \& HobBIE (1999) und BERG \& LASKOWSKI (2006) erwähnen, dass Wurzeln schneller als Blätter umgesetzt werden, da sie wahrscheinlich ein günstigeres Lignin/NährstoffVerhältnis besitzen.

BROUWER (1983) führt an, dass Pflanzen proportional mehr in die Feinwurzelbiomasse und weniger in den Spross investieren, wenn eine geringe Stickstoff-Verfügbarkeit wachstumslimitierend wirkt. Der Stickstoffgehalt des Bodens sinkt im Untersuchungsgebiet mit steigender Meereshöhe kontinuierlich ab (SOETHE, pers. Mitt.), während die Bio- und Nekromassen der Feinwurzeln zunehmen. Dies deckt sich sehr gut mit den Untersuchungen von VoGT et al. (1987). Allerdings konnte kein direkter Zusammenhang zwischen dem Stickstoffgehalt der Feinwurzeln und der entsprechenden Bio- bzw. Nekromasse gefunden werden, so dass diese unabhängig vom Bodengehalt zu sein scheint.

Tab. 5.2: Der Einfluss unterschiedlicher Faktoren auf den Stickstoffgehalt der Feinwurzeln (mmol $\left.\mathrm{g}^{-1}\right)$ (lineare Regressionsanalyse). Irrtumswahrscheinlichkeit $p$, Bestimmtheitsmaß $r^{2}$. Signifikante Abhängigkeiten sind fett gedruckt.

\begin{tabular}{lll}
\hline & \multicolumn{2}{l}{ Nitrogen $\left(\mathrm{mmol} \mathrm{g}^{-1}\right)$} \\
\hline Elevation $(\mathrm{m}$ asl $)$ & $\mathrm{p}$ & $\mathrm{r}^{2}$ \\
\cline { 2 - 3 } Temperature $\left({ }^{\circ} \mathrm{C}\right)$ & $\mathbf{0 . 0 0 5}$ & 0.99 \\
SRA $\left(\mathrm{cm}^{2} \mathrm{~g}^{-1}\right)$ & $\mathbf{0 . 0 0 6}$ & 0.99 \\
Precipitation $(\mathrm{mm})$ & $\mathbf{0 . 0 2 0}$ & 0.99 \\
RAI $\left(\mathrm{m}^{2} \mathrm{~m}^{-2}\right)$ & 0.250 & 0.50 \\
DBH $(\mathrm{cm})$ & 0.059 & 0.97 \\
Stem height $(\mathrm{m})$ & $\mathbf{0 . 0 1 6}$ & 0.99 \\
Fine root mass loss $(\%)$ & 0.054 & 0.97 \\
Biomass & $\mathbf{0 . 0 2 8}$ & 0.98 \\
\hline
\end{tabular}


Mit steigender Meereshöhe kommt es durch eine Kombination aus steigendem Wassergehalt des Bodens, sinkender Sauerstoffversorgung und Beeinträchtigung der Aktivität der Mikroorganismen, durch sinkende Temperaturen sowie der insgesamt geringen Abundanz von Primärdestruenten zu einer deutlich verringerten Streuzersetzung und damit zu einer geringen Verfügbarkeit der in der Nekromassen enthaltenen Nährstoffe.

5.1.1.4 $\delta^{13} \mathrm{C}$ und $\delta^{15} \mathrm{~N}$ in Feinwurzeln aus unterschiedlicher Meereshöhe $\delta^{13} \mathrm{C}$ von lebenden und toten Feinwurzeln zeigt eine geringe, aber signifikante Zunahme mit der Meereshöhe. Bei $1890 \mathrm{~m}$ liegt $\delta^{15} \mathrm{~N}$ bei -3.5 bis $0 \%$ (- 28 bis $\left.-25 \% \delta^{13} \mathrm{C}\right)$. In $2380 \mathrm{~m}$ beträgt der Wert von $\delta^{15} \mathrm{~N}$ zwischen -4 bis $+2 \%$ o $\left(-27\right.$ bis $\left.-25 \% \delta^{13} \mathrm{C}\right)$ und zeigt schließlich auf $3060 \mathrm{~m}$ Höhe Werte von -6 bis $+4 \%$ (- 25 bis $-24 \%$ o $\left.\delta^{13} \mathrm{C}\right)$ (HAUBrich, pers. Mitt.). TRUMBORE et al. (2006) ermitteln in ihren Untersuchungen an lebenden Wurzeln im Amazonastiefland $\delta^{13} \mathrm{C}$-Werte, die im Durchschnitt bei - $27 \%$ liegen und sich damit in derselben Größenordnung befinden wie die Isotopenwerte in dieser Arbeit.

5.1.2 Der Einfluss der Meereshöhe auf die Morphologie und die Kohlenstoffspeicherung der Feinwurzeln

\subsubsection{Morphologie der Feinwurzeln}

Die Wurzelmorphologie hängt neben artspezifischen Eigenschaften stark von den biotischen und abiotischen Umweltfaktoren eines Standortes ab. In ihrer Arbeit an Fichten zeigen OSTONEN et al. (1999) unter anderem, dass die Mykorrhizierung von Wurzeln einen Einfluss auf deren Volumen und Biomasse hat. Der mittlere Durchmesser der Fichtenfeinwurzeln steigt zwar unter besseren Bodenbedingungen an, hat aber keinen bedeutenden Einfluss auf die Wurzeldichte der beobachteten Flächen (OSTONEN et al. 1999).

Durch Veränderungen der spezifischen Wurzeloberfläche (SRA) können Pflanzen möglicherweise auf Umweltveränderungen reagieren (LõHMUS et al. 1989). 
Tab. 5.3: Beziehung unterschiedlicher Faktoren zur spezifischen Wurzeloberfläche SRA (lineare Regressionsanalyse). Irrtumswahrscheinlichkeit $\mathrm{p}$, Bestimmtheitsmaß $\mathrm{r}^{2}$. Signifikante Abhängigkeiten sind fett gedruckt.

\begin{tabular}{lll}
\hline & \multicolumn{2}{c}{ SRA $\left(\mathrm{cm}^{2} \mathrm{~g}^{-1}\right)$} \\
\hline Elevation (m asl) & $\mathrm{p}$ & $\mathrm{r}^{2}$ \\
\cline { 2 - 3 } Temperature $\left({ }^{\circ} \mathrm{C}\right)$ & $\mathbf{0 . 0 1 7}$ & 0.99 \\
$\mathrm{~N}\left(\mathrm{mmol} \mathrm{g}^{-1}\right)$ & $\mathbf{0 . 0 1 5}$ & 0.99 \\
Precipitation $(\mathrm{mm})$ & $\mathbf{0 . 0 2}$ & 0.99 \\
Fine root biomass $\left(\mathrm{g} \mathrm{m}^{-1}\right)$ & 0.23 & 0.56 \\
DBH $(\mathrm{cm})$ & 0.08 & 0.94 \\
Stem height $(\mathrm{m})$ & $\mathbf{0 . 0 0 6}$ & 0.99 \\
\hline
\end{tabular}

HERTEL et al. (2003) ermitteln für tropische Bergregenwälder auf $2900 \mathrm{~m}$ Meereshöhe in Costa Rica spezifische Feinwurzeloberflächen in der organischen Auflage zwischen 591 $\mathrm{cm}^{2} \mathrm{~g}^{-1}$ in einem frühsukzessionalen Waldbestand und $247 \mathrm{~cm}^{2} \mathrm{~g}^{-1}$ in einem Altbestand. Im Mineralboden sinkt die spezifische Feinwurzeloberfläche von $461 \mathrm{~cm}^{2} \mathrm{~g}^{-1}$ auf $180 \mathrm{~cm}^{2} \mathrm{~g}^{-1}$. Die Werte in der vorliegenden Arbeit liegen für die organische Auflage der untersten Untersuchungsfläche $(1890 \mathrm{~m})$ bei $250 \mathrm{~cm}^{2} \mathrm{~g}^{-1}$ und sinken bis zur obersten Untersuchungsfläche $(3060 \mathrm{~m})$ auf $150 \mathrm{~cm}^{2} \mathrm{~g}^{-1}$. Im Mineralboden verringert sich die SRA mit zunehmender Meereshöhe von $210 \mathrm{~cm}^{2} \mathrm{~g}^{-1}$ auf $150 \mathrm{~cm}^{2} \mathrm{~g}^{-1}$. Dies bedeutet, dass die Oberfläche der Feinwurzeln pro Einheit Trockengewicht in geringerer Meereshöhe größer ist und folglich die Wurzeln feiner verzweigt sind. REWALD (2003) ermittelt für einen mitteleuropäischen Wald SRA-Werte in ähnlicher Größenordnung. LEUSCHNER et al. (2004) finden für Feinstwurzeln (Durchmesser $<1 \mathrm{~mm}$ ) in mitteleuropäischen Buchenwäldern Werte zwischen 206 und $422 \mathrm{~cm}^{2} \mathrm{~g}^{-1}$ Trockengewicht, welches sich ebenfalls gut mit diesen in der vorliegenden Arbeit ermittelten Daten decken.

LõHMUS et al. (1989) bemerken, dass das Wurzelsystem von Fichten sich an die vorhandenen Bodenzustände anpasst. Weiterhin folgern sie, dass zunehmend schlechtere Bodenverhältnisse zu einer höheren Feinwurzelmasse $(\leq 6 \mathrm{~mm}$ Durchmesser) der Fichten führen. Diese Bodenzustände werden durch extreme Feuchtigkeit, eingeschränkte Nährstoffzufuhr und niedrigere Temperaturen verursacht (LõHMUS et al. 1989). Eine bessere Nährstoffversorgung des Bodens bewirkt einen Anstieg der SRA (OSTONEN et al. 1999), was sich im ecuadorianischen Höhentransekt bestätigt.

Die Werte der erhobenen spezifischen Wurzelspitzenhäufigkeit in der organischen Auflage und im Mineralboden der drei Untersuchungsflächen liegen zwischen 100-150 Spitzen, 
bzw. bei 60-76 Spitzen pro g Trockengewicht. Die von HerTEL et al. (2003) in einem tropisch montanen Primärwald (Altbestand) Costa Rica's gefundenen Werte der spezifischen Wurzelhäufigkeit sind für die organische Auflage 25fach (3700 g TG) und für den Mineralboden 18 fach höher (1400 g TG) als die in Ecuador gefundenen Daten.

HARTEVeld (pers. Mitt.) fand im tiefmontanen Primärwald (Altbestand) in Indonesien Werte zwischen 1960 Spitzen (0-10 cm Bodentiefe) und 2200 Spitzen pro g Trockengewicht (10-20 cm Bodentiefe). Diese Werte liegen um das 20fache höher als diejenigen der vorliegenden Arbeit. Die Wurzelspitzenhäufigkeit in den untersuchten ecuadorianischen Waldbeständen sinkt mit zunehmender Bodentiefe ab. Da nur wenige Vergleichswerte in der Literatur zu finden sind, lassen sich aus den vorliegenden Daten keine generellen Schlüsse über die Abhängigkeit der spezifischen Feinwurzelspitzenhäufigkeit von der Meereshöhe ziehen.

Die Daten der vorliegenden Arbeit zeigen einen leichten, aber nicht signifikanten Anstieg der Gesamtanzahl der Wurzelspitzen pro $\mathrm{m}^{2}$ Bodenfläche mit zunehmender Meereshöhe.

Die Anzahl der Wurzelspitzen auf den drei Versuchsflächen im ecuadorianischen Bergwald ist im Vergleich zu den von HERTEL et al. (2003) publizierten Daten sehr gering. So sind in der Auflage im ecuadorianischen Höhengradienten zwischen 2.6 und $8.6 \times 10^{4}$ $\mathrm{m}^{-2}$ Feinwurzelspitzen pro Flächeneinheit und im Mineralboden zwischen 0.8 und $2 \times 10^{4}$ $\mathrm{m}^{-2} \mathrm{zu}$ finden. Bei HERTEL et al. (2003) steigen die Werte in einer Sukzessionsreihe tropisch montaner Wälder, auf 2900 m Höhe in Costa Rica, in der organischen Auflage von $0.2 \times 10^{6} \mathrm{~m}^{-2}$ im frühsukzessionalen Wald auf $3.9 \times 10^{6} \mathrm{~m}^{-2}$ im Altbestand an. Die Werte des Mineralbodens schwanken zwischen 0.5 und $0.3 \times 10^{6} \mathrm{~m}^{-2}$. Im Altbestand in Costa Rica sind in der organischen Auflage 45mal mehr Wurzelspitzen pro $\mathrm{m}^{2}$ vorhanden und im Mineralbodens 15fmal mehr als auf der obersten Fläche (3060 m) im Bergwald Ecuadors. Für einen tropischen Primärwald (Altbestand) auf Sulawesi, Indonesien fand HARTEVEld (pers. Mitt.) Werte, die denen in montanen Regenwäldern in Costa Rica (HERTEL et al. 2003) entsprechen. HARTEVELd (pers. Mitt.) stellt für ihren Landnutzungsgradienten fest, dass der Altbestand im Gegensatz zu einer Plantage weniger Feinwurzelspitzen aufweist. Dies spricht dafür, dass in ungestörten oder nur wenig gestörten Waldsystemen eine geringere Feinwurzelproduktion geleistet wird als in gestörten Bereichen. Dieses Ergebnis steht aber im Gegensatz zu den Daten von HERTEL et al. (2003). Bei der hohen Biomasse an Feinwurzeln im ecuadorianischen Höhengradienten scheint die Anzahl an Wurzelspitzen allerdings relativ gering. Möglicherweise kann der „Aufbereitungsvorgang“ zur Gewinnung der Feinwurzeln ein nicht zu unterschätzendes Problem bei der Erhaltung der Feinwurzelspitzen sein oder artspezifische Feinwurzelmerkmale überdecken einen möglichen Einfluss ökologischer Faktoren auf die Feinwurzelspitzenhäufigkeit und -anzahl. 
BERISH (1982) ermittelt in einer Studie von sukzessionalen tropischen Tieflandwäldern einen Anstieg des Wurzelflächenindex (RAI) mit zunehmendem Alter eines Bestandes. So weist in seinen Studien der 70jährige Bestand mit $5.28 \mathrm{~m}^{2} \mathrm{~m}^{-2}$ den höchsten Wert auf. In den bereits erwähnten Untersuchungen von HERTEL et al. (2003) ist der höchste Wert mit etwa $32 \mathrm{~m}^{2} \mathrm{~m}^{-2}$ ebenfalls im Altbestand zu finden. Hertel (1999) berichtet in seiner Arbeit für mitteleuropäische Wälder, dass der RAI an Wuchsorten, die unterschiedlich gut mit Nährstoffen versorgt sind, zwischen 3 und $9 \mathrm{~m}^{2} \mathrm{~m}^{-2}$ liegen kann. In dieser Untersuchung betragen die RAI-Werte, dem Höhengradienten folgend, zwischen 8.8 und $14.8 \mathrm{~m}^{2} \mathrm{~m}^{-2}$.

SCHULDT (2005) erwähnt in seiner Arbeit, dass die theoretische wurzelflächenspezifische (hydraulische) Leitfähigkeit mit der Höhe der Untersuchungsflächen abnimmt. Wegen des abnehmenden Nährstoffangebotes mit der Meereshöhe kommt es zu einer Verschiebung der C-Allokation hin zum Wurzelsystem (LEUSCHNER et al. 2006). Damit die Versorgung gewährleistet bleibt, müssen mehr Feinwurzeln gebildet werden. Die in dieser Arbeit gefunden RAI-Werte zeigen eine eindeutige Tendenz in der Zunahme hinsichtlich des ansteigenden Höhengradienten.

HERTEL (1999) zeigt, dass sich Feinwurzelbiomassen und der RAI von Buchenbeständen nach der Qualität der Wuchsorte richten. Im ecuadorianischen Höhengradienten zeigt die Feinwurzeloberfläche je $\mathrm{m}^{2}$ Bodenfläche (RAI) eine stetige Erhöhung mit steigender Meereshöhe, der entsprechende Blattflächeindex (LAI-Daten von MosER, pers. Mitt.) dagegen ein Absinken mit steigender Meereshöhe von $3.86 \mathrm{~m}^{2} \mathrm{~m}^{-2}$ (1890 m) über $3.63 \mathrm{~m}^{2}$ $\mathrm{m}^{-2}$ (2380 m) und auf $2.94 \mathrm{~m}^{2} \mathrm{~m}^{-2}$ (3060 m Höhe). Daraus ergibt sich für den Quotienten von LAI und RAI ein Absinken mit der Meereshöhe (Abb. 5.4). Dies drückt sich in der Verschiebung der Kohlenstoffallokation von oberirdischen Pflanzenteilen in den Wurzelbereich aus. Das LAI/RAI-Verhältnis im ecuadorianischen Bergwald ist niedriger als die Werte, die für andere nährstoffarme Wuchsorte angegeben werden $(<1.2$ bei KEYES \& GRIER 1981 und 0.79 bei HERTEL 1999).

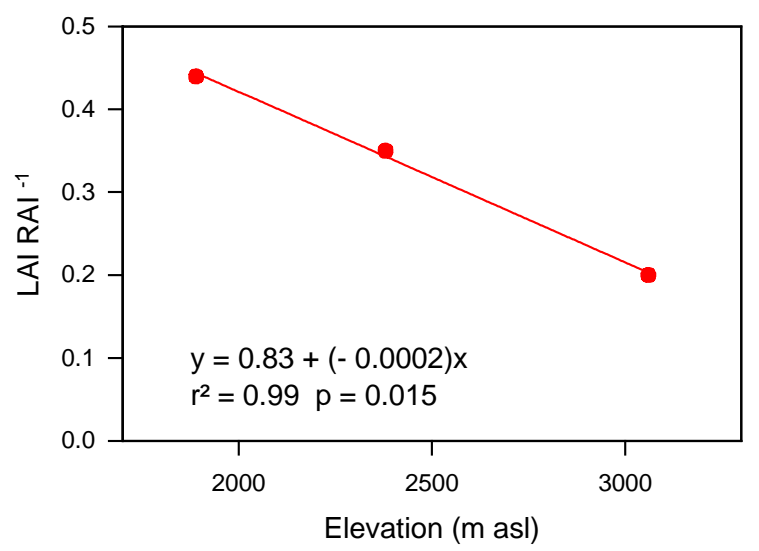

Abb. 5.4: Das Verhältnis von LAI zu RAI auf den drei untersuchten Höhenstufen. (Angabe des LAI der drei Untersuchungsflächen nach MOSER, unveröffentlicht). Lineare Regressionsanalyse, Irrtumswahrscheinlichkeit $\mathrm{p}$, Bestimmtheitsmaß $\mathrm{r}^{2}$. 


\subsubsection{Die Kohlenstoffspeicherung der Wurzeln in tropischen Wäldern}

RAICH \& NADELHOFFER (1989) beschreiben in einer globalen Übersicht für Wälder, dass die oberirdische Streuproduktion und die unterirdische Kohlenstoffspeicherung von den gleichen Faktoren abhängig sind oder sich gegenseitig beeinflussen. SANFORD \& CUEVAS (1996) bestätigen, dass die Kohlenstoffspeicherung tropischer Wälder stark dem Muster von RAICH \& NADELHOFFER (1989) folgt.

Verschiedene Studien (Grier et al. 1981, KEYES \& GrIER 1981, VoGT et al. 1982, Fogel 1985, SANTANTONio \& SANTANTONiO 1987, Cuevas et al. 1991, NADELHOFFer \& RAich, 1992, GOWER et al. 1996, GILL \& JACKSON 2000, HELMISAARI et al. 2002, OSTONEN et al. 2005) geben für Feinwurzeln als Teil der Nettoprimärproduktion (NPP) von Wäldern eine Spanne von 4.6 bis 76 \% an. KEYES \& GRIER (1981) zeigen, dass der Feinwurzelanteil an der NPP von Douglasien (Fichten) standortspezifisch ist. Die hochproduktive Fläche, bezogen auf die oberirdische Biomassenproduktion, hatte nur einen Anteil von $7.9 \%$ Feinwurzeln, die weniger produktive Fläche zeigte hingegen $36.4 \%$ an Feinwurzeln. Die NPP der Feinwurzeln in der vorliegenden Arbeit liegt zwischen $49 \%$ und $87 \%$ mit steigender Meereshöhe. Bei ungünstigen Vorraussetzungen (Boden, Klima etc.) auf den Flächen wird ein höherer Anteil an der NPP den Wurzeln zugeteilt (VOGT et al. 1987, Ostonen et al. 2005). Dies trifft ebenfalls auf den ecuadorianischen Höhengradienten zu.

\subsubsection{Die räumliche Verteilung der Feinwurzeln im Höhengradienten}

Die vertikale Verteilung der Feinwurzeln auf den untersuchten Flächen folgt dem allgemein akzeptierten Muster, dass in den obersten $30 \mathrm{~cm}$ des Bodens die Mehrheit (75\%) der (Fein-) Wurzeln vorhanden sind und die Feinwurzeldichte mit der Tiefe abnimmt (BERISH 1982, VOGT et al. 1996, VELDKAMP 2003). Nach den Untersuchungsergebnissen dieser Arbeit kommt es mit zunehmender Meereshöhe zu einer Erhöhung der Dichte sowohl lebender als auch toter Wurzeln, gleichzeitig ist eine Abnahme der Dichte mit der Bodentiefe zu erkennen (Kap. 4, Abb. 4.6 A-F). Letzteres lässt sich auf allen drei Untersuchungsflächen beobachten.

In der organischen Auflage und im Oberboden liegen die Nährstoffgehalte tropischer Böden im Allgemeinen höher als in tieferen Horizonten (STARK \& SPRATT 1977, KLINGE, Medina \& Hererra 1977, SANFORD 1989, Hertel et al. 2003). Dementsprechend ist dort die höchste Feinwurzeldichte zu finden (Klinge \& HerRera 1978, HerTel 1999). Dieses Muster gilt ebenfalls für die ecuadorianischen Untersuchungsflächen.

JACKSON (1996) gibt in einer Übersicht tropisch immergrüner Wälder an, dass 69 \% der Gesamtwurzelmasse in den oberen $30 \mathrm{~cm}$ des Bodens vorkommen. Dies bestätigen auch SCHENK \& JACKSON (2002). CANADELL et al. (1996) überprüfen bei einer ebenfalls global 
angelegten Studie die maximale Wurzeltiefe in unterschiedlichen Biomen. Für immergrüne tropische Wälder geben sie eine Tiefe von $7.3 \pm 2.8 \mathrm{~m}$ an, wobei die Durchwurzelungstiefe von den Baumarten und der Bodenbeschaffenheit sowie der Höhe des Waldes abhängig ist. SoETHE (pers. Mitteilung) berichtet, dass die Mehrheit an Grobwurzeln der Baumarten auf den ecuadorianischen Untersuchungsflächen nur bis zu einer Tiefe von $40 \mathrm{~cm}$ reichen. Um eine geeignete Stabilität des Baumes zu erreichen, zeigen Wurzeln z.B. in Form der Tiefenerschließung tropischer Berg- und Nebelwälder sehr unterschiedliche Mechanismen (SOETHE et al. 2006). Die Tiefe, bis zu der Grobwurzeln vorkommen, kann sich von dem des Feinwurzelsystems unterscheiden (CONERS et al. 1998). VELDKAMP et al. (2003) stellen in Barro Colorado Island, Panama (Tiefland) fest, dass unterhalb von $2.5 \mathrm{~m}$ Tiefe keine Feinwurzeln mehr vorhanden sind. Nach SoETHE (pers. Mitt.) befinden sich auf den Untersuchungsflächen in Ecuador bis mindestens 1.20 m Bodentiefe Feinwurzeln.

Beeinflusst wird die oberflächliche Lage des Wurzelsystems hierbei hauptsächlich durch die Nährstoffverfügbarkeit (WILCKE et al. 2002), den niedrigen pH-Wert des Bodens und die Bodentemperatur. Ein Einfluss der Bodenfeuchtigkeit kann ausgeschlossen werden, da eine ständige Wasserversorgung im Boden durch die Hanglage gewährleistet wird. Der Einfluss der austauschbaren Kationen $\left(\mathrm{Al}^{3+}, \mathrm{Fe}^{2+}\right)$ kann nicht genau abgeschätzt werden, da diese für die vorliegende Arbeit nicht erhoben wurden. LEUSCHNER (1998) weist auf, dass die oberflächennahen Feinwurzeln früher auf Trockenheit reagieren, sie aber besonders schnell wachsen, wenn genügend Wasser vorhanden ist. Die Feinwurzeln im Mineralboden leisten anteilsmäßig eine höhere wurzeloberflächenbezogene Wasseraufnahme (CONERS 2001). Da die oberflächennahen Feinwurzeln im ecuadorianischen Untersuchungsgebiet kaum der Austrocknung ausgesetzt sind, muss die erhöhte Feinwurzeldichte im Oberboden vor allem durch die Nährstoffverfügbarkeit bestimmt werden.

\subsection{Dynamik des Feinwurzelsystems der drei Bergwälder:}

Produktion, Umsatz, Mortalität

In den Tropen gibt es Gebiete, die auf Grund von unterschiedlich feuchten Jahreszeiten (Regen- und Trockenzeit) eine saisonale Wachstumsdynamik von Feinwurzeln aufweisen (CAVELIER et al. 1999, GREEN et al. 2005). In der vorliegenden Untersuchung sind jahreszeitliche Temperaturschwankungen nur sehr geringfügig. Der Niederschlag ist auch in der trockeneren Jahreszeit so hoch, dass ausreichend Feuchtigkeit vorhanden ist. Zwar sind Veränderungen in der Feinwurzelmasse- und produktion $\mathrm{zu}$ finden, diese können jedoch nicht klar einem sich saisonal verändernden Faktor zugeordnet werden. 


\subsubsection{Methodenvergleich zur Feinwurzelproduktion}

In dieser Arbeit wird die Wurzelproduktion anhand von drei unterschiedlichen Methoden ermittelt. Für die Berechnung der Minimum-Maximum sowie der compartmental flow-Methode werden die Ergebnisse des sequential coring-Verfahrens dargestellt. Die ingrowth core-Methode wird als dritte Methode verwendet. Die verschiedenen Arten der Berechnung führen zu sehr unterschiedlichen Ergebnissen für die Feinwurzelproduktion und die Feinwurzelstreuproduktion.

TINGEY et al. (2003) weisen in ihrer Arbeit darauf hin, dass schon die Zeitspanne zwischen den Probenahmen die Ergebnisse von Produktion und Mortalität beeinflussen kann, unabhängig von der Berechnungsmethode. PERSSON (1983) fand bei einer Gegenüberstellung von sequential coring- und ingrowth core-Methoden keine signifikanten Unterschiede. Im Gegensatz dazu fand NEILL (1992) in Canada viel höhere Werte in einem Marschgebiet mit der ingrowth core-Technik als mit dem sequential coring- Verfahren. Um die Biomasse von (Fein-) Wurzeln zu bestimmen, wird von einer großen Anzahl von Forschern (u. a. ABER et al. 1985, NADELHOFFER et al. 1985, HAYNES \& GOWER, 1995) das sequential coring-Verfahren und für die Berechnung der Feinwurzelproduktion die Minimum-Maximum Methode angewendet. Die Berechnung mit dem compartmental flowModell wird viel weniger genutzt, obwohl dafür nicht unbedingt signifikante Unterschiede zwischen den Feinwurzel-Biomassewerten der einzelnen Probetermine auftreten müssen (McClaugherty et al. 1982, ABer et al. 1985, Burke \& RAYNAL, 1994; HAYNes \& GOWER, 1995).

In der vorliegenden Arbeit werden zwischen der Minimum-Maximum- und der compartmental flow-Methode, abweichend von den bisher vorgestellten Literaturstellen, größere Unterschiede in der Produktion und der Mortalität (siehe Kap. 4. Tab. 5) ermittelt. Im Vergleich mit den Ergebnissen von HAYNES \& GOWER (1995) sind die Werte für Produktion und Mortalität im Bergregenwald Ecuadors zwei- bis dreimal größer. Ihre Untersuchungsflächen befinden sich allerdings in Wäldern der gemäßigten Breiten in Wisconsin und nicht in tropischen Bergwäldern. Bei MCCLAUGHERTY et al. (1982) hingegen zeigen sich ebenfalls ähnlich große Unterschiede (Miniumum-Maximum: $410 \mathrm{~g}$ $\mathrm{m}^{-2}$ und compartmental flow: $1090 \mathrm{~g} \mathrm{~m}^{-2}$ ) zwischen den Methoden.

Neben Autoren wie Vogt \& Persson (1991) und Vogt et al. (1998) haben Hertel \& LEUSCHNER (2002) unterschiedliche Methoden zur Bestimmung der Feinwurzelproduktion in Wäldern der gemäßigten Breiten (Fagus-Quercus) verglichen. Sie beschreiben, dass die compartmental flow-Methode eine stark überhöhte Feinwurzelproduktion, die ingrowth core-Methode hingegen eine Unterschätzung der Feinwurzelproduktion liefert. Ihrer Meinung nach liefert die Minimum-Maximum-Methode die besten Ergebnisse, obwohl diese Methode, bezogen auf die Kohlenstoffbilanzierung der Waldbestände, zu einer 25\%igen Überschätzung der Feinwurzelproduktion führt. Verglichen mit anderen 
Literaturwerten liegen die in dieser Arbeit erhobenen Daten zur Feinwurzelproduktion mit der Minimum-Maximum-Methode auf ähnlichem Niveau und berücksichtigen somit Veränderungen der Bio- und vor allem Nekromasse am besten.

VOGT \& PERSSON (1991) weisen darauf hin, dass gerade bei der ingrowth core-Methode, noch eine Reihe zusätzlicher Probenahmestellen angelegt werden sollten, um damit den Zeitpunkt des beginnenden Einwuchses der Feinwurzeln möglichst genau zu ermitteln. Dieser hängt vor allem von der Bodenbeschaffenheit, den Witterungsverhältnissen und der Artenzusammensetzung ab. VOGT \& PERSSON (1991) empfehlen, dass ingrowth coreVersuche mindestens zwei Jahre im Feld belassen werden sollten, damit sie vergleichbare Daten zu den sonst geläufigen Methoden liefern. OSTONEN et al. (2005) fanden für einen Picea-Bestand in Estland, dass im dritten Jahr des ingrowth core-Versuchs, bei Feinstwurzeln von $<1 \mathrm{~mm}$ Durchmesser eine doppelt so große Menge produziert wurde wie im zweiten Jahr. MAKKONEN \& HELMISAARI (1999) erwähnen in ihrem Artikel ebenfalls, dass Feinwurzeln im dritten Jahr in ingrowth cores stärker einwuchsen. Es bleibt die Frage, wann der von Wurzeln befreite Bodenraum (ingrowth core) durch erneute Bewurzelung dem ursprünglichen Zustand am nächsten kommt. Gerade stärkere Wurzeln, an denen Feinwurzeln auswachsen, werden eine längere Wachstumsphase durchlaufen. Bis heute aber kann die Frage nach der Nekromasse und dem Verlust an toten Feinwurzeln im beobachteten Bodenvolumen während des Versuchzeitraumes für ingrowth cores nicht zufriedenstellend beantwortet werden. Bei dem ingrowth core-Versuch dieser Studie, der etwa 500 Tage lief, sieht man deutlich, dass die Feinwurzelproduktion weit hinter der der sequential coring-Methode zurückbleibt (Kap. 4. Tab. 4.2).

\subsubsection{Die Feinwurzelproduktion}

Im vorherigen Abschnitt wurde gezeigt, welche weitreichenden methodischen Schwierigkeiten bei der Bestimmung der Wurzelproduktion bestehen. Es gibt wenige Publikationen, die Produktion, Umsatz und Mortalität von Feinwurzeln von Wäldern angeben, besonders von tropischen Bergwäldern. Veröffentlichungen von FOGEL (1985) und NADELHOFFER \& RAICH (1992) geben eine Übersicht über die Feinwurzelproduktion von Wäldern verschiedener Klimazonen. Der Schwerpunkt der Arbeiten liegt jedoch auf Wäldern des gemäßigten Klimas. In den Publikationen sind Feinwurzelproduktionen zwischen 350-1100 $\mathrm{g} \mathrm{m}^{-2}$ sowie 52-1668 $\mathrm{g} \mathrm{m}^{-2}$ zusammengestellt. HERTEL \& LEUSCHNER (2006) geben Daten von 75-2193 $\mathrm{g} \mathrm{m}^{-2}$ in tropischen Wäldern in einer globalen Übersicht zur Feinwurzelproduktion an. 
Tab. 5.4: Literaturangaben zur Feinwurzelbiomasse und -produktion tropischer Wälder auf unterschiedlichen Höhenstufen. Angaben bei RÖDERSTEIN et al. (2005) und Moser (pers. Mitt.) Mineralboden bis $20 \mathrm{~cm}$. ECSF $=$ Estación Científica San Francisco und PNP = Podocapus National Park, Ecuador;

\begin{tabular}{|c|c|c|c|c|c|}
\hline Location & $\begin{array}{l}\text { Elevation } \\
\text { in } \mathrm{m}\end{array}$ & $\begin{array}{l}\text { Precipitation } \\
\text { in } \mathrm{mm} \mathrm{yr}^{-1}\end{array}$ & 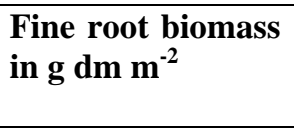 & $\begin{array}{l}\text { Fine root } \\
\text { production } \mathrm{g} \mathrm{m}^{-2} \\
\mathrm{yr}^{-1}\end{array}$ & \\
\hline $\begin{array}{l}\text { San Carlos de } \\
\text { Rio Negro, } \\
\text { Venezuela }\end{array}$ & 100 & 3565 & - & 120 & $\begin{array}{l}\text { CUEVAS \& } \\
\text { MEDINA } 1988\end{array}$ \\
\hline $\begin{array}{l}\text { San Carlos de } \\
\text { Rio Negro, } \\
\text { Venezuela }\end{array}$ & 100 & 3565 & - & 235 & $\begin{array}{l}\text { CUEVAS \& } \\
\text { MEDINA } 1988\end{array}$ \\
\hline $\begin{array}{l}\text { San Carlos de } \\
\text { Rio Negro, } \\
\text { Venezuela }\end{array}$ & 100 & 3565 & - & 1117 & $\begin{array}{l}\text { CUEVAS \& } \\
\text { MEDINA } 1988\end{array}$ \\
\hline $\begin{array}{l}\text { Bombuscaro, } \\
\text { PNP, Ecuador }\end{array}$ & 1050 & 2205 & 112 & 171 & $\begin{array}{l}\text { G. MOSER (pers. } \\
\text { Mitteilung) }\end{array}$ \\
\hline $\begin{array}{l}\text { Big Island, } \\
\text { Hawaii, USA }\end{array}$ & 1170 & 2500 & 257 & 173 & OSTERTAG 2001 \\
\hline $\begin{array}{l}\text { Big Island, } \\
\text { Hawaii, USA }\end{array}$ & 1176 & 2500 & 354 & 169 & OSTERTAG 2001 \\
\hline $\begin{array}{l}\text { Hawaii } \\
\text { USA }\end{array}$ & 1200 & 2500 & 152 & 510 & $\begin{array}{l}\text { HERBERT \& } \\
\text { FOWNES } 1999\end{array}$ \\
\hline $\begin{array}{l}\text { Hawaii } \\
\text { USA }\end{array}$ & 1200 & 2500 & 266 & 840 & $\begin{array}{l}\text { HERBERT \& } \\
\text { FOWNES } 1999\end{array}$ \\
\hline $\begin{array}{l}\text { Hawaii } \\
\text { USA }\end{array}$ & 1200 & 2500 & 203 & 620 & $\begin{array}{l}\text { HERBERT \& } \\
\text { FOWNES } 1999\end{array}$ \\
\hline $\begin{array}{l}\text { Hawaii } \\
\text { USA }\end{array}$ & 1200 & 2500 & 218 & 700 & $\begin{array}{l}\text { HERBERT \& } \\
\text { FOWNES } 1999\end{array}$ \\
\hline $\begin{array}{l}\text { Hawaii } \\
\text { USA }\end{array}$ & 1200 & 2500 & 272 & 550 & $\begin{array}{l}\text { HERBERT \& } \\
\text { FOWNES } 1999\end{array}$ \\
\hline $\begin{array}{l}\text { Bombuscaro, } \\
\text { PNP, Ecuador }\end{array}$ & 1540 & 2500 & 464 & 544 & $\begin{array}{l}\text { G. Moser (pers. } \\
\text { Mitteilung) }\end{array}$ \\
\hline $\begin{array}{l}\text { ECSF } \\
\text { Ecuador }\end{array}$ & 1890 & 1930 & 393 & 676 & $\begin{array}{l}\text { RÖDERSTEIN et al. } \\
2005\end{array}$ \\
\hline $\begin{array}{l}\text { ECSF } \\
\text { Ecuador }\end{array}$ & 2380 & ca. 5790 & 539 & 1249 & $\begin{array}{l}\text { RÖDERSTEIN et al. } \\
2005\end{array}$ \\
\hline $\begin{array}{l}\text { ECSF, PNP, } \\
\text { Ecuador }\end{array}$ & 3060 & 4480 & 978 & 2193 & $\begin{array}{l}\text { RÖDERSTEIN et al. } \\
2005\end{array}$ \\
\hline
\end{tabular}

In dieser Arbeit liegen die Werte für die drei untersuchten Höhenstufen (MinimumMaximum-Methode) zwischen $676 \mathrm{~g} \mathrm{~m}^{-2}$ pro Jahr in der untersten Stufe (1890 m Höhe) und steigen kontinuierlich über $1249 \mathrm{~g} \mathrm{~m}^{-2}$ (2380 $\mathrm{m}$ Höhe) auf $2193 \mathrm{~g} \mathrm{~m}^{-2}$ pro Jahr (3060 m Höhe) an. Die Mehrheit der vorhandenen Studien für Wälder des gemäßigten Klimas zeigt, dass auf nährstoffarmen Böden eine höhere Feinwurzelproduktion auftritt (ABER et al. 1985). Dies scheint ebenfalls für tropische Bergwälder zu gelten, wie anhand der aufgelisteten Feinwurzelbiomassen vermutet werden kann (siehe Tab. 5.1), wenn man annimmt, dass sich im Allgemeinen die Nährstoffversorgung mit steigender Meereshöhe verschlechtert. 
Untersuchungen von FORDE (2002) können nachweisen, dass Pflanzen verschiedene chemische Signale des Bodens (z.B. die $\mathrm{NO}_{3}{ }^{-}$-Verfügbarkeit) wahrnehmen, und dass dies zu einer Erhöhung der Feinwurzelproduktion und -mortalität führen kann. Daraus ergibt sich die Möglichkeit, das neben den klimatischen Bedingungen und den vorhandenen Nährstoffen sowohl interspezifische Konkurrenz (SCHENK et al. 1999, HERTEL 1999) als auch Mykorrhizierung (KoTTKE et al. 2004) eine Rolle spielen. Aus den vorliegenden Daten im ecuadorianischen Untersuchungsgebiet, die sich auf klimatische und bodenchemische Parameter konzentrieren, kann eine reduzierte Nährstoffverfügbarkeit unter kälteren und feuchteren Bedingungen als Hauptursache für die Erhöhung der Produktion mit der Meereshöhe angesehen werden.

Tab. 5.5: Die Beziehung unterschiedlicher Faktoren zur Feinwurzelproduktion (lineare Regressionsanalyse). Irrtumswahrscheinlichkeit $\mathrm{p}$, Bestimmtheitsmaß $\mathrm{r}^{2}$. Signifikante Abhängigkeiten sind fett gedruckt.

\begin{tabular}{lcl}
\hline & Fine root production $\left(\mathrm{g} \mathrm{m}^{-2}\right)$ & \\
\hline & $\mathrm{p}$ & $\mathrm{r}^{2}$ \\
\cline { 2 - 3 } Elevation $(\mathrm{m}$ asl $)$ & $\mathbf{0 . 0 1 5}$ & 0.99 \\
Temperature $\left({ }^{\circ} \mathrm{C}\right)$ & $\mathbf{0 . 0 1 6}$ & 0.99 \\
$\mathrm{~N}\left(\mathrm{mmol} \mathrm{g}^{-1}\right)$ & $\mathbf{0 . 0 1 2}$ & 0.99 \\
Precipitation $(\mathrm{mm})$ & 0.24 & 0.46 \\
DBH $(\mathrm{cm})$ & $\mathbf{0 . 0 2 8}$ & 0.99 \\
Stem height $(\mathrm{m})$ & $\mathbf{0 . 0 6 7}$ & 0.96 \\
\hline
\end{tabular}

\subsubsection{Der Feinwurzelumsatz}

In einer globalen Übersicht über den Umsatz von Wurzeln können GILL \& JACKSON (2000) zeigen, dass je nach angewendeter Methode zwischen unterschiedlichen Baumarten der Umsatz stark variiert. So ist zwar die mittlere Jahrestemperatur für einige Bereiche (z.B. Weideland und Wälder) ein bestimmender Faktor (höherer Umsatz bei höherer Temperatur), jedoch gilt dies nicht für die Beziehung zwischen Niederschlag und Umsatz. Der Feinwurzelumsatz in tropischen Wäldern ist etwas größer, d.h. die Umsatzrate der Feinwurzeln ist kürzer, als in nicht tropischen Regionen (Umsatzrate: (0.63) KEYES \& Grier (1981), (0.59) Persson (1983), (1.0) VogT et al. (1986, 1996)). Hohe Umsätze finden bei ihren Untersuchungen in tropischen Tieflandgebieten mit der „Coring Methode“ Kummerow et al. (1990) in Mexiko (2.6) und Schroth \& ZECH (1995) an der Elfenbeinküste (2.4) für Feinwurzeln $<2 \mathrm{~mm}$ Durchmesser. Einen Umsatz von etwa 1.0 für tropisches Tiefland ( $<1000 \mathrm{~m}$ ü. M.) und etwa 1.7 für tropische Bergwälder $(>2000 \mathrm{~m}$ ü. M.) kann ebenfalls in einer Literaturstudie von HERTEL \& LEUSCHNER (2006) belegt werden. Dies stimmt mit den Daten der vorliegenden Arbeit, die zwischen 1.72 und 2.32 
liegen, sehr gut überein. Hertel (1999) findet für vier Buchenbestände in Deutschland jedoch bis zu 10 fach höhere Umsatzraten als in der Übersicht von GILL \& JACKSON (2000) dargestellt sind. In diesen Buchenwäldern sind Schädigungen an Feinwurzeln vor allem auf einen niedrigen $\mathrm{pH}-\mathrm{Wert}, \mathrm{Al}^{3+}$-Ionen und Frost, konkurrenzbedingte Feinwurzelmortalität, jedoch auch auf sommerliche Trockenheit zurückzuführen (HERTEL 1999). Zwar kommen auf den ecuadorianischen Untersuchungsflächen ebenfalls ein niedriger $\mathrm{pH}-$ Wert, leicht erhöhte Konzentrationen von $\mathrm{Al}^{3+}$-Ionen und anderer Metalle, wie z.B. $\mathrm{Fe}^{2+}$ (IosT, pers. Mitt.) vor, aber durch die ständige Wasserverfügbarkeit, die kühleren Temperaturen und den Nährstoffmangel sind die Umsätze viel stärker beeinträchtigt, wie dies bereits CUENCA et al. (1990) festgestellt haben. MCClaugherTy et al. (1982) führen in ihrem Artikel an, dass der Umsatz von Feinwurzeln viel schneller erfolgt, als der Umsatz der oberirdischen Komponenten, und dass somit die Raten der Feinwurzelzersetzung viel höher seien als diejenigen der gesamten Streu. OsTONEN et al. (2005) erwähnen, dass ein großer Anteil der primären Pflanzenproduktion (NPP) in den Feinwurzelumsatz investiert wird. STEPHENSON \& VAN MANTGEM (2005) weisen nach, dass tropische Wälder einen höheren Umsatz haben als Wälder der gemäßigten Breiten. Allerdings nimmt die Umsatzrate mit weniger fruchtbaren Böden und steigender Höhe ab.

Ein klarer Zusammenhang wurde zwischen dem Niederschlag und dem Feinwurzelumsatz (Abb. 5.7) sowie dem Bodenwassergehalt und dem Umsatz gefunden $\left(p=0.013, r^{2}=\right.$ 0.99). VoGT et al. (1986) finden ebenfalls eine Abhängigkeit des Feinwurzelumsatzes von Niederschlag und Temperatur. Es scheint, dass die Bodenart für den Feinwurzelumsatz ein wichtiger Faktor ist. Da gerade die mittlere Untersuchungsfläche $(2380 \mathrm{~m}) \mathrm{im}$ Mineralboden eine geringere wasserdurchlässige Schicht besitzt und somit von Sauerstoffmangel und geringer werdender Mykorrhizierung (KOTTKE 2004) betroffen ist, verringert sich der Umsatz.

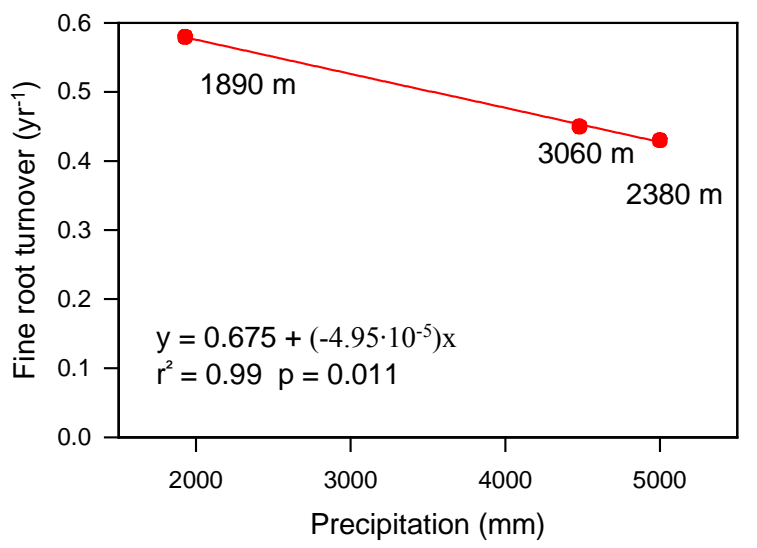

Abb. 5.5: Beziehung zwischen Niederschlag $\left(\mathrm{mm} \mathrm{yr}^{-1}\right)$ und dem Umsatz der Feinwurzeln (in Jahren) auf den drei Höhenstufen. Die Gleichung der linearen Regression sowie Irrtumswahrscheinlichkeit $p$ und das Bestimmtheitsmaß $r^{2}$ sind in der Grafik dargestellt. 


\subsubsection{Die Feinwurzelmortalität}

Die Problematik der Berechnung der Produktion spiegelt sich auch in der Berechnung der Mortalität wider. Da für ingrowth cores keine Angaben zur Mortalität der Feinwurzeln gemacht werden können, ist für ihre Berechnung nur die Minimum-Maximum- und die compartmental flow-Methode geeignet. Hier zeigt sich, dass die Werte, wie schon bei der Produktion für die compartmental flow-Methode, stark erhöht sind (Kap. 4.5.3.4). Die Daten der Feinwurzelmortalität (dem Höhengradienten folgend 527, 1229, $2085 \mathrm{~g} \mathrm{~m}^{-2}$ ) entsprechen in etwa denen der Feinwurzelproduktion $\left(676,1259,2193 \mathrm{~g} \mathrm{~m}^{-2}\right)$. Das bedeutet für die Untersuchungsflächen, dass durch die hohe Produktion die ebenfalls hohe Mortalität ausgeglichen wird und die Feinwurzelbiomasse dadurch im Gleichgewicht ist.

Tab. 5.6: Der Einfluss unterschiedlicher Faktoren auf die Feinwurzelmortalität (lineare Regressionsanalyse). Irrtumswahrscheinlichkeit p, Bestimmtheitsmaß r². Signifikante Abhängigkeiten sind fett gedruckt.

\begin{tabular}{lll}
\hline & Fine root mortality $\left(\mathrm{g} \mathrm{m}^{-2}\right)$ & \\
\hline & $\mathrm{p}$ & $\mathrm{r}^{2}$ \\
\cline { 2 - 3 } Elevation $(\mathrm{m}$ asl) & $\mathbf{0 . 0 1 2}$ & 0.99 \\
Temperature $\left({ }^{\circ} \mathrm{C}\right)$ & $\mathbf{0 . 0 1}$ & 0.99 \\
$\mathrm{~N}\left(\mathrm{mmol} \mathrm{g}^{-1}\right)$ & $\mathbf{0 . 0 1 4}$ & 0.99 \\
Precipitation $(\mathrm{mm})$ & 0.24 & 0.54 \\
DBH $(\mathrm{cm})$ & $\mathbf{0 . 0 0 4}$ & 1 \\
Stem height $(\mathrm{m})$ & $\mathbf{0 . 0 3 8}$ & 0.99 \\
\hline
\end{tabular}

Die Feinwurzelmortalität zeigt sehr ähnliche Abhängigkeiten von den Umweltfaktoren wie die Feinwurzelproduktion. So wirkt mit zunehmender Meereshöhe der Rückgang der Temperatur und der Nährstoffverfügbarkeit signifikant auf die Feinwurzelmortalität.

TINGEY et al. (2003) stellen fest, dass das Intervall der Probennahme ebenfalls ein beeinflussender Faktor zur Berechnung der Mortalität ist. PREGITZER (2002) bemerkt, dass die Ursache für die Mortalität von Feinwurzeln noch nicht geklärt ist. KING et al. (2002) gehen sowohl beim Wachstum als auch bei der Mortalität von Kiefernfeinwurzeln von einem Einfluss der Nährstoffverfügbarkeit, der Mykorrhiza und der Größe der Feinwurzeln aus. Pregitzer et al. (2002) sehen einen Temperaturanstieg im Boden als Ursache einer höheren Wurzelproduktion und -mortalität und daraus resultierend einen größeren C-Fluss in den Boden. TIERNEY et al. (2003) weisen nach, dass die mittleren Bodentemperaturen einen schwachen, aber positiven Einfluss auf die Mortalität haben. Die Lebenserwartung und die Mortalität von Feinwurzeln hängen wahrscheinlich von verschiedenen Faktoren ab, wie u.a. der Baumart (LAL et al. 1995), den C-Assimilationstypen (C3- und C4Pflanzen), der Saisonalität (EISSEnstat \& YANAI 1997), dem Durchmesser und der Position der Feinwurzeln am Wurzelstrang (EISSENSTAT et al. 2000, WeLls \& EISSENSTAT 
2001), den umgebenden Standortfaktoren, wie z.B. der Temperatur (PREgITZER 2002) und der Nährstoffkonkurrenz (COUTTS 1987, GRUBB 1994).

TRUMBORE et al. (2006) finden bei Radiokarbondatierungen mittels ${ }^{14} \mathrm{C}$ heraus, dass die mittlere Verweildauer von Kohlenstoff in Feinwurzeln von Wäldern im Amazonastieflandgebiet etwa zwischen einem und drei Jahren liegt. CuEvas et al. (1991) ermitteln in ihrer Arbeit in tropischen Kieferwaldbeständen, die sie unter denselben edaphischen und klimatischen Voraussetzungen untersucht haben, Lebensspannen der Feinwurzeln zwischen 0.3 und 0.8 Jahren. Sie gehen davon aus, dass es für die Lebensdauer der Wurzeln genetische Unterschiede auf Artebene gibt. Die Daten im ecuadorianischen Höhengradienten zeigen eine Lebensspanne zwischen 0.44 und 0.75 Jahren. VoGT et. al (1991) geben einen Hinweis darauf, dass bei Bäumen von Wäldern des gemäßigten Klimas erhöhte Verfügbarkeit von Wasser die Lebensdauer der Feinwurzeln verlängert.

Dies kann nicht in der vorliegenden Arbeit bestätigt werden, denn Niederschlag und Bodenwassergehalt haben einen signifikant negativen Einfluss auf die Lebensspanne der Feinwurzeln (Abb. 5.6).

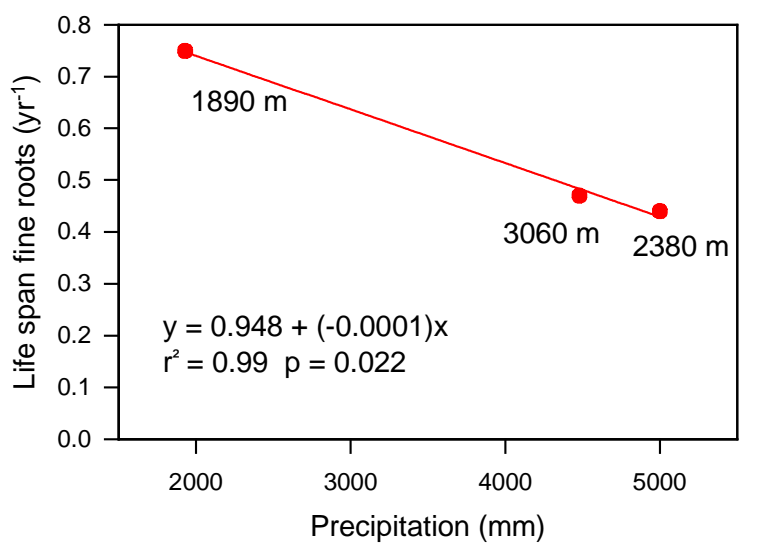

Abb. 5.6: Die Beziehung zwischen Niederschlag $\left(\mathrm{mm} \mathrm{yr}^{-1}\right)$ und der Lebensdauer der Feinwurzeln (in Jahren) auf den drei Höhenstufen. Die Gleichung der linearen Regression sowie Irrtumswahrscheinlichkeit $\mathrm{p}$ und Bestimmtheitsmaß $\mathrm{r}^{2}$ sind in der Grafik dargestellt.

Studien mit Minirhizotronen zur Beobachtung der Feinwurzeldynamik (HENDRICK \& Pregitzer 1996a/b, Tingey et al. 2000) zeigen, dass gerade Wurzeln in Weidelandsystemen und Wäldern eine sehr kurze Lebenserwartung von teilweise nur Tagen und Wochen haben können. Hingegen weist eine Untersuchung von RYSER (1996) an Gräsern darauf hin, dass bei Pflanzen, die unter nährstoffarmen Vorraussetzungen wachsen, die Wurzellebenserwartung durch eine erhöhte Gewebedichte steigt, vermutlich um Nährstoffverluste zu vermeiden. 
5.3. Untersuchungen zur Blattstreuproduktion in tropischen Bergwäldern

\subsubsection{Die Blattstreuproduktion im Höhengradienten}

Für den gesamten Untersuchungszeitraum können für die Blattstreuproduktion (Blattfall) zwei saisonale Maxima, vor allem auf der obersten, windexponierten Untersuchungsfläche gefunden werden. Daten von EMCK (pers. Mitt.) zeigen, dass sowohl die Menge des Niederschlags (4480 mm pro Jahr) als auch die Windgeschwindigkeit $\left(9.12 \mathrm{~m} \mathrm{~s}^{-1}\right)$ in 3060 $\mathrm{m}$ (Cajanuma) und in $2380 \mathrm{~m}$ Höhe (ca. $5000 \mathrm{~mm}$ im Durchschnitt, Windgeschwindigkeit entspricht der auf $3060 \mathrm{~m}$ Höhe), sehr hoch sind. Dies steht im Gegensatz zu der Untersuchungsfläche im stationsnahen Gebiet auf 1890 m Meereshöhe (1930 mm, $1.36 \mathrm{~m}$ $\mathrm{s}^{-1}$ ). Da die Maxima des Streufalls sowohl in der trockeneren als auch in der regenreichen Zeit vorhanden sind, kann man nicht von einer trockenheitsbedingten Ursache ausgehen, zumal die weniger feuchte Periode in diesen Bergregenwäldern keine ausgeprägte Trockenheit mit sich bringt. Hingegen zeigt sich, dass Sturmereignisse in Verbindung mit zunehmenden Regenfällen zumindest den Blattstreufall beeinflussen können. Der Niederschlag und der Bodenwassergehalt haben aber weder einen signifikanten Einfluss auf die Blattstreuproduktion noch auf die Blattproduktion.

HOMEIER (2004) fand bei Untersuchungen zum Stammzuwachs für das Untersuchungsgebiet eine Abnahme der maximalen Bäumhöhe und der oberirdischen Baummasse. Dies steht in Einklang mit der Verringerung der Blattstreu $\left(862-263 \mathrm{~g} \mathrm{~m}^{-2}\right)$ mit zunehmender Meereshöhe. KiTAYAMA \& AIBA (2002) hingegen können keine Abnahme der Blattstreu entlang ihres Höhengradienten am Mt. Kinabalu (700 - 3060 m Höhe) nachweisen. In einer Übersicht der Blattstreumenge zwischen unterschiedlichen Höhenstufen tropischer Bergregenwälder ergeben sich nach RÖDERSTEIN et al. (2005) keine einem Höhengradienten (1000 - 3060 m Höhe) folgende $\mathrm{Zu}$ - oder Abnahmen. Die Werte liegen zwischen 230 und $1259 \mathrm{~g} \mathrm{~m}^{-2}$. Im Vergleich dazu nimmt die Wurzelstreuproduktion im ecuadorianischen Höhengradienten stark zu (1890 m: $527 \mathrm{~g} \mathrm{~m}^{-2}$; $2380 \mathrm{~m}: 1229 \mathrm{~g} \mathrm{~m}^{-2}$; $3060 \mathrm{~m}$ : $2085 \mathrm{~g} \mathrm{~m}^{-2}$ ). Vergleichsdaten anderer tropisch montaner Regenwälder fehlen bisher. SANFORD \& CUEVAS (1996) können in einer Arbeit im tropischen Tiefland von Costa Rica zeigen, dass ein Unterschied im Verhältnis der Feinwurzel- zur Blattstreuproduktion zwischen einem fruchtbaren und einem unfruchtbareren Gebiet besteht (763 und $1483 \mathrm{~g} \mathrm{~m}^{-2} \mathrm{yr}^{-1}$, fruchtbar und 718 und $412 \mathrm{~g} \mathrm{~m}^{-2}$ $\mathrm{yr}^{-1}$, weniger fruchtbar). Dabei zeigt sich, dass die Blattstreu stark, die Feinwurzelstreu aber kaum abnimmt. Neben klimatischen und edaphischen Bedingungen scheinen artspezifische Faktoren einen Einfluss zu haben, da sich die Baumzusammensetzung mit der Meereshöhe im Untersuchungsgebiet ändert.

RUDNICKI (2001) und FRECH (2006) weisen in ihren Arbeiten nach, dass die mechanische Interaktion von benachbarten Baumkronen schon bei geringen Windgeschwindigkeiten zu 
mehr Streufall führt. Da mit zunehmender Meereshöhe die Wälder topographisch bedingt größerer Windintensität ausgesetzt sind (Kap. 2, Abb. 2.3D), ist die Bildung kleinerer Blätter mit längerer Lebensdauer ein großer Vorteil für den Nährstoffhaushalt (CHAPIN 1980, BENNER 2006), denn die Ersetzung von Blättern kostet Nährstoffinvestitionen.

Grundsätzlich weisen jedoch GRUBB \& WHITMORE (1966) und GRUBB (1977) darauf hin, dass tropische Bergwälder nicht windexponiert seien, und dass dies keine allgemeine Erklärung für die Reduzierung der Blätter mit steigender Höhe und für mehr Blattstreu sein kann. Kleine Blätter können in einer windigen Umgebung weniger schnell abgeweht werden als größere (PARKHURST \& LOUCKS 1972), aber gerade leichte Stürme, bzw. Unwetter bringen eine signifikante Menge feiner Streu hervor (OsTERTAG et al. 2003), was ebenfalls im ecuadorianischen Höhengradienten beobachtet werden konnte.

\subsubsection{Der Vergleich von Blatt- zur Wurzelproduktion im Höhengradienten}

Auf den drei Untersuchungsflächen im Höhengradienten lässt sich die Abnahme der Blattproduktion (Daten von Moser, pers. Mitt.) im Vergleich zur steigenden Feinwurzelproduktion gut erkennen (Abb. 5.9). Somit verringert sich das Verhältnis von Blatt- zur Feinwurzelproduktion drastisch von 0.73 auf 0.08 . Vergleiche mit Daten von HeRTEL (1999) zeigen, dass die Werte der vorliegenden Arbeit sehr viel geringer sind als in temperaten Buchenwäldern, bei denen das Verhältnis 0.42-3.32 beträgt. Aus den Werten ist klar zu erkennen, dass die Feinwurzeln auf den untersuchten Flächen im tropischen Bergregenwald eine bedeutende Rolle für den Kohlenstoffhaushalt spielen.

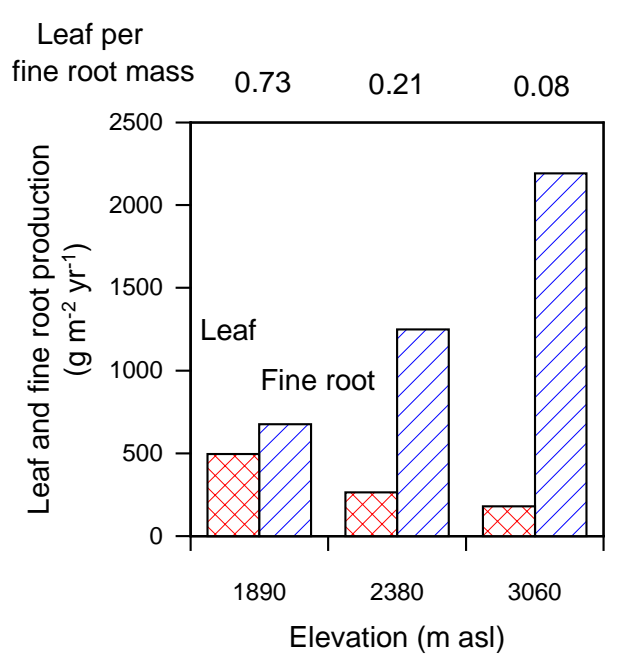

Abb. 5.7: Die Jahresproduktion von Blättern und Feinwurzeln $\left(\mathrm{g} \mathrm{m}^{-2} \mathrm{yr}^{-1}\right)$ und deren Verhältnis auf den drei untersuchten Höhenstufen 2002/03. (Angabe der Blattproduktion der drei Untersuchungsflächen nach MOSER, unveröffentlicht). 
5.3.3 Die spezifische Blattfläche auf den drei Höhenstufen

Die spezifische Blattfläche (SLA) der Blattstreu sinkt mit zunehmender Meereshöhe. Dies stimmt mit Beobachtungen von CORDELL et al. (1998), Unger (2005) und SCHULDT (2005) überein. Die SLA zeigt dabei aber keine signifikanten Unterschiede zwischen 2380 und $3060 \mathrm{~m}$ Meereshöhe und liegt innerhalb eines Bereichs von 72 bis $52 \mathrm{~cm}^{2} \mathrm{~g}^{-1}$. Die Blätter werden mit zunehmender Meereshöhe und abnehmender Temperatur skleromopher und kleiner (WhitMORE 1984, REICH et al. 1992, Richards 1996, BruiJNZEEL \& VENEKLAAS 1998). Nach den Untersuchungen von SCHULDT (2005) und UNGER (2005) an frischen Blättern hat die SLA eine Spannbreite zwischen 93.4 und $46.9 \mathrm{~cm}^{2} \mathrm{~g}^{-1}$ Trockengewicht in deren Höhengradienten von $1050 \mathrm{~m}$ bis $3060 \mathrm{~m}$ Höhe. CORDELL et al. (1998) fanden in einem ähnlichen Höhengradienten (110 bis $2470 \mathrm{~m}$ Höhe) in Hawaii Werte zwischen 93.5 und $24.6 \mathrm{~cm}^{2} \mathrm{~g}^{-1}$. Frühere Untersuchungen von GRUBB (1977) zur SLA zeigen eine Abnahme von 61-58 $\mathrm{cm}^{2} \mathrm{~g}^{-1}$ in einem niedriger gelegenen Bergregenwald (Lower montane rain forest) in Puerto Rico und New Guinea, einen Wert von etwa $56 \mathrm{~cm}^{2}$ $\mathrm{g}^{-1}$ in einem hochmontan gelegenen Bergregenwald (Upper montane rain forest) in Jamaica und Werte zwischen 57-45 $\mathrm{cm}^{2} \mathrm{~g}^{-1}$ in einem ebenfalls hochmontan gelegenen Bergregenwald (Upper montane rain forest) und einem subalpinen Regenwald in New Guinea.

Da sowohl SLA als auch SRA mit steigender Meereshöhe sinken, liegt der Quotient von SLA zu SRA auf allen drei Flächen um 0.32. CAVELIER (1996) spricht in diesem Zusammenhang von der Reduzierung der Blattfläche als Nebeneffekt des Stickstoffmangels.

SCHULDT (2005) findet zwischen 1050 und 3060 m Höhe signifikante Unterschiede der spezifischen Blattoberfläche mit der Meereshöhe. Von den in der vorliegenden Arbeit aufgenommen Daten hatte allein der Stickstoffgehalt der Blätter eine Beziehung zur SLA ( $\left.p=0.038, r^{2}=0.99\right)$. Diese Beziehung haben schon CAVELIER (1996), UNGER (2005) und SCHULDT (2005) nachgewiesen. Die geringere Verfügbarkeit von N kann u.a. zu geringem Blattwachstum (Blattfläche) führen (MoTTA \& MEDiNA 1978). SCHULDT (2005) zeigt, dass außerdem Faktoren wie Temperatur, Bestandeshöhe, Biomasse und Blattlebensdauer entlang des Höhengradienten mit der spezifischen Blattfläche korreliert sind.

\subsubsection{Das C/N-Verhältnis der Blattstreu im Höhengradienten}

Der Stickstoffgehalt der Blattstreu sinkt mit zunehmender Höhe. Es kann aber kein signifikanter Unterschied zwischen den drei Höhenstufen festgestellt werden. UNGER (2005) und SCHULDT (2005) finden an frischen Sonnenblättern entlang des verlängerten Höhengradienten in Ecuador eine sehr starke Abhängigkeit des N-Gehaltes von der Meereshöhe. Daten anderer Autoren (GrubB 1977, Vitousek et al. 1992, Hultine \& 
MARSHALL 1999) unterstreichen diese Ergebnisse. Der Blattstickstoffgehalt (massenbezogen) und das C/N-Verhältnis korrelieren bei SCHULDT (2005) mit fast allen erhobenen Werten (u.a. Meereshöhe, Temperatur, BHD, oberirdische Biomasse und SLA). Dagegen ergibt sich für die Daten der vorliegenden Untersuchung nur eine signifikante Beziehung zwischen dem Stickstoffgehalt $\left(\mathrm{p}=0.04, \mathrm{r}^{2}=0.99\right)$ bzw. dem C/N-Verhältnis $\left(\mathrm{p}<=0.00001, \mathrm{r}^{2}=1\right)$ und der SLA.

Der Kohlenstoffgehalt der Blätter auf den drei Höhenstufen liegt bei $39 \mathrm{mmol} \mathrm{g}^{-1}$. Diese Angaben decken sich mit den von ScHULDT (2005) auf den gleichen Höhenstufen bestimmten Werten von frischen Blättern, die etwa $43 \mathrm{mmol} \mathrm{g}^{-1}$ betragen und denen von BRUIJNZEEL et al. (1993) mit $40 \mathrm{mmol} \mathrm{g}^{-1}$ für Höhengradienten in Malaysia, Brunei und Jamaika. Das C/N-Verhältnis hingegen liegt zwischen 46 und 65, und damit über dem von UNGER (2005) (28-42) ermittelten und in derselben Größenordnung wie dem von SCHULDT (2005) (41-58). 


\section{Zusammenfassung}

Entlang eines Höhengradienten in einem Bergregenwaldgebiet in Südecuador wurden die Struktur und Dynamik des Feinwurzelsystems untersucht. Dazu wurden in Untersuchungsflächen auf 1890 m, 2380 m und 3060 m Meereshöhe die Masse, die räumliche Verteilung und die Morphologie der lebenden und toten Feinwurzeln sowie deren zeitliche Veränderung studiert.

Mit zunehmender Meereshöhe wurde eine Erhöhung der Feinwurzelmasse in der organischen Humusauflage und dem Mineralboden $(0-20 \mathrm{~cm})$ festgestellt. Die Feinwurzelbiomasse stieg entlang des Höhengradienten von 393 auf $978 \mathrm{~g} \mathrm{~m}^{-2}$, die Feinwurzelnekromasse von 640 auf $2398 \mathrm{~g} \mathrm{~m}^{-2}$. Der Bodenwassergehalt betrug zwischen 20 und 30 Vol. \%. Das Verhältnis von Bio- zu Nekromasse schwankte stark. Die zeitliche Schwankung der Feinwurzelmassen zeigte kein mit der klimatischen Saisonalität übereinstimmendes Muster. Die Feinwurzelproduktion erhöhte sich mit steigender Meereshöhe von 676 auf $2193 \mathrm{~g} \mathrm{~m}^{-2}$, ebenso die Feinwurzelstreuproduktion von 523 auf $2085 \mathrm{~g} \mathrm{~m}^{-2}$. Die Lebensdauer der Feinwurzeln betrug zwischen 0.75 und 0.44 Jahren, in etwa derselben Zeit wurde die Feinwurzelmasse umgesetzt. Abbauversuche mit litter bags (Streubeuteln) zeigten eine sich verlangsamende Zersetzung mit Zunahme der Meereshöhe. Die spezifische Wurzeloberfläche SRA sank mit steigender Meereshöhe, genauso wie die spezifische Blattoberfläche (SLA). Der Wurzelflächenindex RAI hingegen stieg durch die starke Zunahme der Feinwurzelbiomasse mit der Meereshöhe an. Die Blattstreuproduktion nahm parallel zu den steigenden Feinwurzelmassen und einer Reduzierung der Baumhöhe mit steigender Meereshöhe ab.

Statistisch ließ sich eine Beziehung zwischen den Feinwurzelmassen bzw. der Blattstreuproduktion und der Meereshöhe feststellen. SRA, Feinwurzelproduktion, Feinwurzelmortalität zeigten eine Abhängigkeit von der Höhe, der Lufttemperatur, dem Stickstoffgehalt, den oberflächenbezogenen (morphologischen) Parametern (SLA, SRA), der mittleren Stammlänge und dem mittleren Brusthöhendurchmesser der Bäume. Der Niederschlag korrelierte negativ mit dem Umsatz und der Lebenserwartung der Feinwurzeln.

Neben dem reduzierten Stickstoffangebot zeigen die oben genannten Faktoren und die verlangsamte Streuzersetzung ein Einwirken von äußeren Faktoren entlang des Höhengradienten auf den Nährstoffhaushalt der Pflanzen, welches zu einer zunehmenden Kohlenstoffallokation hin zum Wurzelsystem in größeren Meereshöhen führt. 


\section{Summary}

In a tropical montane rainforest in the South of Ecuador the effect of increasing altitude on structure and dynamics of fine root system was assessed. Fine root bio- and necromass, morphology, spatial distribution and seasonal dynamics have been studied on three sites at 1890, 2380 and $3060 \mathrm{~m}$ a.s.l. respectively.

An increase in fine root mass with increasing elevation was observed in the organic layer as well as in the first $20 \mathrm{~cm}$ of the mineral soil. Along the elevation gradient fine root biomass increased from 393 to $978 \mathrm{~g} \mathrm{~m}^{-2}$, while fine root necromass showed an increase from 640 to $2398 \mathrm{~g} \mathrm{~m}^{-2}$. Soil water content in the research stands ranged between 20 and $30 \%$. Fine root biomass/necromass ratio showed an overall large variation. Temporal variability in fine root mass did not correspond with climatic seasonal pattern. With rising elevation fine root production increased from 676 to $2193 \mathrm{~g} \mathrm{~m}^{-2}$ and fine root litter production from 523 to $2058 \mathrm{~g} \mathrm{~m}^{-2}$. Life span of fine roots ranged between 0.75 and 0.44 years. Fine root turnover took the same time approximately. Decomposition experiments with litter bags showed that decomposition got slower with increasing elevation. Both specific root area and specific leaf area decreased, while root area index showed an increase with rising elevation. However tree height and leaf litter production declined with increasing elevation.

Along the elevational gradient a significant relationship was found between fine root mass and leaf litter production. Factors influencing specific root area, fine root production and fine root mortality are altitude, mean air temperature, nitrogen content, specific leaf area, specific root area, tree stem height and diameter at breast height. Precipitation showed a negativ correlation with fine root turnover and life span.

In addition to the reduction in nitrogen availability, the above mentioned factors represent external influences on tree nutrition budget, which cause an increasing carbon allocation to the root system with increasing elevation. 


\section{Resumen}

Se investigó la estructura y la dinámica de las raíces finas a lo largo de un gradiente altitudinal en un bosque montano de lluvioso en el sur de Ecuador. Se estudió la biomasa y la necromasa de las raíces finas, la distribución espacial, la morfología de las raíces vivas y muertas asi como su distribución temporal en tres localidades ubicadas a 1890 m, 2380 m y $3060 \mathrm{~m}$ sobre el nivel del mar.

Se pudo comprobar un incremento de la masa de las raíces finas en la capa orgánica y en el suelo mineral $(0-20 \mathrm{~cm})$ con el aumento de altitud. La misma tendencia se observó en la biomasa de las raíces finas y en la necromasa, que aumentaron de 393 a $978 \mathrm{~g} \mathrm{~m}^{-2}$ y de 640 a $2398 \mathrm{~g} \mathrm{~m}^{-2}$, respectivamente. El contenido de agua en el suelo se matuvó entre 20 y 30 Vol. \%. La relación de bio- y necromasa varió bastante. La fluctuación temporal de las raíces finas no mostró ninguna concordancia con las temporadas climáticas. La producción de las raíces finas aumentó con la altitud de 676 a $2193 \mathrm{~g} \mathrm{~m}^{-2}$, así como también la producción de necromasa de raíces finas que aumentó de 523 a $2085 \mathrm{~g} \mathrm{~m}^{-2}$. El tiempo de vida de las raíces finas se estimó entre 0.75 y 0.44 años aproximadamente, al mismo tiempo la masa de las raíces finas era renovada.

Experimentos sobre la descomposición biológica con bolsas de hojarasca (litter bags) monstraron que la tasa de descomposición disminuye con el aumento de altitud. La superficie específica de las raíces (SRA) también diminuyó con el aumento de altitud asi como la superficie específica de las ojas (SLA). El índice areal des las raíces (RAI) aumentó por causa del aumento de la biomasa de las raíces finas. La producción de hojarasca disminuyó con el aumento de altitud, mientras que simultaneamente crecía la masa de las raíces finas y disminuía la altura de los árboles.

Se pudo comprobar estadísticamente una relación entre la masa de las raíces finas y la producción de hojarasca con la altitud sobre el nivel del mar. La superficie específica de las raíces (SRA), la producción de las raíces finas y su mortalidad monstraron también una dependencia con la altitud, la temperatura del aire, el contenido de nitrógeno, los parámetros morfológicos (SLA, SRA), la altura media del tronco y el diámetro medio del tronco (medido a un $1.3 \mathrm{~m}$ ). Se encontró una correlación negativa entre la precipitación y la tasa de retorno y la expectativa de vida de las raíces finas.

Además de la reducida oferta de nitrogenó, los factores mencionados arriba y la retardada descomposición biológica de la capa de hojarasca muestran la influencia de factores externos en la condición de nutrientes en las plantas, conduciendo a una mayor alocación de carbono hacia el sistema radicular con el aumento de altitud. 


\section{Literaturverzeichnis}

ABER, J. D., MELILLO, J. M., NADELHOFFER, K. J., MCCLAUGHERTY, C. A. \& PASTOR, J. 1985. Fine root turnover in forest ecosystems in relation to quantitiy and form of nitrogen availability: a comparison of two methods. Oecologia 66, 317-321.

AIBA, S.-I., TAKYU, M. \& KITAYAMA, K. 2005. Dynamics, productivity and species richness of tropical rainforests along elevtional and edaphic gardients on Mount Kinabalu, Borneo. Ecological Research 20, 279-286.

ARUNACHALAM, A., PANDEY, H. N., TRIPATHI, R. S. \& MAITHANI, K. 1996. Fine root decomposition and nutrient mineralization pattern in a subtropical humid forest following tree cutting. Forest Ecology and Management 86, 141-150.

BAKER, T. T., CONNER, W. H., LOCKABY, B. G., STANTURF, J. A. \& BURKE, M. K. 2001 Fine root productivity and dynamics on a forested floodplain in South Carolina. Soil Science Society of American Journal 65, 545-556.

BALSLEV, H. \& ØLLGAARD, B. 2002. Mapa de vegetación del sur de Ecuador. in Aguirre M., Z., Madsen, J. E., Cotton, E. \& Balslev, H. (eds.). Botánica Austroecuatoriana - Estudios sobre los recursos vegetales en las provincias de El Oro, Loja y ZamoraChinchipe. Danida, Quito - Ecuador. 484 pp.

BAUHUS, J. \& BARTSCH, N. 1996 Fine-root growth in beech (Fagus sylvatica) forest gaps. Canadian Journal of Forest Research 26, 2153-2159.

BENDIX, J., ROLLENBECK, R., GÖTTLICHER, D. \& CERMAK, J. 2006. Cloud occurrence and cloud properties in Ecuador. Climate Research 30, 133-147.

BENNER, J., VITOUSEK, P. \& OSTERTAG, R. 2006 Nutrient cycling and nutrient limitation in tropical montane cloud forest. in Bruijnzeel, L. A. \& Juvik, J. O. (eds.). Mountains in the mist: Science for conserving and managing tropical montane cloud forest. Hawaii Uni Press. (in press)

BERG, B. \& LASKOWSKI, R. 2006. Litter decomposition: a guide to carbon and nutrient turnover, Advances in Ecological Research 38. Elsevier, Amsterdam, Amsterdam. 421 pp.

BERISH, C. W. 1982. Root biomass and surface area in three successional tropical forests. Canadian Journal of Forest Research 12, 699-704.

BERTSCH, C. 2003. Struktur und Vorräte der ober- und unterirdischen Phytomasse entlang eines Höhentransektes an der Andenostabdachung Südecuadors. 50 pp. GeorgAugust Universität, Göttingen, Diplomarbeit

BLOOMFIELD, J., VOGT, K. A. \& VOGT, D. J. 1993. Decay rate and substrate quality of fine roots and foliage of two tropical tree species in the Luquillo Experimental Forest; Puerto Rico. Plant \& Soil 150, 233-245. 
BOLTE, A., RAHMANN, T., KUHR, M., POGODA, P., MURACH, D. \& VON GADOW, K. 2004. Relationships between tree dimension and coarse root biomass in mixed stand of European beech (Fagus sylvatica L.) and Norway spruce (Picea abies [L.] Karst.). Plant \& Soil 264, 1-11.

BREUER, L., KIESE, R. \& BUTTERBACH-BAHL, K. 2002. Temperature and moisture effects on nitrification rates in tropical rain-forest soils. Soil Science Society of American Journal 66, 834-844.

BREUER, L. \& BUTTERBACH-BAHL, K. 2005. Local temperature optimum of $\mathrm{N}_{2} \mathrm{O}$ production rates in tropical rain forest soils of Australia. Australian Journal of Soil Research 43, 689-694.

BÖHM, W. 1979. Methods of studying root systems. Springer Verlag, Heidelberg. 188 pp.

BROUWER, R. 1983. Functional equilibrium: sense or nonsense? Netherlands Journal of agricultural science 31, 335-348.

BROWN, S. \& IVERSON, L. R. Biomass estimates for tropical forests. World Resource Review 4[3], 366-384. 1992.

BROWN, S. 1997 Estimating biomass and biomass change of tropical forests: A pimer. Brown, Sandra. [134], 1-58. Rome, FAO.

BRUIJNZEEL, L. A., WATERLOO, M. J., PROCTOR, J., KUITERS, A. T. \& KOTTERINK, B. 1993. Hydrological observations in montane rain forest on Gunung Silam, Sabah, Malaysia, with special reference to the "Massenerhebung" effect. Journal of Ecology 81, 145-167.

BRUIJNZEEL, L. A. \& PROCTOR, J. 1995. Hydrology and biogeochemistry of tropical montane cloud forest: what do we really know? Pp. 38-78 in Hamilton, L. S., Juvik, J. O. \& Scatena, F. N. (eds.). Tropical Montane Cloud Forests. Springer Verlag Berlin, Heidelberg, 78 pp.

BRUIJNZEEL, L. A. \& VENEKLAAS, E. J. 1998. Climatic conditions and tropical montane forest productivity: the fog has not lifted yet. Ecology 79[1], 3-9.

BRUIJNZEEL, L. A. 2004. Tropical montane cloud forest: a unique hydrological case. Pp. 462-483 in Bonell, M. \& Bruijnzeel, L. A. (eds.). Forest, water and people in the humid tropics: past, present and future; hydrological research for integrated land and water management. Cambridge University Press, Cambridge. 483 pp.

BURKE, M. K. \& RAYNAL, D. J. 1994. Fine-root growth phenology, production and turnover in a northern hardwood forest ecosystem. Plant \& Soil 162, 135-146.

CAIRNS, M. A., BROWN, S., HELMER, E. H. \& BAUMGARDNER, G. A. 1997. Root biomass allocation in the world's upland forests. Oecologia 111, 1-11.

CANADELL, J., JACKSON, R. B., EHLERINGER, J. R., MOONEY, H. A., SALA, O. E. \& SCHULZE, E.-D. 1996. Maximum rooting depth of vegetation types at the global scale. Oecologia 108, 583-595. 
CAVELIER, J. 1992. Fine-root biomass and soil properties in a semideciduous and a lower montane rain forest in Panama. Plant \& Soil 142, 187-201.

CAVELIER, J., ESTEVEZ, J. \& ARJONA, B. 1996. Fine-root biomass in three successional stages of an andean cloud forest in Colombia. Biotropica 28[4b], 728-736.

CAVELIER, J. 1996. Environmental factors and ecophysiological processes along altitudinal gradients in wet tropical mountains. 399-439 in Mulkey, S. S., Chazdon, R. L. \& Smith, A. P. (eds.). Tropical forest plant ecophysiology. Chapman \& Hall, New York, New York. 439 pp.

CAVELIER, J., WRIGHT, S. J. \& SANTAMARÍA, J. 1999. Effects of irrigation on litterfall, fine root biomass and production in a semideciduous lowland forest in Panama. Plant \& Soil 211, 207-213.

CHAPIN, F. S. 1980. The mineral nutrition of wild plants. Annual Review of Ecological Systems 11, 233-260.

CLARK, D. A., BROWN, S., KICKLIGHTER, D. W., CHAMBERS, J. Q., THOMLINSON, J. R. \& NI, J. 2001a) Measuring net primary production in forests: concepts and field methods. Ecological Applications 11[2], 356-370.

CLARK, D. A., BROWN, S., KICKLIGHTER, D. W., CHAMBERS, J. Q., THOMLINSON, J. R., NI, J. \& HOLLAND, E. A. 2001b) Net primary production in tropical forests: an evaluation and synthesis of existing field data. Ecological Applications $11[2], 371-384$.

CONERS, H., HERTEL, D. \& LEUSCHNER, C. 1998. Horizontal- und Vertikalstruktur des Grob- und Feinwurzelsystems von konkurrierenden Buchen und Eichen in einem Mischbestand. Verhandlungen der Gesellschaft für Ökologie Band 28, Sonderdruck, 435440.

CONERS, H. 2001. Wasseraufnahme und artspezifische hydraulische Eigenschaften der Feinwurzeln von Buche, Eiche und Fichte: In situ- Messungen an Altbäumen. 1-118. Universität Göttingen, Dissertation

CORDELL, S., GOLDSTEIN, G., MUELLER-DOMBOIS, D., WEBB, D. \& VITOUSEK, P. M. 1998. Physiological and morphological variation in Metrosideros polymorpha, a dominant Hawaiin tree species, along an altitudinal gradient: the role of phenotypic plasticity. Oecologia 113, 188-196.

COUTTS, M. P. 1987. Developmental processes in tree root systems. Canadian Journal of Forest Research 17, 761-767.

CRAWFORD, R. M. M., WISHART, D. \& CAMPBELL, R. M. 1970. A numeral analysis of high altitude scrub vegetation in relation to soil erosion in the eastern cordillera of Peru. Journal of Ecology 58, 173-191.

CUENCA, G. \& HERRERA, R. 1987. Ecophysiology of alumininum in terrestrial plants, growing in acid and aluminium-rich tropical soils. Annales de la Société Royale Zoologique de Belgique, Société Royale Zoologique de Begique Bruxelles, Supplement 1 ! 117, 57-74. 
CUENCA, G., HERRERA, R. \& MEDINA, E. 1990. Aluminium tolerance in trees of a tropical cloud forest. Plant \& Soil 125, 169-175.

CUEVAS, E., BROWN, S. \& LUGO, A. E. 1991. Above- and belowground organic matter storage and production in tropical pine plantation and a paired broadleaf secondary forest. Plant \& Soil 135, 257-268.

CUEVAS, E. \& MEDINA, E. 1988. Nutrient dynamics within amazonian forests; II. Fine root growth, nutrient availability and leaf litter decomposition. Oecologia 76, 222-235.

DREXHAGE, M. \& COLIN, F. 2001. Estimating root system biomass from breast-height diameters. Forestry 74[5], 491-497.

EDWARDS, N. T. \& HARRIS, W. F. 1977. Carbon cycling in a mixed deciduous forest floor. Ecology 58, 431-437.

EDWARDS, P. J. \& GRUBB, P. J. 1977. Studies of mineral cycling in a montane rain forest in New Guinea I. Journal of Ecology 65, 934-969.

EDWARDS, P. J. 1977 Studies of mineral cycling in a montane rain forest in New Guinea II. Journal of Ecology 65, 971-992.

EDWARDS, P. J. \& GRUBB, P. J. 1982 Studies of mineral cycling in a montane rain forest in New Guinea IV. Journal of Ecology 70[2], 649-666.

EISSENSTAT, D. M. \& YANAI, R. D. 1997. The ecology of root lifespan. Advances In Ecological Research 27, 1-60.

EISSENSTAT, D. M., WELLS, C. E., YANAI, R. D. \& WHITBECK, J. L. 2000 Building roots in a changing environment: implications for root longevity. New Phytologist 147, 3342.

ELLENBERG, H. 1959. Typen tropischer Urwälder in Perú. Schweizerische Zeitschrift für Forstwesen 3,169-187.

FAHEY, T. J., HUGHES, J. W., PU, M. \& ARTHUR, M. A. 1988. Root decomposition and nutrient flux following whole-tree harvest of northern hardwood forest. Forest Science 34, 744-768.

FAIRLEY, R. I. \& ALEXANDER, I. J. 1985. Methods of calculating fine root production in forests. Pp. 37-42 in Fitter, A. H. \& Atkinson, e. al. (eds.). Ecological interactions in soil, plants, microbes and animals. Blackwell Science Publ., Oxford. 42 pp.

FOGEL, R. 1985. Roots as primary producers in below-ground ecosystems. Pp. 23-36 in Fitter, A. H. \& Atkinson, e. a. (eds.). Ecological interactions in soil, plants, microbes and animals. Blackwell Science Publ., Oxford. 36 pp.

FORDE, B. G. 2002. Local and long-range signaling pathways regulating plant responses to nitrate. Annual Review of Plant Biology 53, 203-224.

FÖLSTER, H. \& DE LAS SALAS, G. 1976 Litter fall and mineralization in three tropical evergreen forest stands, Colombia. Acta Científica Venezolana 27, 196-202. 
FRECH, A. 2006. Walddynamik in Mischwäldern des Nationalparks Hainich Untersuchung der Mechanismen und Prognose der Waldentwicklung. 120 pp. GeorgAugust Universität, Göttingen, Dissertation.

GILL, R. A. \& JACKSON, R. B. 2000 Global patterns of root turnover from terrestrial ecosystems. New Phytologist 147, 13-31.

GOWER, S. T., MCMURTRIE, R. E. \& MURTY, D. 1996. Aboveground net primary production decline with stand age: Potential causes. Trends in Ecololgy \& Evolution 11, 378-382.

GREEN, J. J., DWASON, L. A., PROCTOR, J., DUFF, E. I. \& ELSTON, D. A. 2005. Fine root dynamics in a tropical rain forest is influenced by rainfall. Plant \& Soil 276, 2332.

GRIER, C. C., VOGT, K. A., KEYES, M. R. \& EDMONDS, R. L. 1981. Biomass distribution and above- and below-ground production in young and mature abies amabilis zone ecosystems of the Washington cascades. Canadian Journal of Forest Research 11, 155-167.

GRUBB, P. J. \& WHITMORE, T. C. 1966. A comparison of montane and lowland rain forest in Ecuador: II. The climate and its effects on the distribution and physiognomy of the forests. Journal of Ecology 54, 303-333.

GRUBB, P. J. 1977. Control of forest growth and distribution on wet tropical mountains: with special reference to mineral nutrition. Annual Review of Ecological Systems 8, 83107.

GRUBB, P. J. 1994. Root competition in soils of different fertility: a pardoxon resolved? Phytocoenologia 24, 495-505.

HAFKENSCHEID, R. L. L. J. 2000. Hydrology and biogeochemistry of tropical montane rain forests of contrasting stature in the Blue Mountains, Jamaica. 302 pp. Vrije Universiteit Amsterdam, Ph.D. thesis.

HARLING, G. 1979. The vegetation types of Ecuador - a brief survey. Pp. 165-174 in Larsen, K. \& Holm-Nielsen, L. B. (eds.). Tropical Botany. Academic Press, London, London. 174 pp.

HAYNES, B. E. \& GOWER, S. T. 1995. Belowground carbon allocation in unfertilized and fertilized red pine plantations in northern Wisconsin. Tree physiology 15, 317-325.

HELMISAARI, H.-S., MAKKONEN, K., KELLOMAKI, S., VALTONEN, E. \& MALKONEN, E. 2002. Below- and above-ground biomass, production and nitrogen use in Scots pine stands in eastern Finland. Forest Ecology and Management 165, 317-326.

HENDRICK, R. L. \& PREGITZER, K. S. 1996a) Application of minirhzotrons to understand root function in forests and other natural ecosystems. Plant \& Soil 185, 293304.

HENDRICK, R. L. \& PREGITZER, K. S. 1996b) Temporal and depth-related patterns of fine root dynamics in northern hardwood forests. Journal of Ecology 84, 167-176. 
HERTEL, D. 1999 Das Feinwurzelsystem von Rein- und Mischbeständen der Rotbuche: Struktur, Dynamik und interspezifische Konkurrenz. 184 pp Universität Kassel, Dissertationes Botanicae, Band 317, J.Cramer, Berlin - Stuttgart

HERTEL, D. \& LEUSCHNER, C. 2002 A comparison of four different fine root production estimates with ecosystem carbon balance data in a Fagus-Quercus mixed forest. Plant \& Soil 239, 237-251.

HERTEL, D., LEUSCHNER, C. \& HÖLSCHER, D. 2003 Size and structur of fine root system in old-growth and secondary tropical montane forests (Costa Rica). Biotropica 35[2], 143-153.

HERTEL, D. \& LEUSCHNER, C. 2006. Fine root mass and fine root production in tropical moist forests as dependent on soil, climate and elevation. in Bruijnzeel, L. A. \& Juvik, J. O. (eds.). Mountains in the mist: Science for conserving and managing tropical montane cloud forest. Hawaii Uni Press. (in press)

HETSCH, W. \& HOHEISEL, H. 1976 Standorts- und Vegetationsgliederung in einem tropischen Nebelwald. Allgemeine Forst- und Jagdzeitung 147[10/11], 200-209.

HOMEIER, J. 2004 Baumdiversität, Waldstruktur und Wachstumsdynamik zweier tropischer Bergregenwälder in Ecuador und Costa Rica. 207 pp Universität Bielefeld, Dissertationes Botanicae, J.Cramer Berlin - Stuttgart, Band 391

HUECK, K. 1966. Die Wälder Südamerikas: Ökologie, Zusammensetzung und wirtschaftliche Bedeutung. Fischer Verlag, Stuttgart.

HULTINE, K. R. \& MARSHALL, J. D. 1999. Altitude trends in conifer leaf morphology and stable carbon isotope composition. Oecologia 123, 32-40.

ILLIG, J., LANGEL, R., NORTON, R. A., SCHEU, S. \& MARAUN, M. 2005. Where are the decomposers? Uncovering the soil food web of a tropical montane rain forest in southern Ecuador using stable istotopes $\left({ }^{15} \mathrm{~N}\right)$. Journal of Tropical Ecology 21, 589-593.

JACKSON, R. B., CANADELL, J., EHLERINGER, J. R., MOONEY, H. A., SALA, O. E. \& SCHULZE, E.-D. 1996 A global analysis of root distribution for terrestrial biomes. Oecologia 108, 389-411.

JØRGENSEN, P. M. \& LEÓN-YÁNEZ, S. 1999. Catalogue of the Vascular Plants of Ecuador. Missouri Botanical Garden Press, St. Louis, St. Louis. 1181 pp.

KEYES, M. R. \& GRIER, C. C. 1981. Above- and below-ground net production in 40year-old Douglas-fir stands on low and high productitvity sites. Canadian Journal of Forest Research 11, 599-605.

KING, J. S., ALBAUGH, T. J., ALLAN, H. L., BUFORD, M., STRAIN, B. R. \& DOUGHERTY, P. 2002. Below-ground carbon input to soil is controlled by nutrient availability and fine root dynamics in loblolly pine. New Phytologist 154, 389-398.

KITAYAMA, K. \& AIBA, S.-I. 2002. Ecosystem structure and productivity of tropical rain forests along altitudinal gradients with contrasting soil phosphorus pools on Mount Kinabalu, Borneo. Journal of Ecology 90, 37-51. 
KLINGE, H., MEDINA, E. \& HERRERA, R. 1977. Studies of ecology of Amazon Caatinga forest in southern Venezuela. Acta Científica Venezolana 28, 270-276.

KLINGE, H. \& HERRERA, R. 1978. Biomass studies in Amazon Caatinga forest in southern Venezuela. 1. Standing crop of composite root mass in selected stands. Tropical Ecology 19, 93-110.

KOTTKE, I. \& AGERER, R. 1983. Untersuchungen zur Bedeutung der Mykorrhiza in älteren Laub- und Nadelwaldbeständen des südwestlichen Keuperberglandes. Mitteilungen des Vereins für Forstliche Standortskartierung, Forstpflanzenzüchtung, BRD 30, 30-39.

KOTTKE, I., BECK, A., OBERWINKLER, F., HOMEIER, J. \& NEILL, D. 2004. Arbuscular endomycorrhizas are dominant in the organic soil of a neotropical montane cloud forest. Journal of Tropical Ecology 20, 125-129.

KUMMEROW, J., KUMMEROW, M. \& TRABAUD, L. 1990. Root biomass, root distribution and fine-root growth dynamics of Quercus coccifera L. in the garrigue of southern France. Vegetatio 87, 37-44.

LAL, R., KIMBLE, J., LEVINE, E. \& WHITMAN, C. 1995. World soils and greenhouse effect: an overview. Pp. 1-7 in Lal, R., Kimble, J., Levine, E. \& Stewart, B. A. (eds.). Advances in Soil Sciences - Soils and Global Change. CRC Press Lewis Publishers, Boca Raton, Boca Raton. 7 pp.

LEUSCHNER, C. 1998. Mechanismen der Konkurrenzüberlegenheit der Rotbuche. Berichte der Reinh.-Tüxen-Gesellschaft 10, 5-18.

LEUSCHNER, C. \& HERTEL, D. 2003. Fine root biomass of temperate forests in relation to soil acidity and fertility, climate, age and species. Progress in Botany 64, 405-438.

LEUSCHNER, C., HERTEL, D., SCHMID, I., KOCH, O., MUHS, A. \& HÖLSCHER, D. 2004. Stand fine root biomass and fine root morphology in old-growth beech forests as a function of precipitation and soil fertility. Plant \& Soil 285, 43-56.

LEUSCHNER, C., MOSER, G., BERTSCH, C., RÖDERSTEIN, M. \& HERTEL, D. 2006 Large elevation increase in the tree root/shoot ratio in a tropical mountain forest of Ecuador. Basic Applied Ecology. (in press)

LEWIS, S. L., PHILLIPS, O. L., BAKER, T. R., LLOYD, J., MALHI, Y., ALMEIDA, S., HIGUCHI, N., LAURANCE, W. F., NEILL, D. A., SILVA, J. N. M., TERBORGH, J., LEZAMA, A. T., MARTÍNEZ VÁSQUEZ, R., BROWN, S., CHAVE, J., KUEBLER, C., VARGAS NÚÑEZ, P. \& VINCETI, B. 2004. Concerted changes in tropical forest structure and dynamics: evidence from 50 South American long-term plots. Phil.Trans.Royal Society London B 359, 421-436.

LÕHMUS, K., OJA, T. \& LASN, R. 1989. Specific root area: A soil characteristic. Plant \& Soil 119, 245-249.

LÕHMUS, K. \& IVASK, M. 1995. Decomposition and nitrogen dynamics of fine roots of Norway spruce (Picea abies (L.) Karst) at different sites. Plant \& Soil 168-169, 89-94. 
MAKKONEN, K. \& HELMISAARI, H.-S. 1999. Assessing fine-root biomass and production in a Scots pine stand - comparison of soil core and root ingrowth core methods. Plant \& Soil 210, 43-50.

MCCLAUGHERTY, C. A. \& ABER, J. D. 1982. The role of fine roots in the organic matter and nitrogen budgets of two forested ecosystems. Ecology 63[5], 1481-1490.

MCGRODDY, M. \& SILVER, W. L. 2000. Variations in belowground carbon storage and soil $\mathrm{CO}_{2}$ flux rates along a wet tropical climate gradient. Biotropica 32[4a], 614-624.

MEYER, F. H. 1987. Der Verzweigungsindex, Indikator für Schäden am Wurzelsystem. Forstwissenschaftliches Centralblatt 106, 84-92.

MOTTA, N. \& MEDINA, E. 1978. Early growth and photosynthesis of tomato (Lycopersicum esculentum L.) under nutritional deficiencies. Turrialba 28, 135-141.

MURACH, D. 1983. Die Reaktion von Fichtenfeinwurzeln auf zunehmende Bodenversauerung. Allgemeine Forstzeitschrift 26-27, 683-685.

NADELHOFFER, K. J., ABER, J. D. \& MELILLO, J. M. 1985. Fine roots, net primary production, and soil-nitrogen availability: a new hypothesis. Ecology 66, 1377-1390.

NADELHOFFER, K. J. \& RAICH, J. W. 1992. Fine root production estimates and belowground carbon allocation in forest ecosystems. Ecology 73[4], 1139-1147.

NEILL, C. 1992. Comparison of soil coring and ingrowth methods for measuring belowground production. Ecology 73[5], 1918-1921.

NEILL, D. A. 1999. Vegetation. Pp. 13-25 in Jørgensen, P. M. \& León-Yánez, S. (eds.). Catalogue of the vascular plants of Ecuador. 25 pp.

NEPSTAD, D. C., MOUTINHO, P., DIAS-FILHO, M. B., DAVIDSON, E., CARDINOT, G., MARKEWITZ, D., FIGUEIREDO, R., VIANNA, N., CHAMBERS, J., RAY, D., BUERREIROS, J. B., LEFEBVRE, P., STERNBERG, L., MOREIRA, M., BARROS, L., ISHIDA, F. Y., TOHLVER, I., BELK, E., KALIF, K. \& SCHWALBE, K. 2002. The effects of partial throughfall exclusion on canopy processes, aboveground production, and biogeochmistry of an Amazon forest. Journal of Geophysical Research 107[D20, 8085], 53-1 - 53-18.

ODUM, H. T. 1970. Rain forest structure and mineral-cycling homeostasis. in Odum, H. T. \& Pidgeon, R. F. (eds.). A tropical rain forest: a study of Irradiation and ecology at El Verde, Puerto Rico. Division of Technical Information U.S. Atomic Energy Commission, Washington D. C.

OSTERTAG, R. 1998. Belowground effects of canopy gaps in a tropical wet forest. Ecology 79[4], 1294-1304.

OSTERTAG, R. \& HOBBIE, S. E. 1999. Early stages of root and leaf decomposition in Hawaiian forests: effects of nutient availability. Oecologia 121, 564-573.

OSTERTAG, R. 2001. Effects of nitrogen and phosphorus availability on fine-root dynamics in Hawaiian montane forests. Ecology 82[2], 485-499. 
OSTERTAG, R., SCATENA, F. N. \& SILVER, W. L. 2003. Forest floor decomposition following hurricane litter inputs in several Puerto Rican forests. Ecosystems 6, 261-273.

OSTONEN, I., LÕHMUS, K. \& LASN, R. 1999. The role of soil conditions in fine root ecomorphology in Norway spruce (Picea abies (L.) Karst.). Plant \& Soil 208, 283-292.

OSTONEN, I., LÕHMUS, K. \& PAJUSTE, K. 2005. Fine root biomass, production and its proportion of NPP in a fertile middle-aged Norway spruce forest: Comparison of soil core and ingrowth core methods. Forest Ecology and Management 212, 264-277.

PARKHURST, D. F. \& LOUCKS, O. L. 1972. Optimal leaf size in relation to environment. Journal of Ecology 60, 505-537.

PERSSON, H. 1978. Root dynamics in a young Scots pine stand in Central Sweden. Oikos 30, 508-519.

PERSSON, H. 1980a) Spatial distribution of fine-root growth, mortality and decomposition in a young Scots pine stand in Central Sweden. Oikos 34, 77-87.

PERSSON, H. 1980b) Fine-root dynamics in a Scots pine stand with and without near optimum nutrient and water regimes. Acta Phytogeograpica Suecica 68, 101-110.

PERSSON, H. 1983. The distribution and productivity of fine roots in boreal forests. Plant \& Soil 71, 87-101.

PREGITZER, K. S. 2002. Fine roots of trees - a new perspective. New Phytologist 154, 267-273.

PREGITZER, K. S., DEFOREST, J. L., BURTON, A. J., ALLEN, M. F., RUESS, R. W. \& HENDRICK, R. L. 2002. Fine root architecture of nine North American trees. Ecological Monographs 72[2], 293-309.

RAICH, J. W. \& NADELHOFFER, K. J. 1989. Belowground carbon allocation in forest ecosystems: global trends. Ecology 70[5], 1346-1354.

RAICH, J. W. 1998. Abovground productivity and soil respiration in three Hawaiian rain forests. Forest Ecology and Management 107, 309-318.

REICH, P. B., WALTERS, M. B. \& ELLSWORTH, D. S. 1992. Leaf life-span in relation to leaf, plant, and stand characteristics among diverse ecosystems. Ecological Monographes 62, 365-392.

REWALD, B. 2003. Konkurrenz zwischen vier verschiedenen Baumarten in einem Eichenmischbestand im mitteldeutschen Trockengebiet. 139 pp. Georg-August Universität, Göttingen, Diplomarbeit.

RICHARDS, P. W. 1996. The Tropical Rain Forest - an ecological study. Cambridge University Press, Cambridge. 575 pp.

RICHTER, M. 2001. Feuchte Tropen. Pp. 259-294; Subtropen und Tropen. Pp. 311-327 in Blümel, W. D., Fuchs, G., Kraas, F., Kreutzmann, H., Löffler, E. \& Wirth, E. (eds.). Vegetationszonen der Erde. Klett und Perthes Verlag, Gotha und Stuttgart. 
RICHTER, M. 2003. Using epiphytes and soil temperatures for eco-climatic interpretations in Southern Ecuador. Erdkunde 57[3], 161-182.

ROLLENBECK, R., FABIAN, P. \& BENDIX, J. 2005. Precipitation dynamics and chemical properties in tropical mountain forests of Ecuador. Advances in Geosciences 6, 14.

RÖDERSTEIN, M., HERTEL, D. \& LEUSCHNER, C. 2005. Above- and below-ground litter production in three tropical montane forests in southern Ecuador. Journal of Tropical Ecology 21, 483-492.

RUDNICKI, M., SILINS, U., LIEFFERS, V. J. \& JOSI, G. 2001. Measure of simultaneous tree sways and estimation of crown interactions among a group of trees. Trees 15, 83-90.

RYSER, P. 1996. The importance of tissue density for growth and life span of leaves and roots: a comparison of five ecologically contrasting grasses. Functional Ecology 10, $717-$ 723.

SANFORD JR., R. L. 1989. Fine root biomass under a tropical forst light gap opening in Costa Rica. Journal of Tropical Ecology 5, 251-256.

SANFORD, Jr. R. L. \& CUEVAS, E. 1996. Root growth and rhizosphere interactions in tropical forests. Pp. 268-300 in Mulkey, S. S., Chazdon, R. L. \& Smith, A. P. (eds.). Tropical forest plant ecophysiology. Chapman \& Hall, New York, New York. 300 pp.

SANTANTONIO, D., HERMANN, R. K. \& OVERTON, W. S. 1977. Root biomass studies in forest ecosystems. Pedobiologia 17, 1-31.

SANTANTONIO, D. \& SANTANTONIO, E. 1987. Effect of thinning on production and mortality of fine roots in a Pinus radiata plantation on a ferile site in New-Zealand. Canadian Journal of Forest Research 17,919-928.

SAUER, W. 1971. Ausschnitte aus dem Buch Geologie von Ecuador. in Sauer, W. (ed.). Geologie von Ecuador. Gebrüder Bornträger, Berlin, Stuttgart.

SCHENK, J. H., CALLAWAY, R. M. \& MAHALL, B. E. 1999. Spatial root segregation: are plants territorial? Advances In Ecological Research 28, 145-180.

SCHENK, J. H. \& JACKSON, R. B. 2002. Rooting depths, lateral root spreads and belowground/above-ground allometries of plants in water-limited ecosystems. British Ecological Society 90, 480-494.

SCHROTH, G. \& ZECH, W. 1995. Above- and below-ground biomass dynamics in a sole cropping and an alley cropping system with Gliricidia sepium in the semi-deciduous rainforest zone of West Africa. Agroforestry Systems 31, 181-198.

SCHULDT, B. 2005. Untersuchungen zum Wasserhaushalt tropischer Bäume in Abhängigkeit von der Meereshöhe in Süd-Ecuador. 72 pp. Georg-August Universität, Göttingen, Diplomarbeit. 
SILVER, W. L., SCATENA, F. N., JOHNSON, A. H., SICCAMA, T. G. \& SANCHEZ, M. J. 1994. Nutrient availability in a montane wet tropical forest - spatial patterns and methodological considerations. Plant \& Soil 164, 129-145.

SILVER, W. L. \& MIYA, R. K. 2001. Global pattern in root decompostion: comparisons of climate and litter quality effects. Oecologia 129, 407-419.

SOETHE, N., LEHMANN, J. \& ENGELS, C. 2006. Root morphology and anchorage of six native tree species from a tropical montane forest and an elfin forest in Ecuador. Plant \& Soil 279 [1-2], 173-185.

STADTMÜLLER, T. 1987. Cloud forests in the humid tropics. The United Nations University, Tokyo. 81pp.

STARK, N. \& SPRATT, M. 1977 Root biomass and nutrient storage in rain forest oxisols near San Carlos de Rio Negro. Tropical Ecology 18, 1-9.

STEPHENSON, N. L. \& VAN MANTGEM, P. J. 2005. Forest turnover rates follow global and regional patterns of producitivty. Ecology Letters 8, 524-531.

SUNDARAPANDIAN, SM. \& SWAMY, P. S. 1996. Fine root biomass distribution and productivity patterns under open and closed canopies of tropical forest ecosystems at Kodayar in Western Ghats, South India. Forest Ecology and Management 86, 181-192.

TANNER, E. V. J., VITOUSEK, P. M. \& CUEVAS, E. 1998. Experimental investigation of nutrient limitation of forest growth on wet tropical mountains. Ecology 79[1], 10-22.

TIERNEY, G. L., FAHEY, T. J., GROFFMAN, P. M., HARDY, J. P., FITZHUGH, R. D., DRISCOLL, C. T., YAVITT, J. B. 2003. Environmental control of fine root dynamics in a northern hardwood forest. Global Change Biology 9, 679-679.

TINGEY, D. T., PHILLIPS, D. L. \& JOHNSON, M. G. 2000. Elevated $\mathrm{CO}_{2}$ and conifer roots: effects on growth, life span and turnover. New Phytologist 147, 87-103.

TINGEY, D. T., PHILLIPS, D. L. \& JOHNSON, M. G. 2003. Optimizing minirhizotron saple frequency for an evergreen and deciduous tree species. New Phytologist 157, 155161.

TRUMBORE, S., SALSZAR DA COSTA, E., NEPSTAD, D. C., BARBOSA DE CAMARGO, P., MARTINELLI, L. A., RAY, D., RESTOM, T. \& SILVER, W. 2006. Dynamics of fine root carbon in Amazonian tropical ecosystems and the contribution of roots to soil respiration. Global Change Biology 12, 217-229.

ULLOA-UlLOA, U. \& NEILL, D. A. 2005. Cinco años de adiciones a la fora del Ecuador:1999-2004. UTPL, Missouri Botanical Garden, Funbotanica. Editorial Universidad Técnica Particula de Loja, Loja. 75 pp.

UNGER, M. 2005. Veränderung blattchemischer und -morphologischer Eigenschaften von Bäumen im tropischen Regenwald Südecuadors in Abhängigkeit vom Strahlungsregime in einem Höhentransekt. 80 pp. Georg-August Universität, Göttingen, Diplomarbeit. 
VALENCIA, R., PITMAN, N., LEÓN-YÁNEZ, S. \& JØRGENSEN, P. M. 1999. Libro rojo de las plantas endémicas del Ecuador 2000. in Valencia, R., Pitman, N., León-Yánez, S. \& Jørgensen, P. M. (eds.). Libro rojo de las plantas endémicas del Ecuador 2000. Pontificia Universidad Catolica del Ecuador, Conservation, Food \& Health Foundation, Quito, Ecuador. 489 pp.

VAN PRAAG, H. J., SOUGNEZ-REMY, S., WEISSEN, F. \& CARLETTI, G. 1988. Root turnover in a beech and a spurce stand of the Belgian Ardennes. Plant \& Soil 105, 87-103.

VANGUELOVA, E. I., NORTCLIFF, S., MOFFAT, A. J. \& KENNEDY, F. 2005. Morphology, biomass and nutrient status of fine roots of Scots pine (Pinus sylvestris) as influenced by seasonal fluctuations in soil moisture and soil solution chemistry. Plant \& Soil 270, 233-247.

VELDKAMP, E., BECKER, A., SCHWENDENMANN, L., CLARK, D. A. \& SCHULTE-BISPING, H. 2003 Substantial labile carbon stocks and microbial activity in deeply weathered soils below a topical wet forest. Global Change Biology 9, 1171-1184.

VITOUSEK, P. M. \& SANFORD, Jr. R.L. 1986. Nutrient cycling in moist tropical forest. Annual Review of Ecological Systems 17, 137-167.

VITOUSEK, P. M. 1984. Litterfall, nutrient cycling, and nutrient limitation in tropical forests. Ecology 65[1], 285-298.

VITOUSEK, P. M., APLET, G., TURNER, D. \& LOCKWOOD, J. J. 1992. The Mauna Loa environmental matrix: foliar and soil nutrients. Oecologia 89, 372-382.

VOGT, K. A., EDMONDS, R. L. \& GRIER, C. C. 1981. Seasonal changes in biomass and vertical distribution of mycorrhizal and fibrous-textured conifer fine roots in 23- and 180year old subalpine Abies amabilis stands. Canadian Journal of Forest Research 11, 223229.

VOGT, K. A., GRIER, C. C., MEIER, C. E. \& EDMONDS, R. L. 1982. Mycorrhizal role in net primary production and nutrient cycling in Abies amabilis ecosystems in Western Washington. Ecology 63, 370-380.

VOGT, K. A., GRIER, C. C. \& VOGT, D. J. 1986. Production, turnover and nutrient dynamics of above- and belowground detritus of world forests. Advances In Ecological Research 15, 303-377.

VOGT, K. A., VOGT, D. J., MOORE, E. E., FAtUGA, B. A., REDLin, M. R. \& EDMONDS, R. L. 1987. Conifer and angiosperm fine-roots biomass in relation to stand age and site productivity in Douglas-Fir forests. Journal of Ecology 75, 857-870.

VOGT, K. A. \& PERSSON, H. 1991. Measuring growth and development of roots. Pp. 477-501 in Lassoie, J. P. \& Hinckley, Th. M. (eds.). Tecniques and approaches in forest tree ecophysiology. CRC Press, Florida, Boca, Ratas, Florida. 501 pp.

VOGT, K. A. \& BLOOMFIELD, J. 1991. Tree root turnover and senescence. in Waisel, Y., Eshel, A. \& Kafkafi, U. (eds.). Plant roots; the hidden half. Marcel Dekker, New York, New York. 287-306p. 
VOGT, K. A., VOGT, D. J., PALMIOTTO, P. A., BOON, P., O’HARA, J. \& ASBJORNSEN, H. 1996. Review of root dynamics in forest ecosystems grouped by climate, climatic forest type and species. Plant \& Soil 187, 159-219.

VOGT, K. A., VOGT, D. J. \& BLOOMFIELD, J. 1998. Analysis of some direct and indirect methods for estimation root biomass and production of forests at an ecosystem level. Plant \& Soil 200, 71-89.

WALTER, H. 1964. Die Vegetationen der Erde in öko-physiologischer Betrachtung. Fischer Verlag, Stuttgart.

WELLS, C. E. \& EISSENSTAT, D. M. 2001. Marked differences in survivorship among apple roots of different diameters. Ecology 82, 882-892.

WHITMORE, T. C. 1984. Gap size and species richness in tropical rain forests. Biotropica 16[3], 239.

WHITMORE, T. C. 1993. Tropische Regenwälder: eine Einführung. Spektrum, Akademischer Verlag, Heidelberg. 275 pp.

WILCKE, W., YASIN, S., ABRAMOWSKI, U., VALAREZO, C. \& ZECH, W. 2002 Nutrient storage and turnover in organic layers under tropical montane rain forest in Ecuador. European Journal of Soil Science 53, 15-27. 


\section{Abbildungsverzeichnis}

2.1 Lage der drei Untersuchungsflächen im Bereich des Stationsgebietes und im Bereich des Podocarpus Nationalparks. . . . . . . . . . . . . . .

2.2 Monatliche Mitteltemperaturen und Niederschläge. A: 1950 m ü.M. oberhalb der untersten Versuchsfläche (1890 m); B: 2680 m ü.M. oberhalb der mittleren Versuchfläche (2380 m) und C: mittlere monatliche Temperaturen 3070 m ü.M. und Niederschläge 3170 m ü.M. oberhalb der höchsten Versuchsfläche $(3060 \mathrm{~m})$ im Untersuchungszeitraum. . . . . . . . . . . . . D: mittlere Windgeschwindigkeiten im Paramo bei ca. $3400 \mathrm{~m}$ und auf 1950 m ü.M. im Stationsgebiet . . . . . . . . . . . . . . . . . . . .

4.1 Mächtigkeit der organischen Auflage der Waldflächen auf den drei Höhenstufen

4.2 A: Bodenwassergehalt im Bodenprofil (total), B und C: Saisonale Veränderung des Bodenwassergehalts im Untersuchungszeitraum, B: organische Humusauflage, C: Mineralboden . . . . . . . . . . . . .

4.3 Mittlere Bestandesmasse an lebenden und toten Feinwurzeln der Untersuchungsflächen auf drei Höhenstufen in der Humusauflage und den beiden darunter liegenden Mineralbodentiefen im Untersuchungszeitraum. A: Feinwurzelbiomasse, B: Feinwurzelnekromasse $\ldots \ldots \ldots \ldots \ldots \ldots$

4.4 Vertikale Verteilung der Feinwurzeln auf den drei Höhenstufen im Untersuchungszeitraum. A: Dichte der lebenden Feinwurzeln, B: Dichte der toten Feinwurzeln . . . . . . . . . . . . . . . . . . . .

4.5 Saisonale Veränderung der Feinwurzelbio- und nekromasse in Humusauflage und Mineralboden der drei Höhenstufen im Untersuchungszeitraum. A: Feinwurzelbiomasse der organischen Auflage, B: Feinwurzelbiomasse des Mineralbodens, C: Feinwurzelnekromasse der organischen Auflage und D: Feinwurzelnekromasse des Mineralbodens.

4.6 Produktion der Feinwurzeln nach der Minimum-Maximum-Methode auf den drei Höhenstufen für den Untersuchungszeitraum . . . . . . . . . . .

4.7 Saisonaler Verlauf der Feinwurzelproduktion der A: Humusauflage und des B: Mineralbodens der drei Höhenstufen im Untersuchungszeitraum . . . . .

4.8 Saisonaler Verlauf der Gesamtfeinwurzelmasse als Ausgangspunkt für die Berechnung der Wurzelstreuproduktion nach der Minimum-MaximumMethode. A: Humusauflage, B: Mineralboden . . . . . . . . . . . . . .

4.9 Feinwurzelmortalität nach der Minimum-Maximum-Methode auf den drei Höhenstufen für den Untersuchungszeitraum . . . . . . . . . . . . . 
4.10 Saisonaler Verlauf der Feinwurzelstreuproduktion (Mortalität) A: der Humusauflage und B: des Mineralbodens der drei Höhenstufen im Untersuchungszeitraum . . . . . . . . . . . . . . . . .

4.11 Massenverlust an Feinwurzeln in einem Abbauexperiment mit litter bags . . . .

4.12 Mittlerer Durchmesser der Feinwurzeln insgesamt (A) und in Humusauflage und Mineralboden getrennt (B) auf den drei Höhenstufen . . . . . . . . .

4.13 Mittelwert der spezifischen Oberfläche der Feinwurzeln des gesamten Profils (A) und in Humusauflage und Mineralboden getrennt (B) auf den drei Höhenstufen ....................................

4.14 Spezifische Spitzenhäufigkeit der Feinwurzeln auf den drei Höhenstufen im Untersuchungszeitraum (Humusauflage und Mineralboden). . . . . . . . . .

4.15 Bestandesspitzenzahl und Spitzendichte der Feinwurzeln auf den drei Höhenstufen im Untersuchungszeitraum (Humusauflage und Mineralboden). A: Anzahl der Wurzelspitzen pro $\mathrm{m}^{2}$ und B: Anzahl der Wurzelspitzen pro

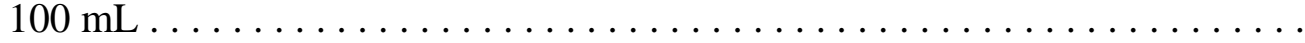

4.16 Mittlerer Wurzelflächenindex der Feinwurzeln (Humusauflage und Mineralboden) in den drei Höhenstufen . . . . . . . . . . . . . . .

4.17 A: Kohlenstoffgehalt, B: Stickstoffgehalt und C: das Verhältnis von C/N auf den drei Höhenstufen im Untersuchungszeitraum (Humusauflage und

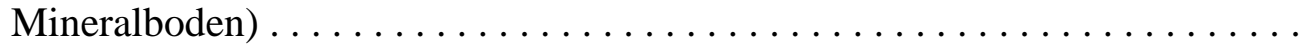

4.18 Der saisonale Verlauf des Blattstreufalls pro Monat auf den drei Höhenstufen im Untersuchungszeitraum . . . . . . . . . . . . . . . . .

4.19 Die Mittelwerte der Summen des Blattstreufalls pro Jahr auf den drei untersuchten Höhenstufen im Untersuchungszeitraum . . . . . . . . . . . .

4.20 Mittlere spezifische Blattoberfläche (SLA) der Blattstreu auf den drei Höhenstufen im Untersuchungszeitraum . . . . . . . . . . . . .

4.21 Blattstreuflächen auf den drei Höhenstufen im Untersuchungszeitraum . . . . .

4.22 A: Kohlenstoffgehalt, B: Stickstoffgehalt und C: das Verhältnis von C/N der Blattstreu auf den drei Höhenstufen im Untersuchungszeitraum . . . . . . . .

5.1 A: Logarithmierte Feinwurzelbiomasse und B: die logarithmierte Gesamtwurzelbiomasse gegen den logarithmierten mittleren Brusthöhendurchmesser auf den drei Untersuchungsflächen. . .

5.2 Die Verteilung der ober- und unterirdischen Biomasse auf den drei Untersuchungsflächen . . 
5.3 Beziehung zwischen logarithmierter zersetzter Feinwurzelmasse und dem logarithmierten C/N-Verhältnis der Feinwurzeln auf den drei Höhenstufen . . 49

5.4 Das Verhältnis von LAI zu RAI auf den drei untersuchten Höhenstufen . . . . .

5.5 Beziehung zwischen Niederschlag und dem Umsatz der Feinwurzeln auf den drei Höhenstufen . . . . . . . . . . . . . . . . . . . .

5.6 Die Beziehung zwischen Niederschlag und der Lebensdauer der Feinwurzeln auf den drei Höhenstufen . . . . . . . . . . . . . . . . . . . .

5.7 Die Jahresproduktion von Blättern und Feinwurzeln und deren Verhältnis auf den drei Höhenstufen 2002/03 


\section{Tabellenverzeichnis}

2.1 Meereshöhe und geografische Lage, mittlere Inklination (2003/04), mittlere Exposition (2003/04), Bodentyp (2002), geologisches Substrat (1971), Median des pH (2002/03), mittlere Jahrestemperatur und Niederschlag im Untersuchungszeitraum(2002/03), mittlere Luftfeuchtigkeit (2003/04). . . . .

2.2 BHD, Basalfläche, Bestandeshöhe, Stammlänge, Stammdichte und oberirdische (Baum-)Biomasse der drei Untersuchungsflächen des Untersuchungsgebietes $\ldots \ldots \ldots \ldots \ldots \ldots \ldots \ldots \ldots \ldots \ldots \ldots \ldots \ldots \ldots$

3.1 Schema zur Erklärung der Einteilung des Berechnungsverfahren nach MCClaugherty et al. (1982) und FAIRley \& AlEXANDER (1985) . . . . . . . 13

4.1 Das Verhältnis von Biomasse zur Nekromasse an acht Terminen im Beprobungszeitraum auf drei Höhenstufen . . . . . . . . . . . . . . . .

4.2 Vergleich der unterschiedlichen Ergebnisse von drei Methoden zur Feinwurzelproduktionsberechnung. Gesamtwerte und Werte je Horizont getrennt nach Humusauflage und Mineralboden der Höhenstufe im Untersuchungszeitraum ....................... 28

4.3 Vergleich der nach zwei Methoden errechneten Feinwurzelstreuproduktion (Feinwurzelmortalität), Gesamtwerte und Werte je Horizont getrennt nach Humusauflage und Mineralboden der Höhenstufe im Untersuchungszeitraum

4.4 Berechnung der Umsatzrate und der Mortalitätsrate mit der MinimumMaximum-Methode, Humusauflage und Mineralboden je Höhenstufe im Untersuchungszeitraum . . . . . . . . . . . . . . . . .

4.5 Vergleich der Umsatz- und Mortalitätsraten aller drei bzw. zwei Methoden, je Höhenstufe im Untersuchungszeitraum . . . . . . . . . . . . 33

5.1 Literaturangaben zur Feinwurzelbiomasse tropischer Wälder auf unterschiedlichen Höhenstufen.$\ldots \ldots \ldots \ldots \ldots \ldots \ldots \ldots$

5.2 Der Einfluss unterschiedlicher Faktoren auf den Stickstoffgehalt der

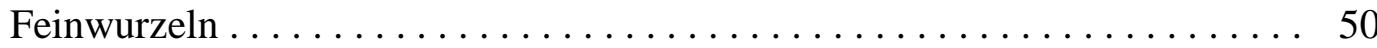

5.3 Die Beziehung unterschiedlicher Faktoren zur spezifischen Wurzeloberfläche

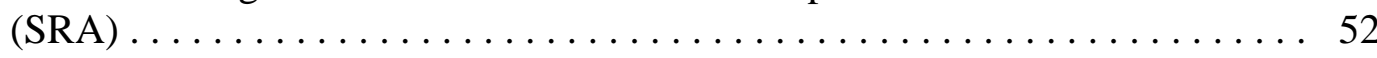

5.4 Literaturangaben zur Feinwurzelbiomasse und - produktion tropischer Wälder auf unterschiedlichen Höhenstufen . . . . . . . . . . . . . . . . 59

5.5 Die Beziehung unterschiedlicher Faktoren zur Feinwurzelproduktion . . . . . . 60 
5.6 Der Einfluss unterschiedlicher Faktoren auf die Feinwurzelmortalität . . . . . . 62 


\section{Abkürzungsverzeichnis}

asl above sea level, über dem Meeresspiegel, Meereshöhe

BHD Brusthöhendurchmesser (1,30 m Höhe)

DBH Diameter at breast height, Brusthöhendurchmesser

$\delta^{13} \mathrm{C} \quad$ delta $13 \mathrm{C}$, Kohlenstoffisoptop

$\delta^{15} \mathrm{~N} \quad$ delta $15 \mathrm{~N}$, Stickstoffisotop

${ }^{14} \mathrm{C} \quad 14 \mathrm{C}$ Isotop des Kohlenstoffs für die Radiocarbonuntersuchung

ECSF Estación Científica San Francisco, Forschungsstation

LAF leaf area fallen $\left(\mathrm{m}^{2} \mathrm{~m}^{-2}\right)$, Blattobeflächenindex der Blattstreu

LAI leaf area index $\left(\mathrm{m}^{2} \mathrm{~m}^{-2}\right)$, Blattoberflächenindex, der sich noch am Baum befindenden Blätter

Mann \&

Whitney Test, Varianzanalyse, nichtnormalverteilt, unbalanciert

n Probenumfang

nd not determined, nicht beprobt

NPP Nettoprimärproduktion

$\mathrm{p} \quad$ Irrtumswahrscheinlichkeit

PNP Podocarpus Nationalpark

$\mathrm{r}^{2} \quad$ Bestimmtheitsmaß

RAI root area index $\left(\mathrm{m}^{2} \mathrm{~m}^{-2}\right)$, (Fein-)Wurzeloberflächenindex

Scheffé Test, Varianzanalyse, normalverteilt, unbalanciert

SLA specific leaf area $\left(\mathrm{cm}^{2} \mathrm{~g}^{-1}\right)$, spezifische Blattoberfläche

sp. oder spec. specie, Art

SRA specific root area $\left(\mathrm{cm}^{2} \mathrm{~g}^{-1}\right)$, spezifische Wurzeloberfläche

TG Trockengewicht

TM Trockenmasse

Vol. \% Volumen Prozent

$\mathrm{yr}^{-1} \quad$ per year, pro Jahr 
Tab. 1 A-C : Vorläufige Liste der Pflanzenarten, nach Familien geordnet, die auf den Versuchsflächen gefunden wurden. Die Pflanzen wurden zusammen mit Alfredo Martínez-Jervez gesammelt. Die Bestimmung erfolgte durch Alfredo Martínez-Jervez und Jürgen Homeier.

A $-1890 m$

\begin{tabular}{|c|c|c|c|}
\hline Family (Familie) & Genus (Gattung) & Species (Art) & Autor \\
\hline Annonaceae & Guatteria & spec. & \\
\hline \multicolumn{4}{|l|}{ Annonaceae } \\
\hline Aquifoliaceae & Ilex & cf. amboroica & LOES. \\
\hline \multicolumn{4}{|l|}{ Araceae } \\
\hline Araceae & Anthurium & giganteum & ENGL. \\
\hline Arecaceae & Chamaedorea & pinnatifrons & (JACQ.) OERST \\
\hline Araliaceae & Schefflera & spec. 1 & \\
\hline Araliaceae & Schefflera & spec. 2 & \\
\hline Chloranthaceae & Hedyosmum & spec. & \\
\hline Clethraceae & Clethra & revoluta & (RUIZ \& PAV.) SPRENG. \\
\hline Clusiaceae & Clusia & spec. & \\
\hline Clusiaceae & Vismia & tomentosa & (RUIZ \& PAV.) \\
\hline Cyatheaceae & Cyathea & spec. & \\
\hline \multicolumn{4}{|l|}{ Ericaeae } \\
\hline Euphorbiaceae & Alchornea & pearcei & BRITTON \\
\hline \multicolumn{4}{|l|}{ Euphorbiaceae } \\
\hline Lauraceae & Aniba & spec. & \\
\hline \multicolumn{4}{|l|}{ Lauraceae } \\
\hline Melastomataceae & Graffenrieda & emarginata & (RUIZ \& PAV.) TRIANA \\
\hline Melastomataceae & Miconia & punctata & (DESR.) D. DON EX DC \\
\hline \multirow{3}{*}{\multicolumn{4}{|c|}{$\begin{array}{l}\text { Melastomataceae } \\
\text { Melastomataceae } \\
\text { Meliaceae }\end{array}$}} \\
\hline & & & \\
\hline & & & \\
\hline Myrsinaceae & Myrsine & coriaceae & $\begin{array}{l}\text { (SW.) R. BR. EX ROEM. \& } \\
\text { SCHULT. }\end{array}$ \\
\hline \multicolumn{4}{|l|}{ Myrthaceae } \\
\hline Piperaceae & Piper & spec. & \\
\hline Poaceae & & spec. 1 & \\
\hline Poaceae & & spec. 2 & \\
\hline Podocarpaceae & Prumnopitys & montana & (HUMB.\& BONPL.)DE LAUB \\
\hline Polygalaceae & Monnina & spec. & \\
\hline Rubiacaeae & Palicourea & spec. & \\
\hline Rubiacaeae & & several & \\
\hline Rubiaceae & Palicourea & angustifolia & KUNTH \\
\hline Rubiaceae & Palicourea & subtomentosa & (RUIZ \& PAV.) DC \\
\hline Sapindaceae & Matayba & inelegans & SPRUCE EX RDLK. \\
\hline Solanaceae & & & \\
\hline
\end{tabular}


B - $2380 m$

\begin{tabular}{|c|c|c|c|}
\hline Family (Familie) & Genus (Gattung) & Species (Art) & Author \\
\hline Aquifoliaceae & Ilex & rimbachii & STANDL. \\
\hline Aquifoliaceae & Ilex & spec. 2 & \\
\hline Araceae & Anthurium & spec. & \\
\hline Araliaceae & Schefflera & spec. 1 & \\
\hline Araliaceae & Schefflera & spec. 2 & \\
\hline Araliaceae & Schefflera & spec. 3 & \\
\hline Asteraceae & Mikania & spec. & \\
\hline Asteraceae & & several & \\
\hline Chloranthaceae & Hedyosmum & translucidum & CUATREC \\
\hline Clusiaceae & Clusia & spec. 1 & \\
\hline Clusiaceae & Clusia & spec. 2 & \\
\hline Cunoniaceae & Weinmannia & spec. 1 & \\
\hline Cunoniaceae & Weinmannia & spec. 2 & \\
\hline Cunoniaceae & Weinmannia & spec. 3 & \\
\hline Cyrillaceae & Purdiaea & nutans & PLANCH. \\
\hline Ericaceae & Cavendishia & spec. & \\
\hline Ericaceae & & several & \\
\hline Euphorbiaceae & Alchornea & pearcii & BRITTON \\
\hline \multicolumn{4}{|l|}{ Euphorbiaceae } \\
\hline Gentianaceae & Macrocarpaea & revoluta & \\
\hline Lauraceae & & several & \\
\hline Loranthaceae & Aetanthus & dichotomus & (RUIZ \& PAV.) KUIJT \\
\hline Melastomatacea & Graffenrieda & emarginata & (RUIZ \& PAV.) TRIANA \\
\hline Melastomataceae & Miconia & spec. & \\
\hline Melastomataceae & & several & \\
\hline Melastamataceae & Graffenrieda & spec. 2 & \\
\hline \multicolumn{4}{|l|}{ Meliaceae } \\
\hline Moraceae & & several & \\
\hline Myrsinacae & Myrsine & coriacea & $\begin{array}{l}\text { (SW.) R. BR. EX ROEM. \& } \\
\text { SCHULT. }\end{array}$ \\
\hline Myrsinaceae & Geissanthus & spec. & \\
\hline Myrsinaceae & Cybianthus & spec. & \\
\hline \multicolumn{4}{|l|}{ Myrtaceae } \\
\hline Podocarpaceae & Podocarpus & oleifolius & D. DON EX LAMB. \\
\hline Podocarpaceae & Prumnopitys & montana & (HUMB.\& BONPL.)DE LAUB \\
\hline Rosaceae & Prunus & spec. & \\
\hline \multicolumn{4}{|l|}{ Rosaceae } \\
\hline Rubiaceae & Faramea & spec. 1 & \\
\hline Rubiaceae & Faramea & spec. 2 & \\
\hline Rubiaceae & Palicourea & angustifolia & KUNTH \\
\hline Rubiaceae & & several & \\
\hline \multicolumn{4}{|l|}{ Sapotaceae } \\
\hline Symplocaceae & Symplocos & spec. & \\
\hline
\end{tabular}


C - 3060m

Family (Familie)

Aquifolicaceae

Aquifolicaceae

Araliaceae

Araliaceae

Chloranthaceae

Chloranthaceae

Clusiaceae

Clusiaceae

Cunoniaceae

Cunoniaceae

Ericaceae

Grossulariaceae

Loranthaceae

Melastomataceae

Melastomataceae

Myrsinaceae

Myrsinaceae

Myrsinaceae

Myrthaceae

Polygonaceae

Rubiaceae

Rubiaceae

Rubiaceae

Styracaceae

Symplocaceae

Theaceae

Genus (Gattung)

Ilex

Ilex

Schefflera

Schefflera

Hedyosmum

Hedyosmum

Clusia

Clusia

Weinmannia

Weinmannia

Escallonia

Aetanthus

Miconia

Myrsine

Myrsine

Monnina

Palicourea

Palicourea

Styrax

Symplocus

Freziera
Species (Art)

Author

spec.

spec. 2

spec.

spec. 2

spec.

spec. 2

spec.

spec. 2

loxensis

HARLING

spec. 2

several

spec.

dichotomus

(RUIZ \& PAV.) KUIJT

spec.

several

spec.

spec. 2

spec.

several

spec. 1

spec. 2

foveolaria

(Ruiz \& Pav.) Perkins

spec.

spec. 


\section{Lebenslauf}

\section{Persönliche Angaben}

$\begin{array}{ll}\text { Name } & \text { Marina Röderstein } \\ \text { Geburtsdatum } & 14.03 .1971 \\ \text { Geburtsort } & \text { Alsfeld } \\ \text { Staatsangehörigkeit } & \text { deutsch }\end{array}$

\section{Bildungsgang}

1977-1981

1981-1983

1983-1987

1987-1990

1990

1990-1993

1993

1993-1997

$1997-2000$

2000

2001

2001-2006
Astrid-Lindgren-Schule, Grebenau

Gerhart-Hauptmann-Schule, Alsfeld

Haupt- und Realschule, Alsfeld

Albert-Schweitzer-Gymnasium, Alsfeld

Allgemeine Hochschulreife

Ausbildung zur Krankenschwester an der Krankenpflegeschule

Alsfeld und dem Eichhof-Krankenhaus Lauterbach

Staatsexamen als Krankenschwester

Grundstudium Biologie an der Justus-von-Liebig Universität, Gießen

Hauptstudium Biologie an der Justus-von-Liebig Universität, Gießen

Examen als Diplom-Biologin

Ergänzungsstudiengang Grundlagen der Informatik

an der Justus-von-Liebig Universität Gießen

Vorbereitung auf die Promotion an der Georg-August-Universität, Göttingen 